Linköping Studies in Science and Technology

Dissertation No. 1707

Doctoral School in Information Engineering, XXVI Cycle

SSD: ING-INF/o6 - Bioingegneria, Elettronica e Informatica

\title{
EVALUATION OF THE DUAL-MODAL USAGE OF CONTRAST AGENTS BY MEANS OF SYNCHROTRON X-RAY COMPUTED MICROTOMOGRAPHY AND MAGNETIC RESONANCE IMAGING
}

using Macrophages loaded with Barium Sulphate and Gadolinium Nanoparticles for Detection and Monitoring in Animal Disease Models

EMANUEL LARSSON

Supervisors:

Prof. Kajsa Uvdal (Linköping University)

Prof. Agostino Accardo (University of Trieste)

Co-Supervisor:

Dr. Giuliana Tromba (Elettra Sincrotrone Trieste S.C.p.A.)

Biomedical Instrumentation and Signal Processing Laboratory

Department of Engineering and Architecture

University of Trieste, Trieste, Italy



Division of Molecular Surface Physics and Nanoscience

Department of Physics, Chemistry and Biology

Linköping University, Linköping, Sweden

Trieste \& Linköping 2015

Academic Year: 2014-2015 
Cover: Fused Computed Tomography (СT) and Magnetic Resonance Imaging (MRI) image of the lung region of a severe acute asthmatic BALB/c mouse injected with contrast agent loaded macrophages. Regions marked in red show soft-tissue, while as spots marked in yellow show clusters of Barium Sulfate $\left(\mathrm{BaSO}_{4}\right)$ loaded macrophages, all imaged with Synchrotron Radiation Computed Microtomography $(\mathrm{SR} \mu-\mathrm{CT})$. Regions marked in green show T1-contrast enhanced softtissue, due to the presence of non-clustered Gadolinium nanoparticles (GdNP) loaded macrophages inside the soft-tissue, as imaged with Micro Magnetic Resonance Imaging ( $\mu$-MRI).

(C) Copyright 2015 Emanuel Larsson, unless otherwise noted. All rights reserved.

Evaluation of the Dual-Modal usage of contrast agents by means of Synchrotron X-ray Computed Microtomography and Magnetic Resonance Imaging, using Macrophages loaded with Barium Sulphate and Gadolinium Nanoparticles for Detection and Monitoring in Animal Disease Models

Emanuel Larsson

ISBN: 978-91-7685-936-o

ISSN: 0345-7524

Linköping Studies in Science and Technology. Dissertation No. 1707

Printed in Sweden by LiU-Tryck, Linköping 2015. 
To My Family. 

Technical improvements of imaging devices during the last two decades have led to the development of so called hybrid imaging modalities, containing at least two different imaging modalities in the same machine. Hybrid imaging allows the combination of multi-modal images and the extraction of both complementary and synergistic information, which is useful for more accurate and reliable diagnosis. Within this framework there was an increased need for multi-modal contrast agents. During the last decade development of multi-modal contrast agents have hence received further attention.

Recent developments of X-ray based imaging techniques now also offers imaging in other regimes, than standard absorption based imaging, e.g. phase contrast imaging, which exploits the refraction and phase-shift of the incident X-ray beam at tissue-interfaces. It has been shown that phase contrast imaging is more sensitive than classical clinical radiography, especially in soft-tissue applications, such as mammography.

This thesis focuses on evaluating the dual-modal Computed Tomography (CT) and Magnetic Resonance Imaging (MRI) capabilities of contrast agents. For such purposes a gadolinium based contrast agent is of high interest, due to its paramagnetic properties, which while present inside a magnetic field will hence interact with the protons spins of water (in tissue and fat) and shorten their the TI relaxation time, thereby creating a positive image contrast in MRI. Furthermore, the X-ray Mass Attenuation Coefficient (MAC) of gadolinium is relatively high, thus suggesting its potential use, also as a CT contrast agent.

Gadolinium nanoparticles can be loaded into cells, such as macrophages, which offers the possibility to track cells inside entire organisms. In the first step the uptake of gadolinium nanoparticles inside cells was investigated, together with a test for toxicity. To show the potential of using gadolinium nanoparticle loaded macrophages for functional imaging of inflammation, an acute allergic airway inflammation mouse model (mimicking asthma in humans) was used and analyzed by in-situ synchrotron phase contrast CT. This animal model was chosen, since macrophages are one of the main effector cells in asthma, where especially their ability to migrate is of crucial interest, which up until now was not possible to study in-situ. 
In the first step this approach was evaluated using macrophages loaded with a clinical contrast agent containing barium sulphate, since this agent is known to provide high contrast in CT. In the ultimate step a combination of both barium sulphate and gadolinium nanoparticle loaded macrophages was used in the same mouse model (mimicking human asthma) and analyzed by dual modal Synchrotron phase contrast CT and Micro Magnetic Resonance Imaging ( $\mu$-MRI).

Complementary results in terms of the biodistribution of injected macrophages could only be obtained by the combination of both synchrotron phase contrast $\mathrm{CT}$ and $\mu$-MRI, where the first modality allows a detailed localization of clustered barium sulphate loaded macrophages, but fails to detect single macrophages, which could instead be indirectly observed by $\mu$-MRI as an increase of the T1contrast, coming from the soft tissue of mice injected with gadolinium nanoparticle loaded macrophages.

In conclusion, the results obtained on cells loaded with gadolinium nanoparticles showed that the contrast can not be maximized for both modalities in parallel, as the MRI-signal decays for higher concentrations of gadolinium. To circumvent this, an alternative pathway could be to develop a dual-modal contrast agent optimized for MRI in combination with phase contrast $\mathrm{CT}$, instead of absorption based CT. 
Den tekniska förbättringen av bildgivande tekniker under de senaste två decennierna har lett till utvecklandet av så kallade hybrida bildgivande modaliteter, innehållande minst två stycken olika bildgivande tekniker i samma system. Hybrid bildgivning möjliggör kombinationen av multimodala bilder med både komplementär och synergistisk information, vilka kan användas för att ställa en mer noggrann och tillförlitlig diagnos. Inom detta område ökade därmed behovet av multimodala kontrastmedel, vilket har varit ett fokus för utveckling under det senaste decenniet.

Den senaste utvecklingen inom röntgenbaserade bildgivningstekniker tillåter nu även bildgivning inom fler regimer än vanlig röntgenabsorption, t.ex. bildgivning med faskontrast, vilken utnyttjar refraktionen och fasförskjutningen som uppstår när den infallande röntgenstrålen träffar ytan hos mjukvävnad. Det är bevisat att bildgivning med faskontrast är mer känslig, än klassisk klinisk radiologi, speciellt vid undersökning av mjukvävnad, som ex. vid mammografi.

Det här avhandlingsarbetet har syftat till att utvärdera de bimodala Computed Tomography (CT)- och Magnetic Resonance Imaging (MRI)egenskaperna hos kontrastmedel. För sådana ändamål är gadoliniumbaserade kontrastmedel av högt intresse, på grund av dess parmagnetiska egenskaper, vilka när placerade inuti ett magnetfält kommer att interagera med protonspinnen hos vatten (i mjukvävnad och fett) genom att förkorta deras T1-relaxationstid och därmed skapa en positiv bildkontrast i MRI. Dessutom är massattenueringskoefficienten hos gadolinium relativt hög, vilket därmed styrker dess potential också som ett kontrastmedel inom CT.

Gadoliniumnanopartiklar kan tas upp av celler, som ex. makrofager och man kan därigenom följa cellernas migration inuti en organism. I ett första steg undersöktes cell-upptaget av gadoliniumnanopartiklar, följt av ett toxicitetstest. För att påvisa potentialen av användandet av gadoliniumnanopartiklar som ett intracellulärt kontrastmedel för funktionell bildgivning av inflammation, så analyserades en musmodell med akut allergisk luftvägsinflammation (imitation av astma hos människor) in-situ med synkrotron-faskontrast-CT. Denna djurmodell valdes ut eftersom makrofager är en av de huvudsakliga effektorcellerna vid astma, där deras förmåga att migrera är av avgörande intresse, vilket var omöjligt att studera in-situ fram till nu. 
Denna metod utvärderades först med makrofager som tagit upp ett kliniskt kontrastmedel innehållande bariumsulfat, då detta kontrastmedel påvisats ge god kontrast i CT. I det slutliga steget användes en kombination av både bariumsulfat och gadoliniumnanopartiklar som intracellulära kontrastmedel i makrofager i en och samma musmodell (imitation av astma hos människor) och undersöktes med bimodal synkrotron-faskontrast-CT och $\mu$-MRI.

Komplementära resultat rörande biodistributionen av injicerade makrofager kunde endast erhållas tack vare kombinationen av både synkrotron-faskontrast-CT och $\mu$-MRI, där den förstnämnda tekniken tillåter en detaljerad lokalisering av kluster av makrofager med upptaget bariumsulfat, men är otillräcklig för att detektera enskilda makrofager, vilket å andra sidan indirekt kan observeras i $\mu$-MRI som en ökning av T1-kontrasten av mjukvävnad i möss injicerade med makrofager som tagit upp gadoliniumnanopartiklar.

Sammanfattningsvis visade resultaten från cellstudierna att för celler som tagit upp gadoliniumnanopartiklar kunde kontrasten inte maximeras för båda modaliteterna samtidigt, då Magnetic Resonance (MR)signalen förfaller vid en hög koncentration av gadolinium. För att kringgå detta skulle en alternativ idé vara att utveckla ett bimodalt kontrastmedel som är optimerat för MRI i kombination med faskontrast$\mathrm{CT}$, istället för vanlig röntgenabsorptions-CT 
Gli avanzamenti della tecnologia nell'ambito dei dispositivi di imaging avvenuti negli ultimi due decenni hanno portato allo sviluppo della cosiddetta modalità di imaging ibrido, che prevede l'inserimento di almeno due diverse modalità di imaging nello stesso macchinario. L'imaging ibrido consente la combinazione di immagini multimodali con l'estrazione di informazioni complementari e sinergiche, utili per una diagnosi più accurata ed affidabile. Di conseguenza, in questo contesto, è nato e si è andato sviluppando il bisogno di agenti di contrasto multimodali che sono stati oggetto, durante l'ultimo decennio, di una grande attenzione.

Recenti sviluppi delle tecnologie di imaging basate sui raggi $X$ hanno permesso di ottenere oltre che l'imaging ad assorbimento anche l'imaging a contrasto di fase, che sfrutta la rifrazione e lo sfasamento del fascio incidente di raggi $X$ sulle interfacce dei tessuti. È stato dimostrato che il contrasto di fase è più sensibile rispetto la classica radiografia clinica soprattutto nelle applicazioni su tessuti molli, come la mammografia.

La presente tesi si concentra sulla valutazione delle capacità di un particolare agente di contrasto utilizzabile nel modello ibrido di tomografia assiale computerizzata (TAC) e di Risonanza Magnetica (RM). L'agente di contrasto esaminato è a base di gadolinio che presenta grande interesse a causa delle sue proprietà paramagnetiche. Quando presenti all'interno di un campo magnetico, tali proprietà consentono al gadolinio di interagire con gli spin dei protoni delle molecole d'acqua (presenti nei tessuti e nei grassi), riducendo il tempo di rilassamento $\mathrm{T}_{1}$, migliorando così il contrasto nell'immagine della risonanza magnetica. Inoltre, il coefficiente di attenuazione ai raggi $X$ nel gadolinio è relativamente alto, suggerendo il suo potenziale uso anche come agente di contrasto per la TAC.

D'altra parte alcune tipologie di cellule, come per esempio i macrofagi, possono essere caricate con nanoparticelle di gadolinio, consentendo il loro trasporto all'interno degli organismi sino ai punti di interesse consentendo di realizzare l'imaging funzionale. Durante il dottorato, in una prima fase oltre allo studio dell'assorbimento di nanoparticelle di gadolinio all'interno delle cellule è stato effettuato un test di tossicità di tali particelle. Per dimostrare le potenzialità dell'utilizzo delle nanoparticelle di gadolinio, caricate nei macrofagi per l'imaging funzionale, è stato utilizzato il modello animale (utilizzando i topi) affetto da una infiammazione allergica acuta (imitando l'asma negli 
esseri umani), analizzando le immagini ottenute mediante contrasto di fase realizzate col tomografo a luce di sincrotrone. È stato scelto questo particolare modello animale in quanto i macrofagi attaccano le cellule presenti nell'asma ed è quindi di particolare interesse studiare la loro migrazione, cosa fino ad oggi non possibile da analizzare in-situ.

Per valutare questo approccio, in una prima fase sono stati utilizzati macrofagi carichi di agenti di contrasto, in particolare contenenti solfato di bario, noti per garantire un elevato contrasto nelle immagini TAC. In una fase successiva sono state utilizzate le cellule di macrofagi cariche di nanoparticelle di entrambi gli agenti, solfato di bario e nanoparticelle di gadolinio, nello stesso modello animale (di topo, imitando l'asma umana) e sono state analizzate le immagini acquisite col sistema tomografico bimodale a luce di sincrotrone a contrasto di fase e $\mu$ RM.

I risultati in termini di distribuzione dei macrofagi iniettati nei tessuti infiammati possono essere ottenuti solo dalla combinazione di entrambe le modalità di imaging a luce di sincrotrone a contrasto di fase e di micro risonanza magnetica. La prima modalità consente una localizzazione dettagliata dell'ammasso dei macrofagi, ma non rileva il singolo macrofago cariche di solfato di bario, come può invece essere indirettamente osservato dalla $\mu \mathrm{MRI}$. In questo caso esso verrebbe rilevato come un aumento del contrasto $\mathrm{T} 1$ della risonanza magnetica, proveniente dai macrofagi caricati con nanoparticelle di gadolinio e iniettati nel tessuto molle dei topi.

In conclusione, i risultati ottenuti su cellule caricate con nanoparticelle al gadolinio mostrarono che il contrasto non può essere massimizzato contemporaneamente per entrambe le metodologie in quanto se alte concentrazioni di gadolinio migliorano la qualità di immagini tomografiche ad assorbimento, d'altra parte il segnale nella modalità RM decade per alte concentrazioni di gadolinio. Per superare il problema, una strada alternativa potrebbe essere lo sviluppo di un agente di contrasto bimodale ottimizzato per RM in combinazione con un sistema tomografico a contrasto di fase, invece dell'utilizzo di sistemi tomografici ad assorbimento. 
Papers included in the thesis:

I Quantitative evaluation of a single-distance phase-retrieval method applied on in-line phase-contrast images of a mouse lung Sara Mohammadi, Emanuel Larsson, Frauke Alves, Simeone dal Monego, Stefania Biffi, Chiara Garrovo, Andrea Lorenzon, Giuliana Tromba and Christian Dullin, Journal of Synchrotron Radiation, 2014, 21(4):784-789.

II Functionalized synchrotron in-line phase-contrast computed tomography: a novel approach for simultaneous quantification of structural alterations and localization of barium-labelled alveolar macrophages within mouse lung samples

Christian Dullin*, Simeone dal Monego*, Emanuel Larsson*, Sara Mohammadi, Martin Krenkel, Chiara Garrovo, Stefania Biffi, Andrea Lorenzon, Andrea Markus, Joanna Napp, Tim Salditt, Agostino Accardo, Frauke Alves and Giuliana Tromba, Journal of Synchrotron Radiation, 2015, 22(1):143-155.

III Quantification of structural alterations in lung disease - a proposed analysis methodology of CT scans of preclinical mouse models and patients

Emanuel Larsson, Giuliana Tromba, Kajsa Uvdal, Agostino Accardo, Simeone dal Monego, Stefania Biffi, Chiara Garrovo, Andrea Lorenzon and Christian Dullin,

Biomedical Physics \& Engineering Express, 2015, 1(3):035201.

IV Optimization of the loading efficacy for dual-modal CT/MRI macrophage tracking in lungs of an asthma mouse model

Emanuel Larsson, Christian Dullin, Natalia Abrikossova, Caroline Brommesson, Urša Mikac, Chiara Garrovo, Agostino Accardo, Giuliana Tromba, Igor Serša and Kajsa Uvdal,

(in manuscript - to be submitted to the Journal of Macrophage)

V Dual-modal CT and MRI functional and anatomical imaging using barium sulphate and gadolinium nanoparticle loaded macrophages in a preclinical asthma mouse model

Emanuel Larsson, Christian Dullin, Natalia Abrikossova, Urša Mikac, Caroline Brommesson, Agostino Accardo, Giuliana Tromba, Kajsa Uvdal and Igor Serša, (in manuscript - to be submitted to the Journal of Magnetic Resonance Materials in Physics, Biology and Medicine)

* These authors contributed equally to this work. 



\section{Author's Contribution:}

\section{Paper I:}

I took part in data acquisition and in the optimization of the reconstruction work flow. I actively participated in the scientific discussion and in modifying the manuscript.

\section{Paper II:}

This paper was performed in close collaboration with the other first authors (equal contribution). I took part in data acquisition and sample reconstructions. My main responsibilities were to perform the post processing, 3-dimensional $(3 \mathrm{D})$-rendering and quantitative evaluation of the CT data. I was strongly involved in the scientific discussion and I took part in writing the manuscript, especially the methods' and results' sections related to my main responsibilities.

\section{Paper III:}

I took part in data acquisition at the synchrotron and sample reconstructions. I was main responsible for the evaluation of the obtained data and for writing the manuscript. I was the corresponding author for this paper.

\section{Paper IV:}

I actively participate in the design of the experiment and independently performed the data acquisition at the synchrotron and sample reconstructions. I participated in MR scanning together with our external collaboration partner. I was main responsible for the evaluation of the data and for writing the manuscript.

\section{Paper V:}

I actively participate in the design of the experiment and independently performed the data acquisition at the synchrotron and sample reconstructions. I participated in MR scanning together with our external collaboration partner. I was main responsible for the evaluation of the data and for writing the manuscript. 

Related publications, not included in thesis:

- Phase-contrast computed tomography for quantification of structural changes in lungs of asthma mouse models of different severity, Christian Dullin, Emanuel Larsson, Giuliana Tromba, Andrea M. Markus and Frauke Alves, Journal of Synchrotron Radiation, 2015, 22(4):1106-1111.

- Morphological characterization of the human calvarium in relation to the diploic and cranial thickness utilizing x-ray computed microtomography, Emanuel Larsson, Francesco Brun, Giuliana Tromba, Palmina Cataldi, Kajsa Uvdal and Agostino Accardo, XIII Mediterranean Conference on Medical and Biological Engineering and Computing 2013, Volume 41 of the series IFMBE Proceedings pp 194-197, Springer International Publishing, 2013 Seville, Spain.

- In vivo regenerative properties of coralline-derived (biocoral) scaffold grafts in human maxillary defects: Demonstrative and comparative study with beta-tricalcium phosphate and biphasic calcium phosphate by synchrotron radiation $x$-ray microtomography, Alessandra Giuliani, Adrian Manescu, Emanuel Larsson, Giuliana Tromba, Giuseppe Luongo, Adriano Piattelli, Francesco Mangano, Giovanna Iezzi, and Carlo Mangano, Clinical Implant Dentistry and Related Research, 2014, 16(5):736-750.

- Microstructural characterization and in vitro bioactivity of porous glass-ceramic scaffolds for bone regeneration by synchrotron radiation x-ray microtomography, Chiara Renghini, Alessandra Giuliani, Serena Mazzoni, Francesco Brun, Emanuel Larsson, Francesco Baino, and Chiara Vitale-Brovarone, Journal of the European Ceramic Society, 2013, 33(9):1553-1565.

- Quantification of structural differences in the human calvarium diploe by means of x-ray computed microtomography image analysis: A case study, Emanuel Larsson, Francesco Brun, Giuliana Tromba, Palmina Cataldi, Kajsa Uvdal and Agostino Accardo, 5:th European Conference of the International Federation for Medical and Biological Engineering, Volume 37 of the series IFMBE Proceedings pp 599-602, Springer Berlin Heidelberg, 2011, Budapest, Hungary. 



\section{CONTENTS}

1 INTRODUCTION 1

1.1 Objective 1

1.2 Thesis outline 1

2 CONTRAST AGENTS 3

2.1 Contrast agents for Computed Tomography 3

2.2 Contrast agents for Magnetic Resonance Imaging 4

2.3 Selection and development of a multi-modal contrast agent for MRI and CT 5

3 ANIMAL DISEASE MODELS 9

3.1 Experimental design 9

3.1.1 Pilot studies \& sample sizes 10

3.2 Selection of an animal disease model expressing inflammations 10

3.2.1 Animal model used in this thesis - an asthmatic mouse model 10

4 TOMOGRAPHIC IMAGING MODALITIES 15

4.1 Computed Tomography 16

4.1.1 Production of Conventional X-rays 16

4.1.2 Experimental setup of CT vs $\mu$-CT 16

4.1.3 Synchrotron Radiation- $\mu-C T \quad 17$

4.1.4 Synchrotron Radiation- $\mu-C T$ vs conventional $\mu$ CT 21

4.1.5 X-rays interaction with matter and the attenuation of X-rays 21

4.1.6 Image quality 25

4.2 Magnetic Resonance Imaging 27

4.2.1 NMR Background 27

4.2.2 Net magnetization 27

4.2.3 Relaxation 29

4.2.4 Image contrast 31

4.2.5 Encoding the MR-signal 32

4.2.6 Imaging parameters 34

5 IMAGE POST PROCESSING 39

5.1 Image Quality 39

5.2 Segmentation Techniques 40

5.3 Volume Rendering 43

5.4 Selection of Volume of Interest 43

5.5 Quantitative \& Statistical Image Analysis 45

5.6 Image Registration 46

6 SUMMARY OF PAPERS 49

6.1 Paper I: 49

6.2 Paper II: 50 
xviii

CONTENTS

6.3 Paper III: 52

6.4 Paper IV: $\quad 54$

6.5 Paper V: 55

7 FINAL DISCUSSION 59

8 FUTURE OUTLOOK 61

BIBLIOGRAPHY 65

i PAPER I 75

ii PAPER II 83

iii PAPER III 99

iv PAPER IV 119

V PAPER V 133 


\section{ACRONYMS}

2D 2-dimensional

${ }_{3} \mathrm{D} \quad 3$-dimensional

${ }_{3} \mathbf{R} \quad$ The three R:s

Abs Absorption

AM Animal Model

Ba Barium

BALB/c Bagg Albino - inbred research mouse strain

$\mathrm{BaSO}_{4}$ Barium Sulfate

BL Blank

CA Contrast Agent

CCD Charge-Coupled Device

CN Control

CNR Contrast-to-Noise Ratio

CT Computed Tomography

DiD dialkylcarbocyanine dye

DTPA diethylentriamine pentaacetic acid

EEI Edge-Enhancement Index

EMR Electromagnetic Radiation

FBP Filtered Back Projection

FID Free Induction Decay

FOV Field of View

FRI Fluorescence Reflectance Imaging

Gd Gadolinium

GdNP Gadolinium nanoparticles

GdO-NP Gadolinium Oxide nanoparticles

HRCT High Resolution Computed Tomography 
ICGdNP Iodine Gadolinium nanoparticles

LAC Linear Attenuation Coefficient

LINAC Linear Accelerator

MAA Mild Acute Asthma

MAC Mass Attenuation Coefficient

н-CT Computed Microtomography

$\mu$-MRI Micro Magnetic Resonance Imaging

MR Magnetic Resonance

MRI Magnetic Resonance Imaging

NIRF Near Infrared Fluorescence

NMR Nuclear Magnetic Resonance

PAS Periodic Acid-Schiff

PBI Propagation-based imaging

PCX-CT Phase Contrast X-ray Computed Tomography

PD Proton Density

PercVol Percentage Volume

PET Positron Emission Tomography

PhC Phase Contrast

PhR Phase Retrieval

RF Radio Frequency

RF Radiofrequency

SAA Severe Acute Asthma

SCN Severe Control

SD Standard Deviation

SNR Signal-to-Noise Ratio

SPECT Single-Photon Emission Computed Tomography

SR Synchrotron Radiation

SR HR $\mu$-CT High-Resolution Synchrotron-Radiation-based X-ray Phase-Contrast Computed Microtomography 
SR $\mu$-CT Synchrotron Radiation Computed Microtomography

StTh Structure Thickness

SYRMEP SYnchrotron Radiation for MEdical Physics

TE Time to Echo

TIE Transfer of Intensity Equation

TR Time to Repeat

UHV Ultra-High Vaccum

US Ultrasound

VoI Volume Of Interest

OVA Ovalbumin

theranostic combination of therapy and diagnosis

in-situ a structure in its normal state

Mn Manganese

ZnGdNP Zinc Gadolinium nanoparticles

USPIO Ultrasmall Superparamagnetic Particles of Iron Oxide 

Many wide spread diseases, such as atherosclerosis, asthma, diabetes and cancer have inflammation as a common pathway in the disease progression. Improved possibilities to identify and diagnose sites of inflammation would therefore be of great interest. As the development of hybrid imaging modalities, combining at least two modalities, such as Computed Tomography (СТ) and Magnetic Resonance Imaging (MRI) in one, allowing the extraction of both complementary and synergistic information, the need for advanced imaging probes incorporating both CT and MR properties increased. The usage of of so called multi-modal contrast agents will potentially lead to earlier and more accurate diagnosis of inflammatory diseases.

\section{I OBJECTIVE}

The main objectives of this thesis work were to:

- Distinguish morphological alterations and signs of inflammation in mouse animal disease models, using a dual-modal CT and MRI imaging approach.

- evaluate and optimize the efficiency of labeling immune cells with dual-modal CT-MRI based contrast agents, aiming to track the homing of these cells to inflammatory sites, using CT and MRI.

- develop an image processing \& analysis scheme, to allow for quantification of typical morphological hallmarks of lung diseases, in order to characterize the state of the illness, as well as to monitor treatment response and to allow for a future combination of therapy and diagnosis (theranostic) approach in these diseases.

\subsection{THESIS OUTLINE}

This thesis is divided into the following main chapters:

Chapter 2 CONTRAST AGENTS

Chapter 3 ANIMAL DISEASE MODELS

Chapter 4 TOMOGRAPHIC IMAGING MODALITIES

Chapter 5 IMAGE POST PROCESSING 

The success of imaging is crucially dependent on the quality of the acquired images. The image quality can further be described as a combination of two contrast contributing factors, one being the difference in brightness of two adjacent tissues, which is crucial for separating two tissue types from each other and the second being their sharpness, thus meaning the lack of blurring of the tissue interfaces.

Besides the successful usage of Contrast Agent (CA)s in both CT and MRI, they only exploit the differences in the accumulation of these CAs in certain tissues, without providing any specific targeting of certain structures of interest, such as tumor cells. Nanoparticle based CAs on the other hand, can be used for specific targeting, by modifying their surface, e.g. by attaching a fragment of an antibody (tag) for recognition. Another way is to use macrophages as carrier of CA to specific sites of inflammation, as shown in this thesis work.

\subsection{CONTRAST AGENTS FOR COMPUTED TOMOGRAPHY}

$\mathrm{CT}$ is without doubts superior in spatial resolution, but by its nature the contrast formation is related to the atomic number, $\mathrm{Z}$ of the imaged materials, which therefore leads to a very poor contrast of soft-tissue. A common technique to increase this contrast, thereby enabling the usage of $\mathrm{CT}$ to image soft-tissue is the application of contrast agents, such as contrast based solutions containing iodine, barium or gold. Accumulated CT contrast agent will be directly visualized in the acquired image.

In order to determine the X-ray absorption effects of a certain CA for CT one can have a look at the X-ray Mass Attenuation Coefficient (MAC) as a figure of merit, which can be interpreted as the effective area per unit mass needed for absorbing a certain element, commonly written in units of $\left(\mathrm{cm}^{2} / \mathrm{g}\right)$. Figure 1 shows the tabulated MAC for a set of common CT CAs, such as zinc, barium, iodine, silver and gold. 


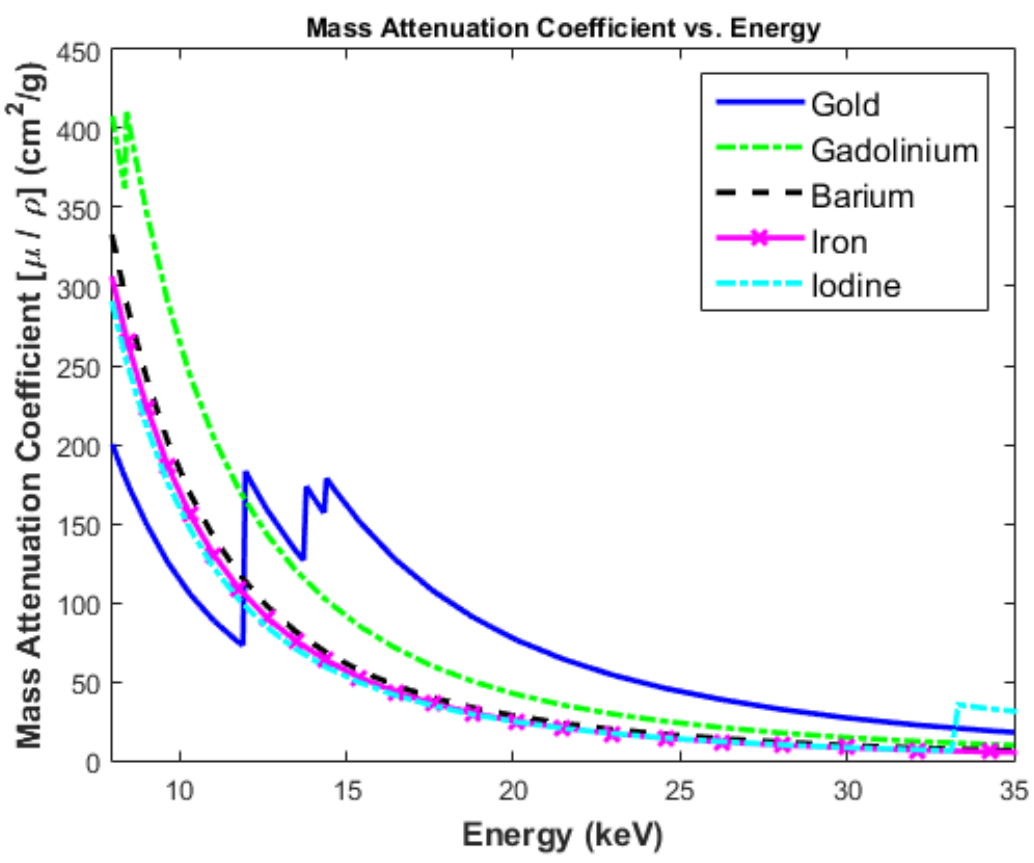

Figure 1: The X-ray MAC of a set of common elements used in CT contrast agents vs. the scanning energy. Data from source: [1].

\subsection{CONTRAST AGENTS FOR MAGNETIC RESONANCE IMAGING}

MRI contrast agents on the other hand are not directly visualized, as for CT contrast agents. Instead it is the effect that the MR contrast agents have on the varied water proton relaxation times that is used for contrast enhancement.

Even though the source of contrast in MRI is of a different nature and also more sensitive than $\mathrm{CT}$, there is still a need to increase the contrast of targeted structures such as tumors or metastasis to further facility their visualization.

The idea behind MR CAs is to shorten the T1 or T2 relaxation times of the protons spins of water in tissue, in order to obtain a contrast difference between two different tissues. CAs shortening the Ti relaxation time give rise to a positive contrast enhancement (bright images) and are thus referred to as positive or T1-weighted CAs, whereas CAs shortening the $\mathrm{T} 2$ relaxation time lead to a negative contrast enhancement (dark images) and are therefore referred to as negative or T2weighted CAs. A more detailed description of the theory behind MR is given in section 4.2 .

Examples of positive CAs are paramagnetic metal complexes, such as Manganese (Mn) (II) (5 unpaired electrons) and Gadolinium (Gd) (III) 
(7 unpaired electrons). Unpaired electrons have a magnetic dipole moment, that can interact with and shorten the Ti relaxation times of the surrounding nuclei, such as the hydrogen atom, which is present in water, making up around $60 \%$ of the body weight in a human adult male [2]. More unpaired electrons of a CA implies stronger magnetic relaxation effects on hydrogen [3].

Today clinically used MR CAs are based on complexes incorporating Gd and Mn. The first clinical CA was a Gd based complex (Gd-DTPA), developed in the early 1980s, FDA approved for intravenous administration in 1988 and sold under the trading name Magnevist $@[4,5]$. Recent developments of CAs for MR based on the usage of nanoparticles, such as e.g. $\mathrm{Gd}_{2} \mathrm{O}_{3}$ nanoparticles $[6,7,8,9,10,11]$ show that they can be used to further increase the relaxivity of water, due to the distribution of more Gd-atoms on a larger surface area, yet on a small volume. where more Gd surface atoms are thus able to interact with hydrogen protons. Ahrén et al. [12] and $\mathrm{Hu}$ et al. [13] reported a water relaxivity increment of a factor of 2 per $\mathrm{Gd}$ atom for $\mathrm{Gd}_{2} \mathrm{O}_{3}$ nanoparticles, compared to Magnevist $\AA$.

\subsection{SElECtion AND DEVELOPMENT OF A MULti-MOdal CON- TRAST AGENT FOR MRI AND CT}

The usage of so called hybrid multi-modal contrast agent in noninvasive image capturing techniques, such as CT and MRI, allows to extract both complementary and synergistic information, thereby being able to make a more reliable comparison between the obtained images, while as permitting easier diagnosis.

A dual-modal CA should have both MR and CT capabilities. Therefore, a natural step would be to localize potential MR CA with a relatively high X-ray MAC. Figure 2 shows the tabulated MAC for a set of common MR CAs. A potential contrast agent for dual-modal imaging in both MR and CT is thus Gd based CA, with clear MR capabilities, as described above, as well as a high MAC, thus suggesting its potential use, as a CA also in CT. Also in comparison to common CT CAs, Gd shows a very high MAC, as shown in Figure 1. 


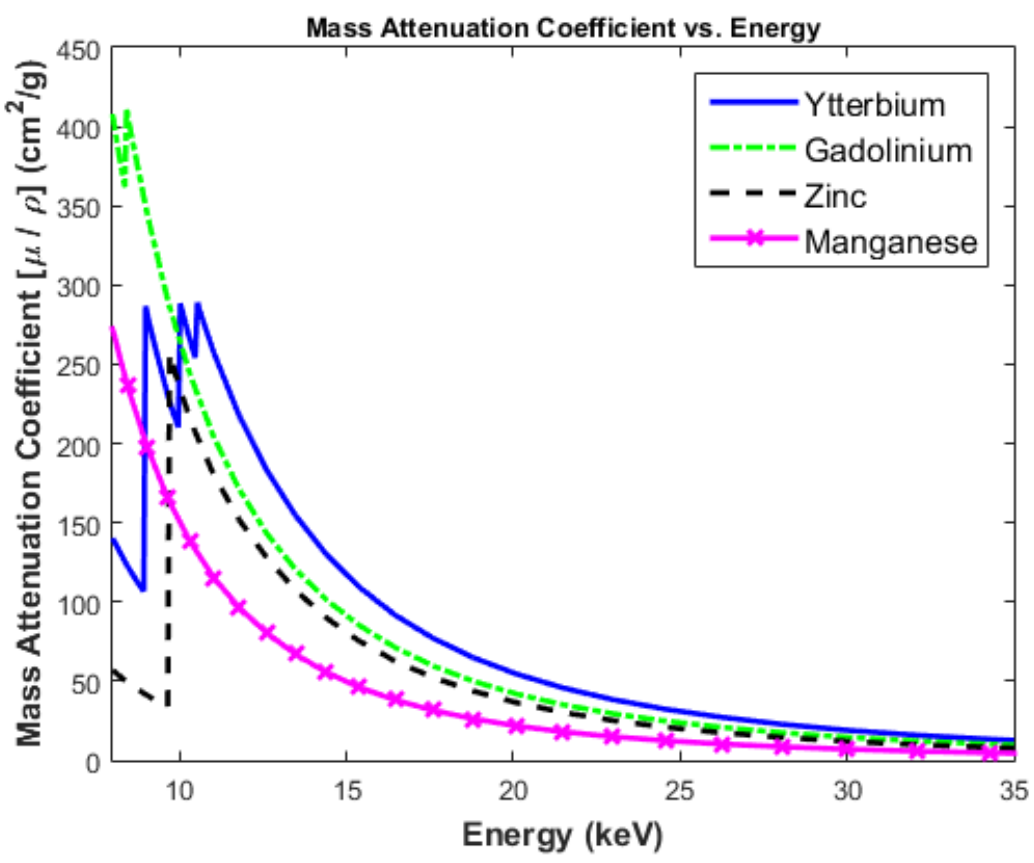

Figure 2: The X-ray MAC of a set of common elements used in MRI contrast agents vs. the scanning energy. Data from source: [1].

The CT capability of Gd has been clinically tested in some selected studies [14, 15]. In the study by Bloem and Wondergem [14], two patients receiving an intravenous administration of Gd-DTPA, were first examined with MRI, followed by examination with CT. The CT examination showed a high attenuation of concentrated Gd-DTPA in the urinary bladder and renal system [14]. In a preclinical study by Gierada et al. [16] the CT capability of gadolinium in the CA Gadodiamide was investigated in porcine model, by injection of CA into a peripheral vein in the hind limb of the pigs, where the contrast enhancement in the aorta, pulmonary arteries, liver and kidneys were studied as an effect of time after injection [16].

Other ways, to benefit from both MR and CT capabilities is to combine an MR CA with an CT CA. Ahmad et el. [17] investigated the T1 MRI and CT dual imaging capability of a hybrid CA, consisting of GdNPs coated with various iodine compounds (IC). The IC-GdNPs showed both stronger $\mathrm{X}$-ray absorption and higher relaxivities, than commercial CT or MR CAs [17]. Alric et al. [18] developed gadolinium chelate coated gold nanoparticles for usage as a CA in both SR $\mu$-CT and MRI, which was confirmed by in-vivo scanning of rats and mice, injected with the CA.

Marinescu et al. [19] instead used a negative T2 CA, based on Ultrasmall Superparamagnetic Particles of Iron Oxide (USPIO) to perform 
dual-modal CT-MRI cell tracking in a murine model of stroke, by injecting USPIO loaded macrophages for homing of the brain lesion. The results showed that SR $\mu$-CT was capable of providing an accurate location of the USPIOs, meanwhile in MRI a signal loss was observed, that exceeded further away then the actual location of the USPIOs.

\subsubsection{Sample preparation}

In this thesis a combination of a clinically approved CT contrast agent based on a suspension of Barium Sulfate $\left(\mathrm{BaSO}_{4}\right)$ with Sorbitol (sugar molecule), referred to as Micropaque $® C T$ (originally a gastrointestinal CA [20]) and a positive MR contrast agent based on Gadolinium Oxide nanoparticles (GdO-NP) (hereinafter referred to as GdNP) [12] were tested as intracellular contrast agents in an animal disease model of asthma. 

In general, any type of model has by definition characteristics that resemble the target, but can however be different in other ways [21]. Diseases however are too complex to model with tissue models, cell based assays or with computer programs. Due to the complex nature of diseases they therefore need to be studied in living animals.

Human animal disease models are therefore today used to model a human disease as accurately as possible on a preclinical level. Animal Model (AM) experiments contribute to an increased understanding of the involved mechanisms in a disease, although their capability in predicting the treatment efficacy in followed clinical trials is still quite controversial. [22, 23, 24]. Moreover, some critics also state that the results obtained from using AMs can not always be translated to humans, due to biological differences between the species and that the results therefore are biased by the type of animal model used [25]. Representative AMs are therefore needed, with a well accepted and studied disease type and an outbread laboratory strain [26].

Mouse models are commonly used to model human diseases, as they are easy to handle, have a fast reproduction cycle and are cost effective, compared to other species. Mouse models are also based on an inbreed mouse strain and therefore show low inter-sample variation for the parameter of interest. Furthermore, due to the small size of mice, in comparison to the human, high end imaging strategies need to be utilized, when studying a disease on a preclinical level, as shown in Paper I and II. The obtained results about a disease can then be translated to a clinical level where standard imaging devices are used, as shown in Paper III.

\subsection{EXPERIMENTAL DESIGN}

For both ethical and economical reasons it is important that the AM experiments are well designed [21]. In order to make sure that the experimental plan complies with these ideas, one can follow the principle of the The three R:s $\left.{ }_{3} R\right)$ s. The ${ }_{3} R$ states that if possible one should 1) Replace an animal model with a less sentient alternative, such as a less complex invertebrates or use in vitro methods [21], 2) Refine the experimental plan, in order to minimize any negative effects, such as pain, suffering and distress for the animals [27] and 3) Reduce the number of used animals, in order not to perform unnecessary repeti- 
tions of an experiment [21] or by obtaining more info from the same number of animals [27].

\subsubsection{Pilot studies $\mathcal{E}$ sample sizes}

Pilot studies involving the usage of only one single animal are sometimes necessary to test the logistics of a given animal experiment. The usage of a larger sample size, will permit the extraction of mean and standard deviations, thus allowing the prediction of a likely response, which can also be followed up with a statistical Power Analysis, where the minimal sample size needed for detecting a significant result with a low error [20] in an upcoming experiment can be determined [21].

\subsection{SELECTION OF AN ANIMAL DISEASE MODEL EXPRESSING IN- FLAMMATIONS}

In order to test the both the capability and specificity of a dual-modal contrast agents in both $\mathrm{CT}$ and MRI there was hence the need for a preclinical case, in which important disease-related information could be revealed, due to the presence and usage of contrast agents. As earlier mentioned under Chapter 2, one way of performing specific targeting of a contrast agent is to attach a fragment of an antibody to the surface of nanoparticle based contrast agents. Another way of performing specific homing of CAs, is to let macrophages act as carriers of the CAs. Macrophages are phagocytic immune cells (a type of white blood cells) present in high numbers in tissue, where they are responsible for a wide range of tasks including phagocytosis and clearance of pathogens, microbes and cellular debris, as well as the upholding of haemostasis. Furthermore, macrophages also have a wide range of receptors and surface molecules, and release mediators (e.g. cytokines), which govern the inflammatory processes. Since macrophages play an important role in inflammation and are capable of engulfing large particles, such as CA, a proposed idea was therefore to use an animal disease model expressing inflammation and then use macrophages (subtype M2-macrophages) as carriers of intracellular contrast agents to the sites of interests [28].

\subsubsection{Animal model used in this thesis - an asthmatic mouse model}

The chosen animal model to be investigated in this thesis work was an asthmatic mouse model. Furthermore, asthma is a global burden and affects around 329 million people worldwide [29]. There are different of asthma (acute and chronic) with several subgroups [30, 31]. The mechanism of asthma is not yet fully understood and only about $10 \%$ of the cases can be treated today. Asthma also has a strong in- 
flammatory component, which is preferably studied by MRI. Mizue et al. [32] demonstrated that the lack of the migration inhibitory factor (MIF) in mice commonly used for studying asthma, lead to that no asthma could be induced, thus suggesting that the migration of macrophages plays an important role in the disease progression of asthma.

Asthma only exists naturally in humans. Therefore in order to study asthma in a mouse model, asthma-like symptoms need to be induced artificially. This can be done using Ovalbumin (OVA), where also different severities of asthma can be induced [33]. The induction of an asthmatic attack is further described in Paper II [34]. Asthma-related anatomical changes are also very subtle and therefore require an exceptional good image quality and resolution, which can be offered by $\mathrm{SR} \mu-\mathrm{CT}$.

Moreover, since asthma is a complex disease, involving the immune system and there are no in-vitro models mimicking the complex processes of the immune system within the lung, the usage of an animal model mimicking asthma is therefore required. With this in mind, while following the principles of the ${ }_{3}$ Rs, the term Replace, was realized by choosing a less complex invertebrate, such as a mouse model. The Refinement term was considered, since the proposed OVA-induced model, based on previous studies causes no pain and only slight stress for the mice. Furthermore, the challenge with OVA may cause asthma-like symptoms, such as short breath for a limited time for the mice. The Reduce term was considered by one mouse per sample group for the initial proof of principle studies and by extracting as much information as possible from each mouse.

For this thesis work an OVA-induced allergic airway inflammation model (mimicking human asthma [35]) was used, utilizing female aged matched Bagg Albino - inbred research mouse strain (BALB/c) mice. The mice were injected intranasally with either Barium Sulfate ( $\left.\mathrm{BaSO}_{4}\right)$ or Gadolinium nanoparticles (GdNP) [12] loaded alveolar murine macrophages [36], 24 hours after the asthma attack. Since the strongest inflammation had been observed 48 hours after the asthma attack, the biggest involvement of macrophages was expected at this time point, which is why each mouse was sacrificed at this time point. Herein-after the lung was inflated with air at constant pressure of 30 $\mathrm{cm}$ water column and each mouse was embedded in $1 \%$ agarose gel confined inside a $30 \mathrm{ml}$ tube, wherein after the lung was scanned a structure in its normal state (in-situ) (in its natural condition inside the mouse) with SR $\mu$-CT and $\mu$-MRI. 
Moreover, despite the known differences in transferring results from a murine system to humans, this model is valid, since the central signaling pathways are similar in both species. Furthermore, murine macrophages have an average diameter of $10 \mu \mathrm{m}$, whereas human macrophages have a diameter of $20 \mu \mathrm{m}$, thus implying a scaling effect by a factor of 2 .

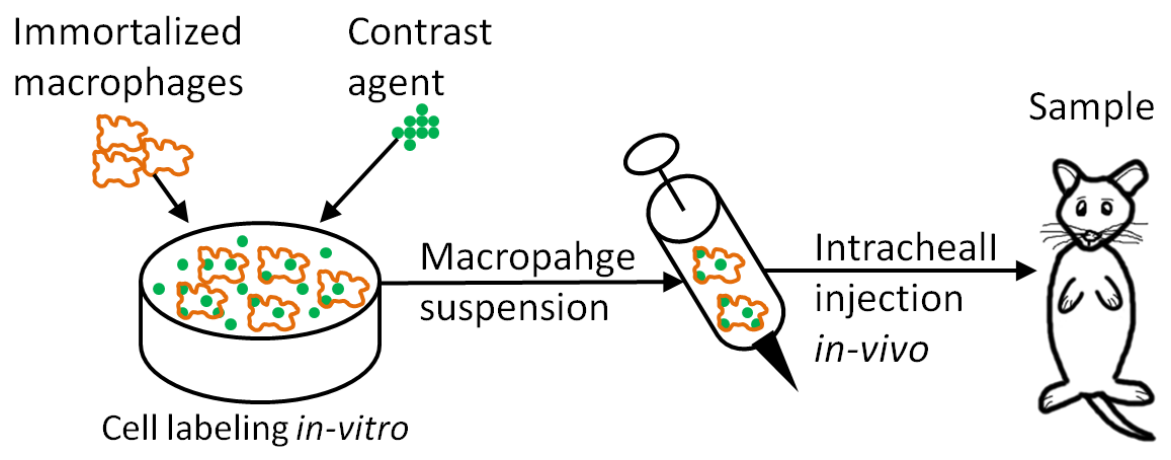

Figure 3: Scheme of the in-vitro cell loading approach followed by the intracheal injection of macrophages in the mouse sample in-vivo.

\subsubsection{Alveolar Macrophages as carriers of intracellular contrast agents}

However, prior to injecting the cells into the AM there was the need to optimize the cell loading efficacy of the given contrast agents, making the contrast loaded cells distinguishable from other non-loaded cells in SR $\mu$-CT. The CT-slices in Figure 4 and 5 show an increased uptake of $\mathrm{BaSO}_{4}$ loaded and Gd-loaded alveolar macrophages respectively, when increasing the two parameters 1 ) culturing concentration of contrast agent or 2) cell culturing time. The results showed an increased detectability of $\mathrm{BaSO}_{4}$-loaded cells, meanwhile the detectability was less for GdNP loaded cells.

Although the MAC $(\mathrm{cm} 2 / \mathrm{g})$ is higher for Gd than for Barium (Ba), please see Figure 1, the crucial factor for the success of an intracellular contrast agent in $\mathrm{CT}$ is dependent on the amount of material taken up by the cell, where the uptake of more material increases the detectability. The results above clearly show that the amount of uptaken Ba is much higher then the amount of uptaken Gd. Therefore, in order to be able to use GdNP as an intracellular contrast agent in this case more precisely in SR $\mu$-CT at an energy range between $17-22 \mathrm{keV}$ (for our purposes), there is the need to boost the cell uptake. In paper IV the possibility that the increased cell uptake of Ba is related to the immersion in Sorbitol is further investigated by capping/immersing Sorbitol to GdNP. A high concentration of Gd is more optimal for CT, but can if being to high lead to a black out of the positive T1-weighted signal in MRI, due to an increased T2 effect of Gd at higher concen- 
trations. Therefore a trade off between an acceptable contrast in both CT and MRI, directly related to the cell uptake of the GdNP needs to be established. A second alternative for performing dual-modal cell tracking in both CT and MRI is also based on the idea of mixing cell colonies, separately loaded with either $\mathrm{BaSO}_{4}$ or GdNP, which is further investigated in Paper IV.

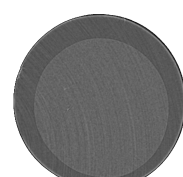

Pure Cells

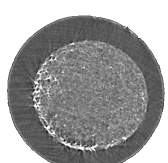

Ba $2 \mathrm{~h}$



Cells Ba

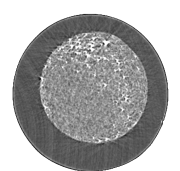

Cells Ba

$1.5 \mathrm{mM}$

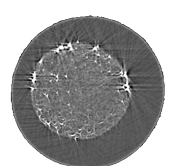

Ba 8h

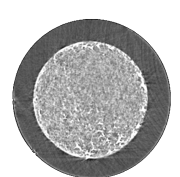

Cells $\mathrm{Ba}$

$2.5 \mathrm{mM}$



Ba 24h

Cells

Figure 4: Ba-loaded alveolar macrophages as a function of increasing 1) incubation concentration of contrast agent or 2) incubation time.

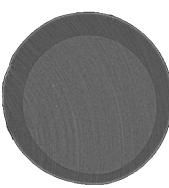

Pure Cells

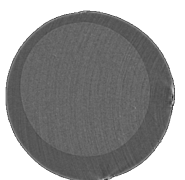

Gd 2h

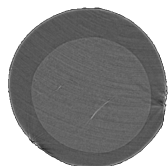

Cells Gd
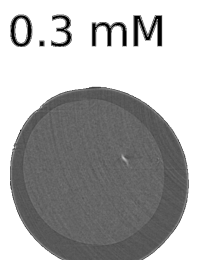

Gd $4 \mathrm{~h}$

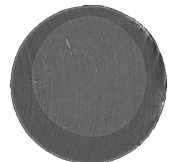

Cells Gd $0.9 \mathrm{mM}$

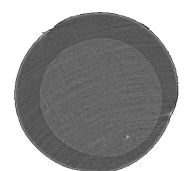

Gd 8h

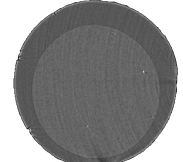

Cells Gd

$1.5 \mathrm{mM}$

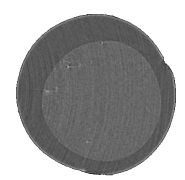

Gd 24h

Figure 5: Gd-loaded alveolar macrophages as a function of increasing 1) incubation concentration of contrast agent or 2) incubation time. Please notice that some minor accumulations of Gd-loaded cells give rise to a higher contrast. 
A test of metabolic ACtivity, to EVAluate toxic efFects Apart from obtaining an optimal contrast in either CT or MRI, the most important factor for performing cell tracking in an AM is to make sure that the cell viability is acceptable. For Gd-based contrast agents it is important to design the contrast agent so that no free $\mathrm{Gd}$ ions are exposed to the living cells, since free $\mathrm{Gd}_{3}+$ ions are very toxic [37]. In the commercial contrast agent Magnevist $(\mathrm{B}, \mathrm{Gd}$ is capped to the organic molecule diethylentriamine pentaacetic acid (DTPA), in order to create a more biocompatible contrast agent, with the chemical name Gd-DTPA, thereby reducing the possible toxic effects of any released $\mathrm{Gd}$ ions. The effect that each contrast agent had on the cell viability was assessed by a WST-1 cell metabolic activity test. Active and viable cells will cleave tetrazolium salt WST-1 to a water-soluble formazan dye with the help of the enzyme mitochondrial succinate-tetrazolium reductase, where the measured absorbance of the dye is proportional to the quantity of viable cells [38]. Such a WST-1 test was performed in Paper IV on both the GdNP- and $\mathrm{BaSO}_{4}$-loaded macrophages. 
With every imaging modality comes both strengths and limitations [20], related to the very technical nature of the given scanning system. Furthermore, for non-invasive imaging, the modality should be chosen with respect to the investigated parameter of interest, in order for the study to be as effective as possible [20].

Preclinical research of small animal models also requires tomographic imaging modalities with higher resolution, in order to be able to translate the obtained results back to the clinic [20]. This has lead to the need for dedicated preclinical tomographic imaging modalities (including ways for improving the spatial resolution). Through so called reversed translation of clinical tomographic imaging modalities such as e.g. Positron Emission Tomography (PET), Single-Photon Emission Computed Tomography (SPECT), Computed Tomography (CT) and Magnetic Resonance Imaging (MRI) these techniques are today also available for preclinical research [20].

IMAGING PROPERTIES

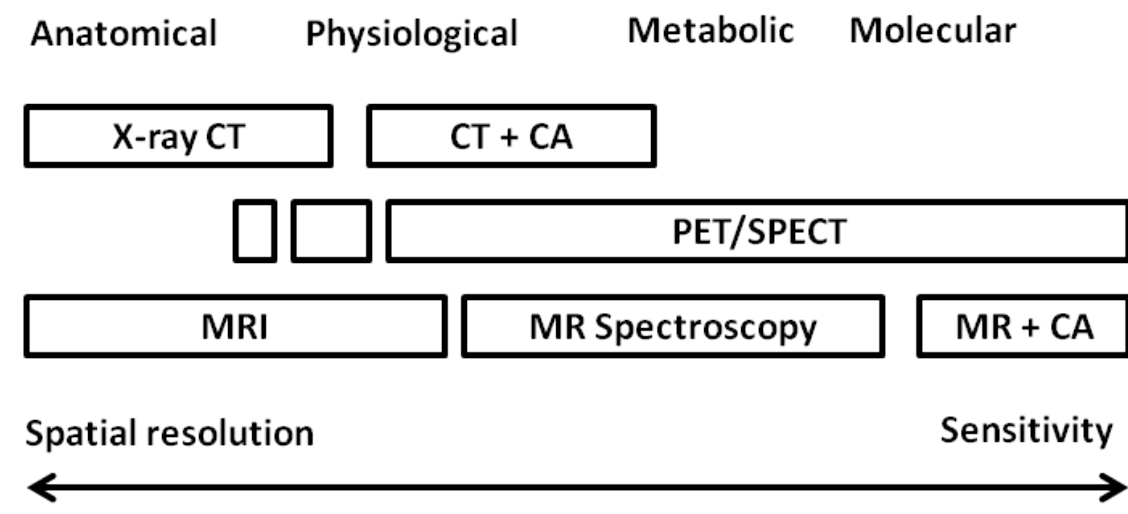

Figure 6: Comparison of tomographic imaging modalities: CT, PET/SPECT and MR, in terms of spatial resolution and sensitivity and their ability to image anatomical structure, as well as physiological, metabolic and molecular processes. Also the impact of using Contrast Agent (CA)s in CT and MRI is outlined.

The corresponding preclinical imaging modality to $\mathrm{CT}$ is referred to as Computed Microtomography $(\mu-\mathrm{CT})$, where the spatial resolution can be improved by the usage of a so called micro-focus X-ray tube, which 
is further explained under Chapter 4.1.2. Micro Magnetic Resonance Imaging ( $\mu$-MRI) is the preclinical implementation of standard MRI, where the limited resolution issues are improved by using dedicated coils [20], with a size specifically fabricated with respect to the size of the sample to be scanned.

\subsection{COMPUTED TOMOGRAPHY}

The principle behind $\mathrm{CT}$ is related to the acquisition of a sufficient number of planar projections (using either one or more detectors), at different viewing angles of a given sample. For $\mu$-CT however it is instead the sample that is rotated, while the detector is fixed.

A projection image contains information about the attenuated X-rays through the sample for a certain rotation angle. The acquired projections images (one for each angle of rotation) the ${ }_{3} \mathrm{D}$ distribution of the Linear Attenuation Coefficient (LAC) within the sample can be calculated, through a process referred to as slice reconstruction [39], which is further described in Section 4.1.5.

\subsubsection{Production of Conventional X-rays}

Conventional X-rays are produced by an X-ray tube, where a filament (cathode) is heated using an electrical current, which will hence cause electrons to be emitted. These electrons are then accelerated towards a target material (anode), e.g. Tungsten, using an applied high voltage. Furthermore, the incident electrons are abruptly de-accelerated when they interact with the electrons in the anode material, wherein-after X-rays are emitted.

\subsubsection{Experimental setup of CT $v$ s $\mu-C T$}

The difference in the experimental setup between a standard CT and a $\mu$-CT is mainly related to which one of the following components: 1) X-ray source (focal spot), 2) sample or 3) detector(s) that should undergo a rotation, in order to permit the acquisition of projections from different viewing angles. In the 4 :th generation CT scanner the sample/patient is surrounded with a fixed ring of detector elements (can be seen as multiple detectors) together with a rotatable X-ray source producing a fan/cone shaped $x$-ray beam. Where as for $\mu-\mathrm{CT}$ they the different viewing angles are obtained by rotating the sample.

The X-ray beam used for both normal $\mathrm{CT}$ and $\mu$-CT is cone shaped. However, the word micro in $\mu$-CT is coming from the usage of a so called micro-focus X-ray tube, which produces a much smaller focal spot, with respect to the one obtainable in standard CT. A smaller fo- 
cal spot gives the advantage of being able to reach higher resolutions. Furthermore, a small focal spot also leads to partial coherent $\mathrm{X}$-rays, thus allowing to benefit from some limited Phase Contrast $(\mathrm{PhC})$ effects. The obtainable resolution for a clinical body scan CT is in the sub-millimeter range, and for a High Resolution Computed Tomography (HRCT) around 80-90 $\mu \mathrm{m} /$ pixel, meanwhile resolutions down to a few micrometers/pixel can be obtained using a $\mu$-CT scanner.

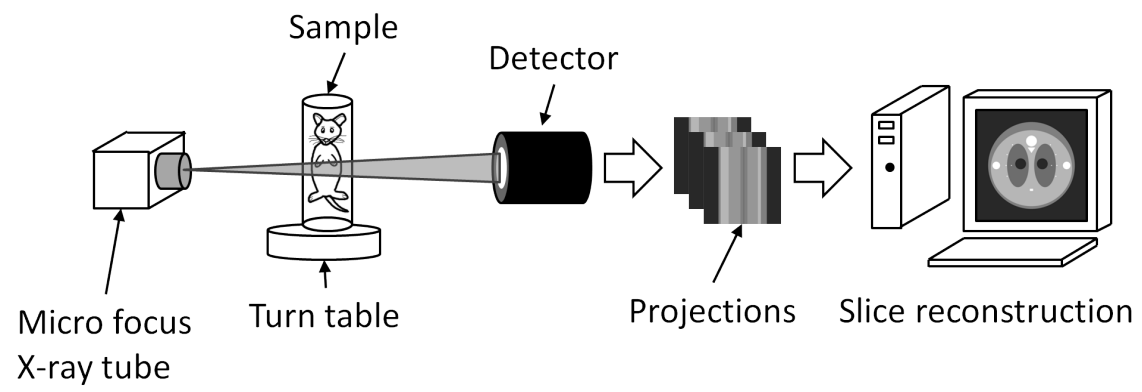

Figure 7: Sketch of a $\mu$-CT setup, showing the X-ray tube, sample, detector (from left to right), including the work flow for slice reconstruction.

\subsubsection{Synchrotron Radiation- $\mu-C T$}

Implementing the technique of $\mu$-CT at an experimental end station at a so called Synchrotron Light, allows the utilization of high intensity monochromatic X-rays, with an X-ray range optimal for absorption of low-absorbing samples, e.g. biological samples, together with $\mathrm{PhC}$ effects of sample-edges, due to the high coherence of the near-parallel $\mathrm{X}$-ray bean, providing a resolution between 1-10 $\mu \mathrm{m} /$ pixel.

\subsubsection{Production of Synchrotron Radiation}

Synchrotron Radiation (SR) (electromagnetic radiation) is generated when charged particles (e.g. a proton or an electron) moving close to the speed of light are exposed to the presence of a strong magnetic field, which will hence force them to follow a curved trajectory, at which point SR is emitted perpendicular to the direction of the moving particles. SR can occur naturally in outer space, when astrophysical sources and the presence of a magnetic field are causing electrons to accelerate radially along helical paths [40]. However, SR was first discovered back in 1947 during a particle physics experiment using the General Electric particle accelerator aiming to investigate the "unwanted energy loss" of the moving particles. This unwanted energy loss was however shown to be related to the creation of SR. Soon later the first dedicated synchrotron light sources were developed, with the aim of using SR as a tool for revealing the inner structure of vari- 
ous materials. In the beginning these Synchrotron light sources were however considered to be parasitic facilities, since accelerators were usually built for conducting high-energy and nuclear physics experiments. However, half a decade later we now have even the fourth generation of Synchrotron Light Sources, being capable of producing $\mathrm{SR}$ within the range from ultraviolet light to $\mathrm{x}$-rays.

\subsubsection{The principle and setup of a Synchrotron Light Source}

The process of creating SR at a synchrotron commence with the generation of discretely separated electron bunches by an electron gun (usually located inside the storage ring in a 3:rd generation synchrotron source), wherein-after the electron bunches are initially accelerated by the Linear Accelerator (LINAC). Here-inafter the electron bunches are let to pass into the booster ring, which will allow the electron bunches to be accelerated to their nominal working energy, wherein-after they are finally injected into the storage ring (4), experiencing Ultra-High Vaccum (UHV).

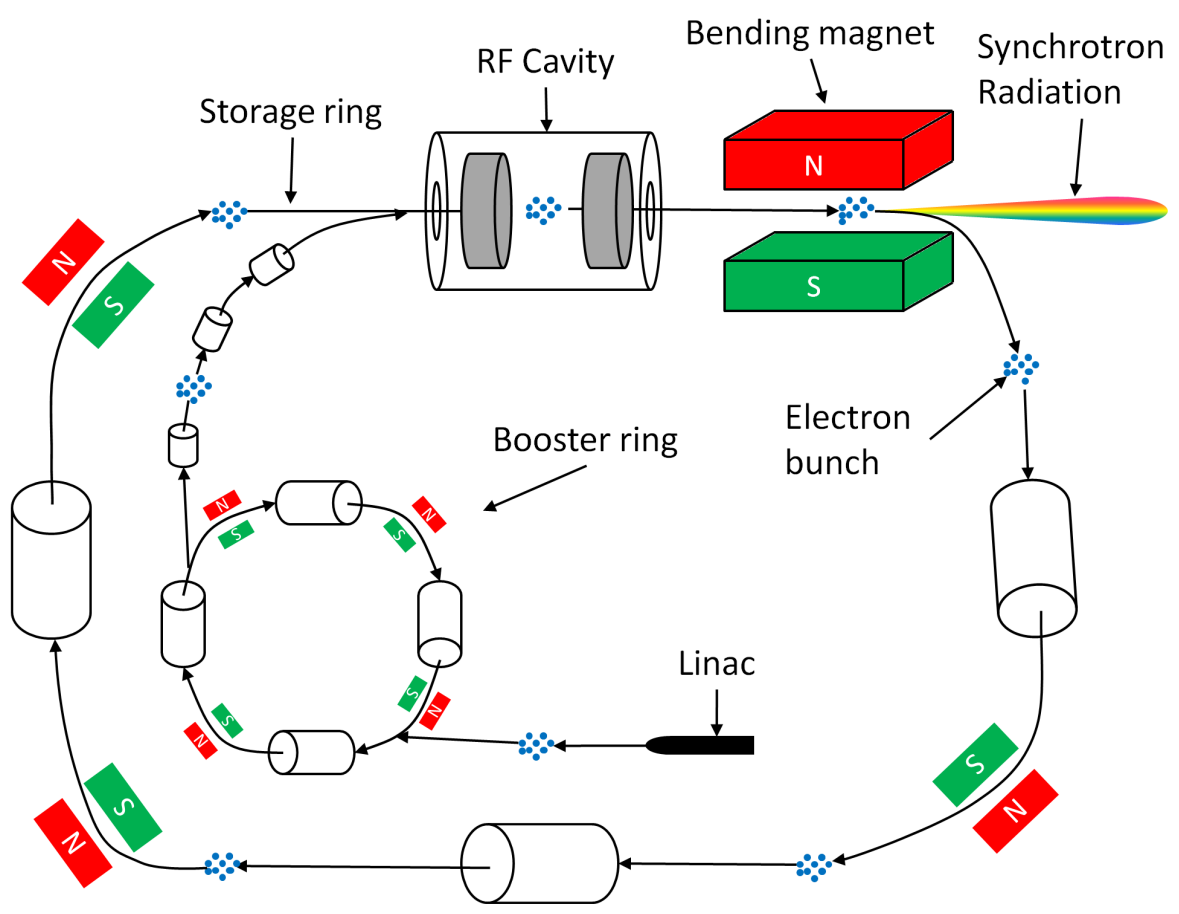

Figure 8: Scheme of a 3:rd generation Synchrotron Light Source including a booster ring. The produced SR from a bending magnet is folded into a narrow forward radiation cone, with continuous photon energies [41].

Well inside the storage ring the electron bunches are imposed to follow a curved trajectory with the help of so called bending magnets, which are located in between the straight positions of the storage ring. The magnetic field present inside the bending magnets will cause the 
electrons to bend from their initial path, which will lead to an energy loss of the electrons, represented by the a narrow angular cone of emitted continuous SR [40]. Even brighter SR can also be generated by so called insertion devices (Wiggler and Undulator), located in between the straight sections of the storage ring. Insertion devices are capable of creating an alternating magnetic field, causing the electrons to oscillate and radiate energy at every turn, thus creating discretly distributed SR.

The produced SR are the let to pass through a set of vacuum pipes, referred to as a beamline [40], after which they reach the experimental hutch, which has been designed to host a given experimental technique (absorption, diffraction, etc.), with respect to the energy of the incoming photons.

Furthermore, by using so called Radiofrequency (RF) cavities, which are placed out at the straight sections of the storage ring, the energy loss is synchronously restored to the passing electron bunches [41]. With time the current of the electron bunches slowly decays, due to electron-to-electron collisions or collisions with any other molecules present in UHV. In order to counter-act this the booster synchrotrons can today be run in a so called Top-Up mode, where electron bunches are injected periodically into the storage ring, thus making sure that the electron beam current is kept at a constant level. This also implies that the flux of the beam is kept at the same level, which is useful when long scanning times are needed for a given sample.

\subsubsection{Beamline setup for hard synchrotron X-rays tomographic imaging}

The experiments performed during this thesis have been performed at the SYnchrotron Radiation for MEdical Physics (SYRMEP) beamline located $23 \mathrm{~m}$ far away from the source at the Elettra Synchrotron Light Source in Trieste, Italy [42]. The source of the SR is a bending magnet optimized for producing Hard $\mathrm{X}$-rays in the energy region of (8-35 keV) (optimal for X-ray imaging of biological tissue) [43], which can be made monochromatic at a narrow energy bandwidth $(\Delta \mathrm{E} / \mathrm{E})$ of $2 \cdot 10^{-3}$, using a double-crystal Silicon monochromator, $\operatorname{Si}(1,1,1)$. Furthermore the produced X-rays also have a near parallel geometry [43], high flux, high brilliance and a high coherence, optimal for scanning in the PhC mode. The available flux at the SYRMEP Beamline as a function of the scanning energy, for various ring currents are shown in Figure 10. Available scanning modes include Absorption (Abs), PhC and diffraction imaging, utilizing scanning techniques such as planar projection imaging, as well as tomographic imaging. 
For this thesis a Charge-Coupled Device (CCD) camera (Photonics Science XDI-VHR) was used, which was coupled to a Gadox scintillator screen [43], with a full frame of $2008 \times 2672$ pixels, a dynamic range of $12-16$ bit and a Field of View (FOV) of $18 \times 12 \mathrm{~mm}^{2}$, a pixel size of 4.5 micrometers and binning $2 \times 2$, thus giving a final resolution of 9 $\mu \mathrm{m} /$ pixel.

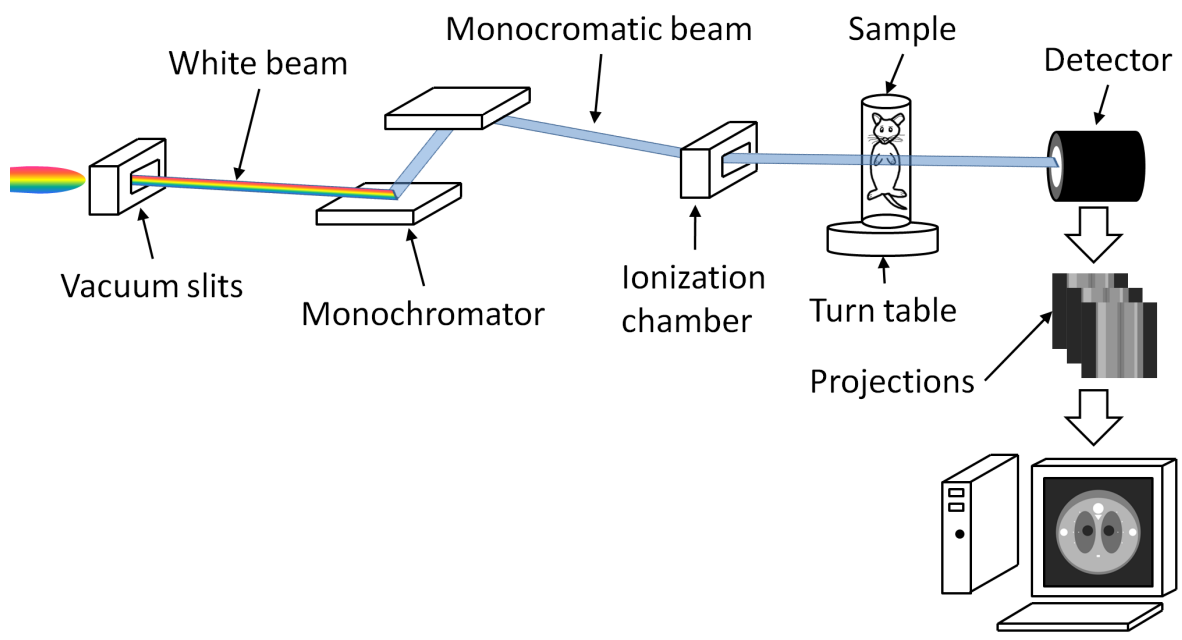

Slice reconstruction

Figure 9: Sketch of the SYRMEP Beamline with the implemented technique $\mathrm{SR} \mu-\mathrm{CT}$, including the work flow for slice reconstruction.

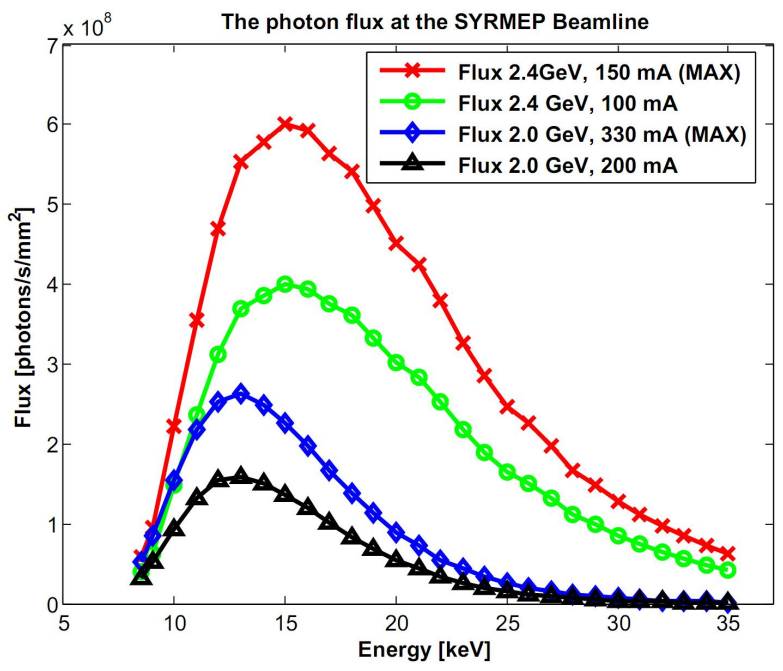

Figure 10: The flux at SYRMEP as a function of the energy, selected by the monochromator, for various ring currents (modes of operation). Please note that the peak of the flux-energy curve is shifted towards lower energies and frequencies. 


\subsubsection{Synchrotron Radiation- $\mu-C T$ vs conventional $\mu-C T$}

A SR-source offers; 1) high flux, which allows to filter to quasi-monochromatic X-rays; 2) a near-parallel geometry of the beam and 3) a large source-to-sample distance, in the range of $20-100 \mathrm{~m}$, which in combination create coherent $\mathrm{X}$-rays. The coherence of the beam allows to exploit the wave nature of X-rays, which is virtually not possible with conventional X-ray sources. For classical $\mu$-CT on the other hand the flux is much lower, thus resulting in much longer scanning times and poor Signal-to-Noise Ratio (SNR).

\subsubsection{X-rays interaction with matter and the attenuation of X-rays}

X-ray photons penetrating through a sample will be attenuated, which means that their initial intensity, $\mathrm{I}_{0}$ (number of photons) will decrease to $I_{x}$, as a function of the sample thickness, $x$, according to the BeerLambert law [44], which states that for a conventional (polychromatic) $\mathrm{X}$-ray beam, the detected X-ray intensity is given by [44]:

$$
I_{x}=\int_{E} I_{O}(E) e^{-\int_{l} \mu(x, E) d x} d E,
$$

where $I_{x}$ is the $X$-ray photon intensity, as detected by a given detector element (for a given row), and defined as the line integral (sum) of all the Linear Attenuation Coefficient (LAC), also referred to as $\mu(x)$, along the path, $x$ of the $\mathrm{X}$-rays and by the line integral of the photon energy, E.

For a monochromatic X-ray beam the Energy-dependency is removed and the Beer-Lambert law is thus reduced to the following relationship:

$$
I_{x}=I_{0} e^{-\int{ }_{l} \mu(x) d x}
$$

Furthermore, $\mu(x)$ is also affected by both the physical and chemical composition of the scanned sample, as well as the sample density, $\rho$, the atomic numbers, $\mathrm{Z}$ making up the scanned material [44] and by the processes that occurs when X-rays interact with electrons in the scanned material. The most important processes are the photoelectric effect (absorption), inelastic scattering (Compton scattering), elastic scattering (Thomson scattering and Rayleigh scattering) and pair production.

A projection image represents the sum of all local attenuations, $\mathrm{I}_{x}$ through the object along the path of the X-rays, as shown in Figure 11 . 




Figure 11: Scheme showing the detection of attenuated $\mathrm{X}$-rays passing through a chest. The attenuation of X-rays is dependent on sample properties and thickness.

\subsubsection{Imaging Modes}

When X-rays interact with matter they undergo absorption, refraction and diffraction, where the two subsequent ones are related to phase shift effects. The complex index of refraction equation is stated below:

$$
n=1-\delta+i \beta
$$

where the imaginary part $\beta$ is responsible for the attenuation of the sample, while as the term $\delta$ is the refractive index decrement related to the phase-shift of the incident $X$-rays interacting with the sample [45].

ABSORPTION IMAGING In conventional attenuation-based X-ray CT-imaging the image-formation is based on the absorption of $\mathrm{X}$ rays, where $\mu(x)$ (LAC) is the reconstructed parameter in the CT-slice, herein-after also referred to as $\mu_{A b s}(x)$.

This technique is well suited for scanning high absorbing samples, which are very thick or consists of elements with a high atomic number, $\mathrm{Z}$. However, using the Abs imaging method to scan soft matter, which has a low $Z$, gives rise to poor contrast in the images, due to poor absorption of the samples. 
PHASE CONTRAST IMAGING However, if the sample-to-detector distance is increased, while the utilized incident $X$-rays have a sufficient coherency (as in the case when using SR X-rays or micro-focus generated X-rays), the image-formation will apart from absorption, also be based on a sample-induced phase-shift [46], occurring when the X-rays are refracted on the borders between two sample components (with different indices of refraction), such as the air-to-tissue interface/edge inside the lung. This is referred to as Phase Contrast $(\mathrm{PhC})$-imaging. The reconstructed slice will comprise three contributing parameters, thus being:

$$
\mu_{\text {Recon }}(x)=\mu_{\text {Abs }}(x)+\mu_{P h C}(x)+\mu_{\text {Mixed }}(x),
$$

where $\mu_{A b s}$ is the map of the LAC of tissue (in this case), $\mu_{P h C}$ is the map of the Laplacian of the tissue refraction index decrement, which is the cause of the observed dark and bright fringes in the reconstructed slice, as observed in Figure 13 on the borders/edges, between two different materials, e.g. tissue and air. Furthermore, $\mu_{\text {Mixed }}(x)$ is an artifact related to the overall variations of $\mu_{A b s}$ and $\mu_{\mathrm{PhC}}$, which will hence lead to a distortion of the local structure of the imaged lung sample [45]. The estimation of the $\mu_{\text {Recon }}(x)$ for tissue will therefore be slightly inaccurate [45].

Furthermore, $\mathrm{PhC}$ is optimal for scanning soft matter, i.e. samples with a low Z, which are poor absorbers of X-rays [47]. Wu et al. [45] estimated $\delta$ and $\beta$ values for biological tissues, where it was further shown that $\delta$ is around 1000 times stronger than $\beta$ in the X-ray range of $10-100 \mathrm{keV}[48,49]$. This also implies that the difference in terms of $\delta$ between two given tissues are larger, than the differences in $\beta$, thus suggesting that $X$-ray based PhC-imaging is more sensitive, than standard Abs-imaging [50, 51, 52, 48, 49, 53] 


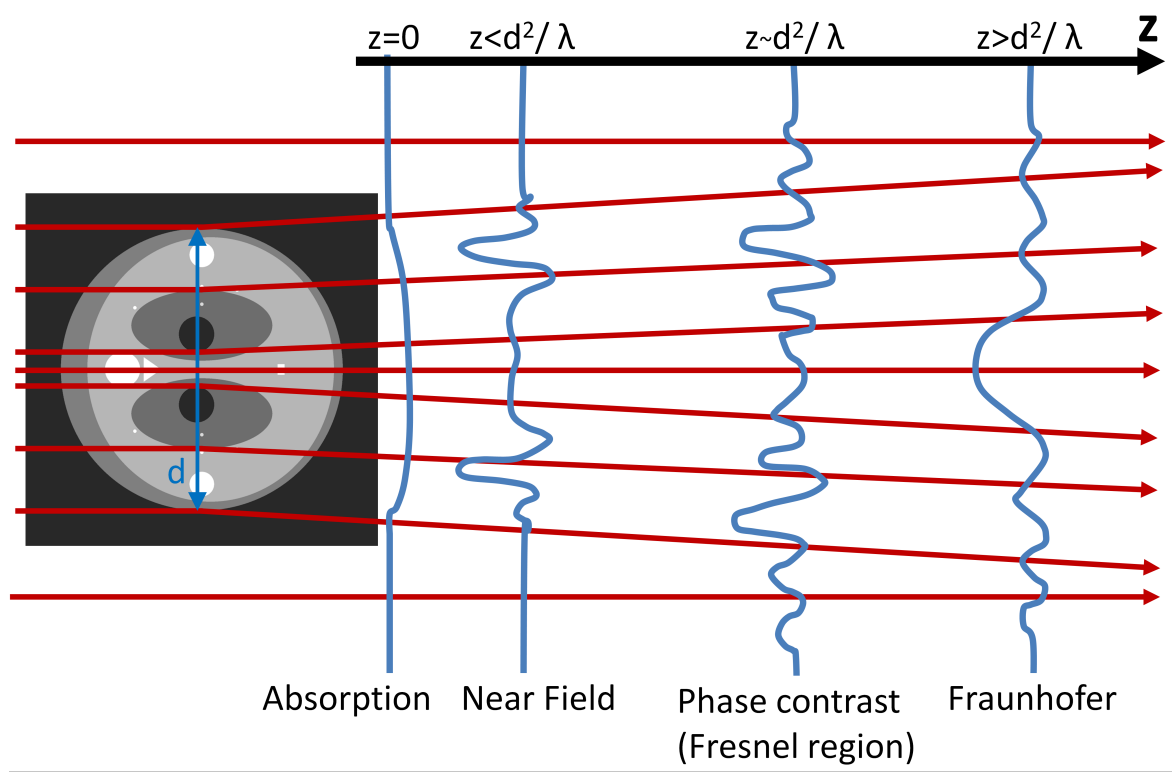

Figure 12: Illustration of the diffraction of X-rays for Absorption vs. propagation based imaging, for various sample-to-detector distances, $z$, where $\lambda$ is the X-ray wavelength and $d$ is the size of a sample structure orthogonally to the beam direction [47]. Allowing the diffracted X-rays to propagate the short altered distance $z$ beyond the sample a Fresnel diffraction will occur, under the circumstances that $\mathrm{z} \sim \mathrm{d}^{2} / \lambda[50,47]$. This is referred to as in-line PhC imaging method [47].

PHASE RETRIEVAL However, if the PhC-effects are to strong, they will prevent further segmentation and quantitative analysis steps [54]. By a applying a so called Phase Retrieval algorithm on the projection images followed by a standard reconstruction algorithm, e.g. Filtered Back Projection (FBP), a slice that predominately shows the $\delta$-term of the complex index of refraction, without any enhanced phase-effects can be obtained $[55,54]$. Single distance Phase Retrieval (PhR) algorithms require a regularization parameter [46], herein-after referred to as the $\delta / \beta$-parameter, in order to more precisely reduce the phase effects from a given sample. The delta-to-beta parameter can be obtained experimentally by scanning a sample at multiply distances and then estimating the $\delta$ and $\beta$ values at each distance. The delta-to-beta ratios for various biological tissues are also available in certain lookup tables $[56,57]$ based on data found in Henke et al. [1] Hubell et al. [58] and White et al. [59]. Furthermore, in Paper I, it was demonstrated that by suppressing phase-effects, as done by using PhR, a more precise grey level thresholding of the slices can be performed. $\mathrm{Wu}$ et al. [45] also stated that for more accurate characterization of tissue, the acquired projections should be used to reconstructed two different data sets, one based on only the linear attenuation coefficient of tissue, $\beta$ and the other one based on the tissue refraction, $\delta$. 


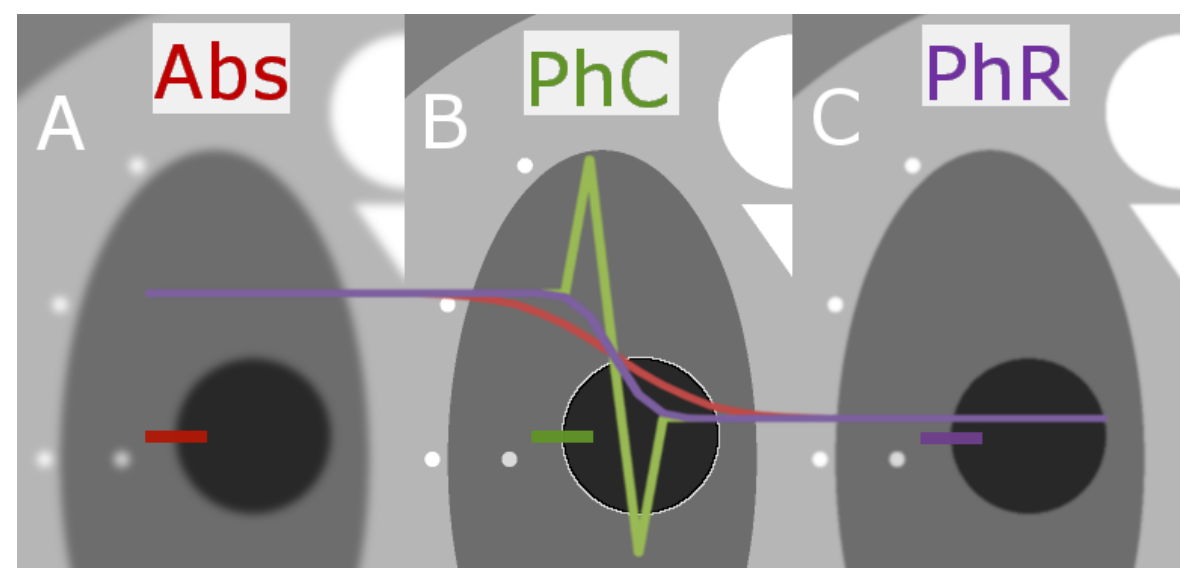

Figure 13: Line profile for each considered air-to-tissue interface for the given imaging modes Abs, $\mathrm{PhC}$ and PhR.

\subsubsection{Image quality}

The quality, $Q$ of an image in $\mathrm{CT}$ is affected by mainly 4 factors, the spatial resolution, $s$, the image noise, $\sigma$, the dose, $D$ and the slice thickness, $z$ through the following relationship:

$$
\mathrm{Q} \propto \sqrt{\frac{1}{s^{3} \cdot \sigma^{2} \cdot z \cdot D}}
$$

where a high $\mathrm{Q}$ factor implies better image quality. According to this expression there is an interplay between the three imaging parameters, spatial resolution, the image noise, the dose, and the slice thickness.

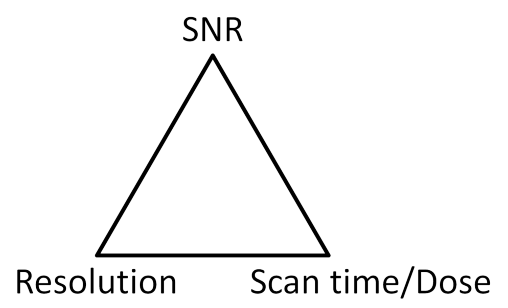

Figure 14: Illustration of the trade off between SNR, Resolution and Scan Time/Dose in CT

When scanning biological matter it is often crucial to reduce the scanning time and hence the delivered dose, in order to avoid x-ray damage. This can be achieved by increasing the amount of detector elements used for forming 1 pixel in the obtained image, also referred to as the binning of the detector. A binning $1 \times 1$ means that 1 detector element on the detector is corresponding to 1 pixel on the readout image. By increasing the binning from $1 \times 1$ detector elements to $2 \times 2$, the average signal of 4 detector elements will instead be used to record 
the grey value of 1 pixel in the readout image, as shown in Figure 15. This will hence decrease the final spatial resolution, as well as the noise, the slice thickness and the scanning time and the delivered dose, which might be preferable. From the above relationship it can be shown that by decreasing the spatial resolution with a factor of 2, while maintaining the same noise, image quality and slice thickness, the delivered dose and hence also the scanning time are reduced with a factor of 8 .

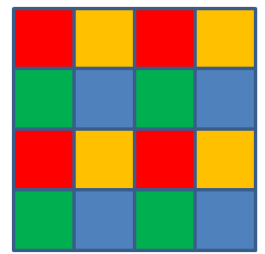

$1 \times 1$

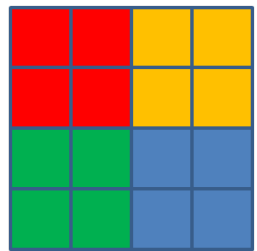

$2 \times 2$

Figure 15: Illustration of binning $1 \times 1$ and $2 \times 2$ of a detector.

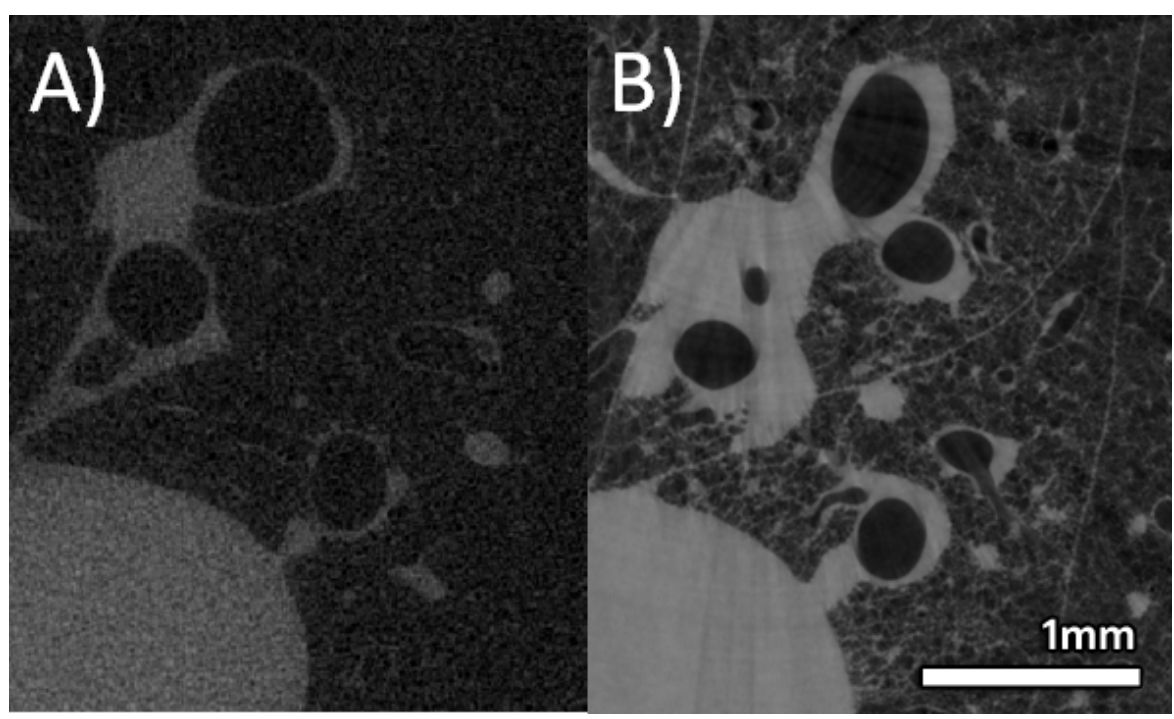

Figure 16: Shows a comparison of two lung data sets from A) a mouse scanned in Abs mode using an eXplore Locus SP (GE HealthCare) (MPI, Göttingen, Germany), pixel resolution $=26 \mu \mathrm{m}$ and B) a mouse scanned in PhC mode at the SYRMEP Beamline and after applied PhR, pixel resolution $=9 \mu \mathrm{m}$. 


\subsection{MAGNETIC RESONANCE IMAGING}

\subsubsection{NMR Background}

The Electromagnetic Radiation (EMR) phenomena entails that if a proton (or other nuclei) with a spin is placed inside a magnetic field, wherein-after EMR is sent onto them, the protons will absorb the EMR and re-emit the EMR, which will hence induce a voltage in a wire (reception coil) that is placed around the protons.

In order for a nuclei to give rise to an EMR signal, it needs to be EMR-active. Isotopes with an odd number of protons and/or neutrons have a magnetic moment and angular momentum, thus meaning a non-zero spin and are hence EMR-active, while nuclides with an even number of protons and neutrons have a total spin of zero and are thus EMR-inactive. Examples of EMR-active nuclei are ${ }^{1} \mathrm{H},{ }^{3} \mathrm{He},{ }^{13} \mathrm{C}$, ${ }^{15} \mathrm{~N},{ }^{17} \mathrm{O},{ }^{19} \mathrm{~F},{ }^{23} \mathrm{Na},{ }^{31} \mathrm{P}$ and ${ }^{129} \mathrm{Xe}$.

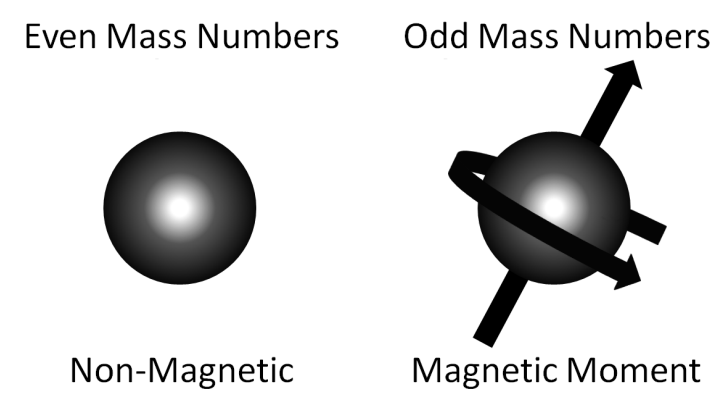

Figure 17: Magnetic Properties of nuclei for odd and even mass numbers

Each type of nuclei has an independent Nuclear Magnetic Resonance (NMR) (footprint) signal, where the characteristic resonance frequency (Larmor frequency) of the nuclei is proportional to the applied magnetic field. The Larmor frequency (frequency of precession) is given by the Larmor equation as: $f_{0}=\gamma \cdot B_{0}$, where $f_{0}$ is the Resonant Frequency, $\gamma$ is the Gyro-magnetic Constant and $B_{0}$ the Static Magnetic Field (in Tesla).

\subsubsection{Net magnetization}

NMR-active nuclei present inside an applied magnetic field, $\mathrm{B}_{0}$ will either align its magnetic moment along the direction of the magnetic field $B_{0}$, referred to as the $+1 / 2$ spin state (of the proton) or in the opposed direction of $B_{0}$, thus meaning $a-1 / 2$ spin state. In a large population of hydrogen atoms, such as the tissue in the human body, slightly more than half of them will align themselves with the $+1 / 2$ spin (lower energy level) and the rest with the $-1 / 2$ spin (higher energy level). If enough amount of protons are aligned in the lower 
energy state, the spin excess or net magnetization, $M$ is big enough to be detected.

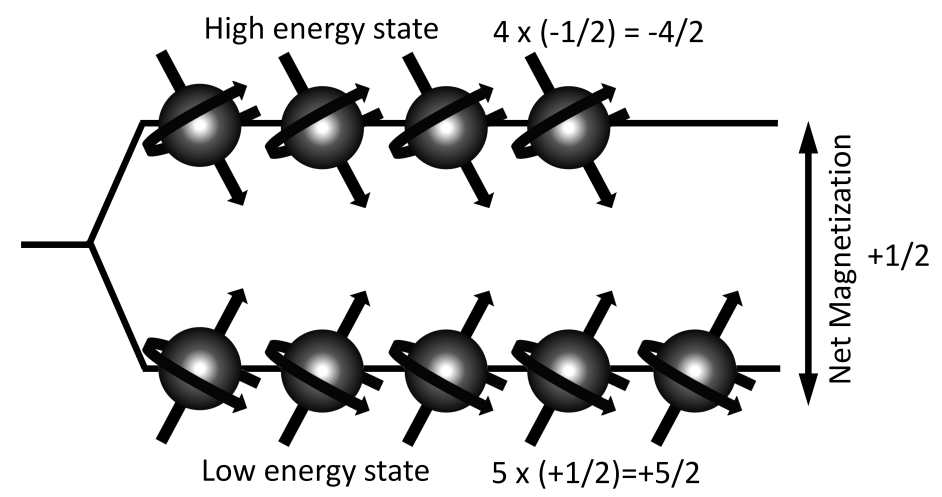

Figure 18: Illustration of the net magnetization.

When a proton in a spin state $+1 / 2$ is exposed to EMR by an RF-pulse (perpendicular to the direction of the $\mathrm{B}_{0}$ field) with a frequency corresponding to its precessional frequency (Larmor frequency), it will flip to the higher energy level of $-1 / 2$ spin state, thus undergoing an excitation, creating a resonance condition where the proton will start to exhibit precessional motion with a characteristic frequency around the vertical axis aligned with the direction of $\mathrm{B}_{0}$.

A)

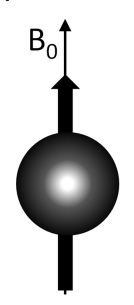

B)

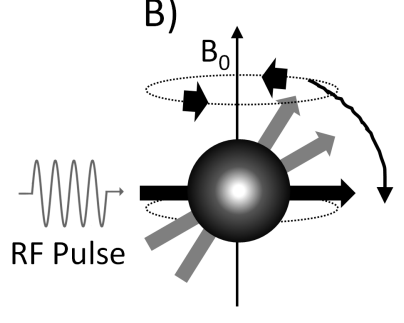

C)

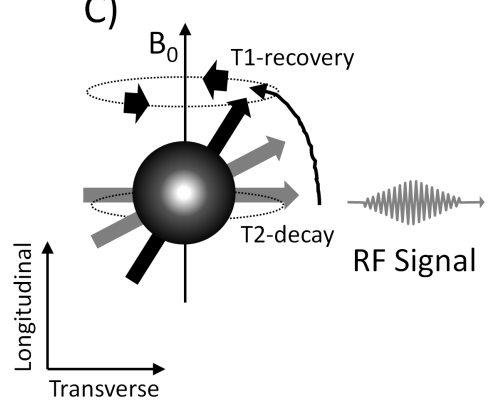

Figure 19: A) An average proton inside a magnetic field aligned with $B_{0}, B$ ) RF-pulse will cause the proton to precess around $B_{0}$ and $C$ ) when the RF-pulse is shut off an RF-signal will be produced.

The source of the MR-signal is the net magnetization, M. In equilibrium, $M$ is aligned with $B_{0}$ and no precession around $B_{0}$ is present, thus meaning that no EMR is emitted. When an RF transmitter coil produces an RF pulse that is sent onto the protons, this will cause $\mathrm{M}$ to be tipped down from its vertical position onto the transverse plane, which will cause the protons to start to precess around $B_{0}$, thereby inducing a voltage in a very sensitive RF-coil (via Faraday's law of induction) placed in the vicinity of the sample. 


\subsubsection{Relaxation}

\subsubsection{Free Induction Decay}

Once the RF transmitter coil is turned off the protons will start to reemit the absorbed energy, meanwhile the signal will start to decay, which is called a Free Induction Decay (FID). The initial amplitude of the FID signal is determined by the Magnetization vector, $M_{x y}$ (transverse component around the $\mathrm{z}$-axis and perpendicular to $\mathrm{B}_{0}$ ), which has been tipped onto the xy-plane, where the highest amplitude is obtained at the flip angle $90^{\circ}$, where $\sin (90)=1$, directly after the RF-pulse has been switched off. Furthermore, the rate of decay is dependent on the $\mathrm{T} 2$ time constant.

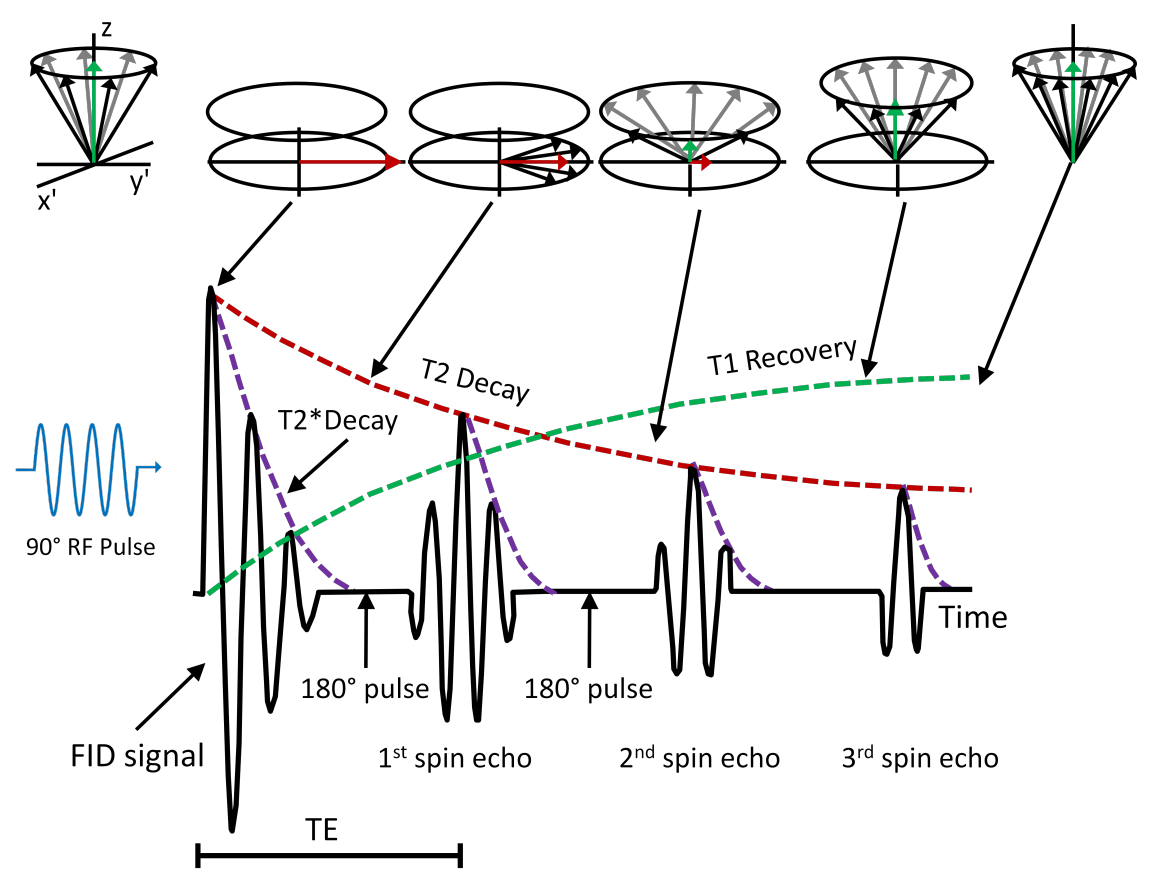

Figure 20: Illustration of the processes Free induction decay, $\mathrm{T}_{1}$ recovery, $\mathrm{T} 2$ decay and T2 star decay in MRI.

TRANSVERSE RELAXATION (T2) T2 relaxation is the process which occurs when the transverse component of the magnetic vector, $M_{x y}$ decays to the value zero, due to spin-dephasing, cause by random spin-spin proton interactions, where the small magnetic fields from neighboring protons effect each other. 


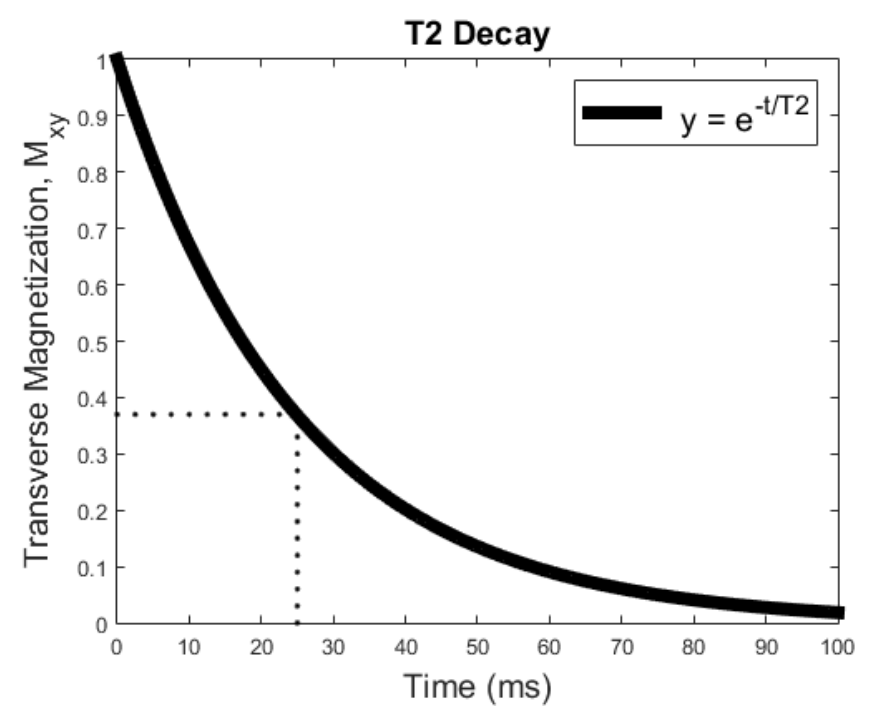

Figure 21: T2 decay signal. The T2 time constant is the time it takes for the transverse magnetization to decay to a value of $1 / e=0.37=37 \%$ of $M_{0}$, following the formula $M_{z}=M_{0} \cdot e^{-t / T_{2}}$.

T2 STAR RELAXATION ( $\left.2^{*}\right) \quad \mathrm{T} 2^{*}$ (T2 star) relaxation is due to both T2 relaxation and due to field inhomogeneities of the static magnetic $B_{0}$ field, magnetic susceptibilities and chemical-shift artifacts. A rephasing can however be performed by using a chain of 180 degrees flip RF-pulses, which will then generate $\mathrm{T}_{2} *$ echoes. These echoes will however have a lower and lower amplitude (for each repetition), due to the T2 decay effects.

LONGITUDINAL RELAXATION (TI) TI relaxation is the recovery of the longitudinal component of the magnetic vector, $M_{z}$ along the $\mathrm{z}$-axis (direction of the $\mathrm{B}_{0}$ field). The Ti process occurs when protons (excited from the RF-pulse) spin around and return to their lower energy state at which they generate small magnetic field fluctuations also affecting surrounding protons, leading to the restoration of the longitudinal magnetization vector, $M_{z}$. 


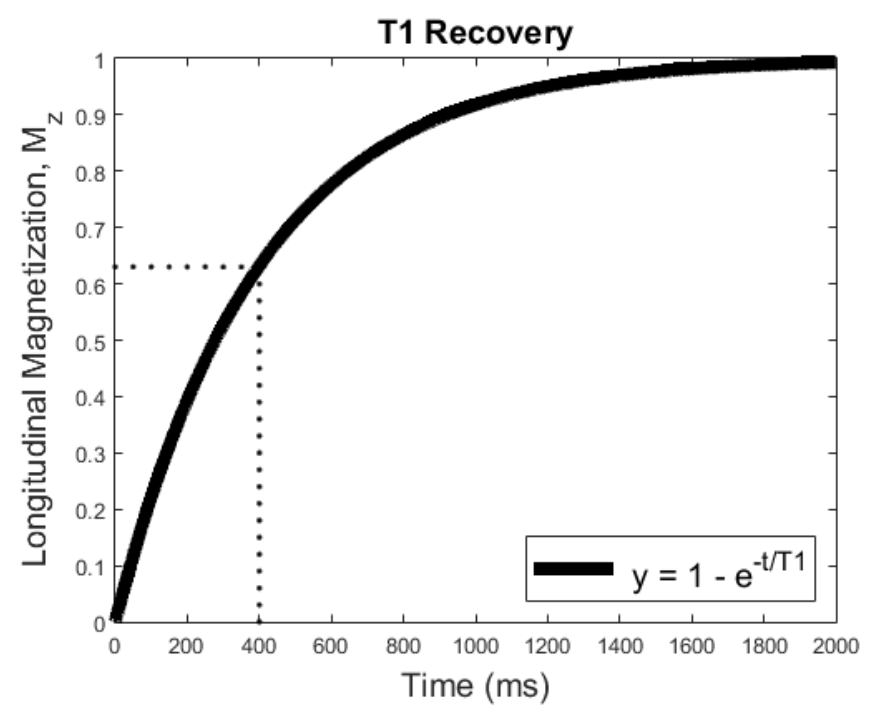

Figure 22: $T_{1}$ recovery signal. The $\mathrm{T}_{1}$ time constant is the time it takes for the longitudinal magnetization to reach $(1-1 / e)=0.63=63 \%$ of the $M_{0}$ value, following the formula $M_{z}=M_{0} \cdot\left(1-e^{-t / T_{1}}\right)$.

4.2.4 Image contrast

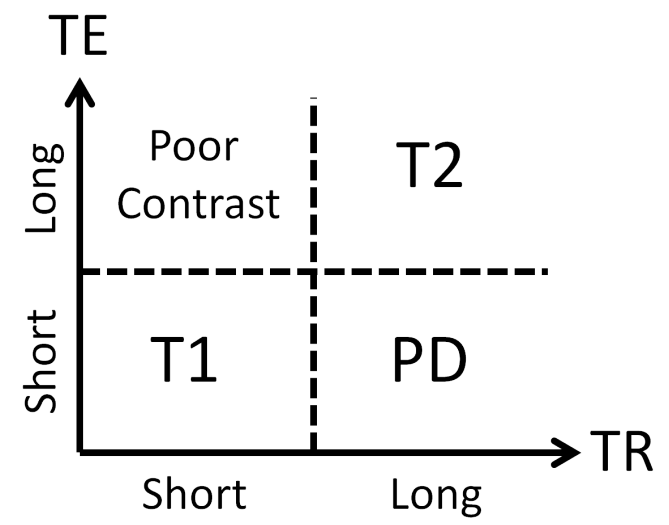

Figure 23: Illustration of the contrast formation as a function of the Time to Repeat (TR) and Time to Echo (TE)

\subsubsection{T2 contrast}

T2 contrast (or T2-weighted) images are produced based on the different T2-relaxation times of tissues inside the scanned sample. T2 contrast is achieved by scanning with Long TR, in order to minimize T1-weighting and with Long TE, in order to enhance the T2-weighting. The obtained MR-signal is proportional to the product of the proton density and the inverse exponential of TE divided by T2, according to the following expression: MRI $\propto p_{0} \cdot e^{-T E / T_{2}}$. 


\subsubsection{T1 contrast}

Ti contrast (or T1-weighted) images are produced based on the different T1-relaxation times of tissues inside the scanned sample. $\mathrm{T}_{1}$ contrast is achieved by scanning with Short TR, in order to enhance T1-weighting and Short TE, in order to minimize the T2-weighting. The obtained MR-signal is proportional to the product of the proton density and the factor 1 subtracted with the inverse exponential of TR divided by $\mathrm{T}_{1}$, according to the following expression:

$$
M R I \propto p_{0} \cdot\left(1-e^{-T R / T_{1}}\right) .
$$

\subsubsection{PD contrast}

Another type of contrast apart from $\mathrm{T}_{1}$ and $\mathrm{T}_{2}$ contrast is the Proton Density (PD) contrast, which is based on the amount of hydrogen atoms (water content) present inside the scanned sample. PD contrast is achieved by scanning with Long TR, in order to minimize T1-weighting, thus allowing a complete recovery of the longitudinal magnetization and Short TE in order to minimize the T2-weighting. The obtained MR signal is directly proportional to the proton density, according to the following expression: $S_{M R I} \propto p_{0}$.

\subsubsection{Encoding the MR-signal}

In order to spatially encode the MR-signal to a certain voxel in the image space, three different types of orthogonal magnetic field gradients, (that can be switched on and off), one for each spatial dimension $(x, y, z)$, are needed $[60,61,62]$, thus being $A)$ a frequency encoding gradient, $\left.G_{x}, B\right)$ a phase encoding gradient, $G_{y}$ and $C$ ) a slice selective gradient, $G_{z}$. In order to produce such linear varying magnetic fields, a hardware piece referred to as a gradient coil is needed. For readout of the generated MR-signal a receiver coil is used. Both coils are placed around the sample to be scanned. 

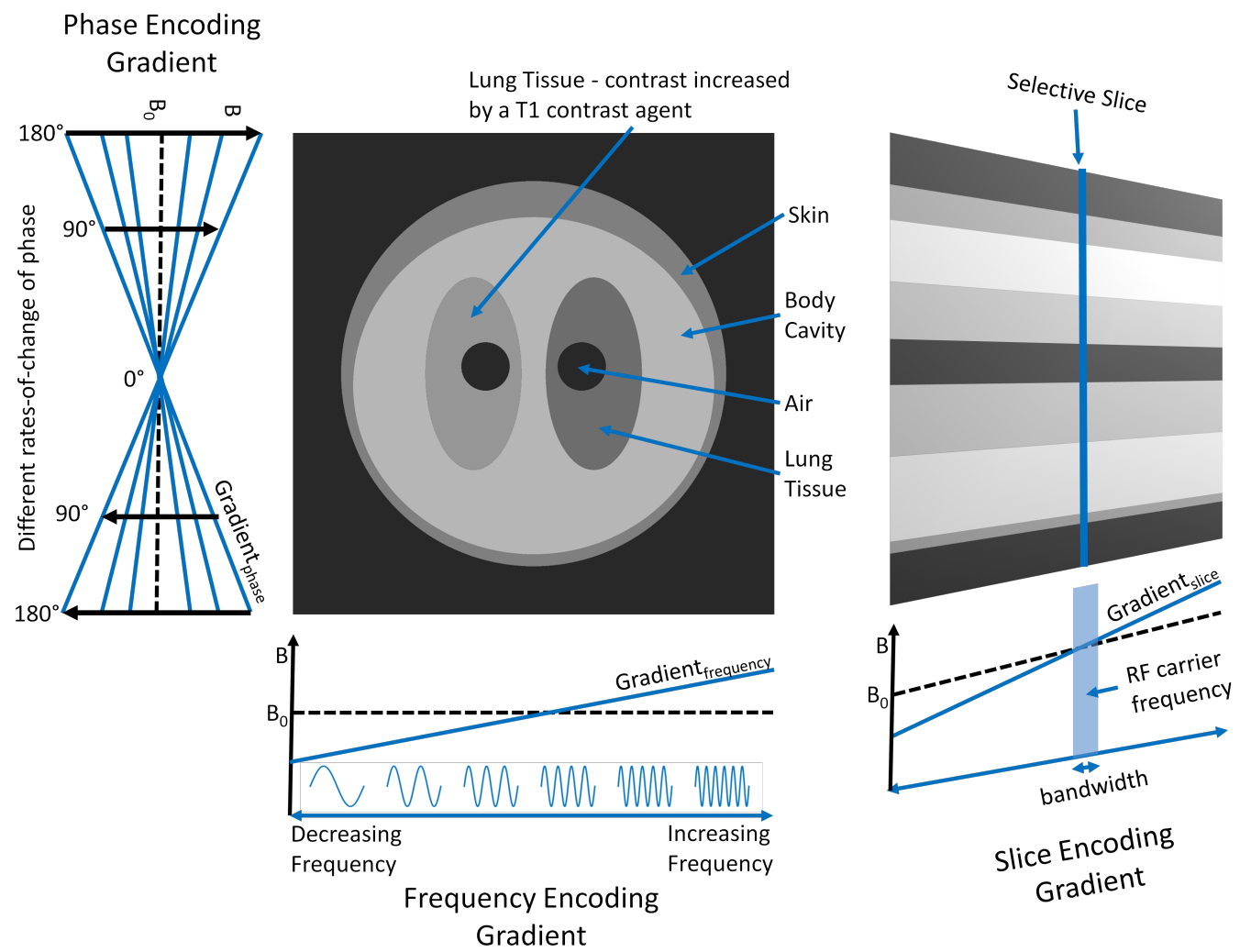

Figure 24: Frequency, phase and slice selective encoding gradient. Please notice that bones can in general not be visualized with T1-contrast, due to the very low amount of water content in bones.

\subsubsection{Frequency-encoding}

Frequency-encoding of the spins is performed by applying a constant gradient $G_{x}$, also referred to as $G_{\text {read }}$, along the x-direction of the image space, during the readout of the MR-signal. This will cause the spins to start precessing at different resonance frequencies, related to their position along the applied frequency-encoding gradient. The spins are thereby frequency-modulated along the readout direction. The resonance frequency of the proton spin is hence proportional to the position of the spin, as given by the following formula:

$$
\omega_{0}(x)=\gamma \cdot\left(B_{0}+G_{\text {read }} \cdot x\right)
$$

where $G_{F E}$ is the frequency encoding magnetic field gradient at the given position $x$.

\subsubsection{Phase-encoding}

Phase-encoding of the spins is obtained by applying a constant gradient, $G_{y}$, also referred to as $G_{\text {phase }}$, along the $y$-direction of the image space, during a specific time frame (pulsed), prior to the readout of 
the MR-signal, which is repeated with different phase-encoding steps, $\mathrm{N}_{\text {phase }}$. When the phase-encoded gradient is turned on it will cause the spins to start precessing at different resonance frequencies, related to their position along the applied phase-encoding gradient (similar to Frequency ending), and when the gradient is turned off the spins will start to precess with the same frequency as proportional to the external magnetic field, Bo, but with different phases, during a given time point (dephasing).

Furthermore, protons in the same row perpendicular to the direction of the gradient will precess at the same phase. The received MR-signal for each row will be slightly out of phase. For an image with $\mathrm{N}$ number of rows, $\mathrm{N}$ number of acquisitions using different phase encoding gradients, $\mathrm{N}_{\text {phase }}$ will be performed. The spins are thereby phasemodulated along the phase-encoding direction.

\subsubsection{Slice encoding}

Slice encoding is achieved by applying a combination of a constant gradient, $\mathrm{G}_{z}$, also referred to as $\mathrm{G}_{\text {slice, }}$, along the $\mathrm{z}$-direction of the image space, together with an RF-pulse containing a narrow bandwidth of particular frequencies around the Larmor frequency, thereby only exciting spins that resonate with the same frequencies as present within the bandwidth of the applied RF-pulse. The position of the slice is defined by the central frequency of the RF-pulse, meanwhile the slice thickness is determined by the bandwidth of the RF-pulse. The formula for the slice selection of the Larmor frequency is given by:

$$
\omega_{0}=\gamma \cdot\left(B_{0}+G_{\text {slice }} \cdot z\right)
$$

where $G_{S S}$ is the magnetic gradient field at the given slice position $\mathrm{z}$.

\subsubsection{Imaging parameters}

The signal in MRI is proportional to the $B_{0}$ squared over absolute temperature, $S_{M R I} \propto B_{0}^{2} / T$. The noise $\sigma$ in MRI comes from two different sources 1) noise from the resistance coil, where $\sigma \propto B_{0}^{1 / 2}$ and 2) noise from the body (sample), where the $\sigma \propto B_{0}^{2}$. Moreover, for big sample (such as humans) the noise increases proportionally to $B_{0}$ as earlier stated, while as for smaller samples (such as mice) the noise is more limited by the performance of the coil and other other components in the detection chain of the system. 
4.2.6.1 Signal-to-Noise Ratio and relationship to resolution and scan time

The Signal-to-Noise Ratio (SNR) is defined as the quote between the signal and noise and is explained in general under Section 5.1. For MR the SNR is dependent on the noise coming from both the coil and the scanned sample as given by the following expression:

$$
\mathrm{SNR}_{\mathrm{B}_{0}}=\frac{\mathrm{S}_{\mathrm{MRI}}}{\sigma}=\frac{\mathrm{S}_{\mathrm{MRI}}}{\sqrt{\sigma_{\text {coil }}^{2}+\sigma_{\text {body }}^{2}}}=\frac{\mathrm{B}_{0}^{2}}{\sqrt{\alpha \cdot \mathrm{B}_{0}^{1 / 2}+\beta \cdot \mathrm{B}_{0}^{2}}}
$$

where the $\alpha$-parameter is related to the coil characteristics, such as number of turns, conductivity and filling factor, while as $\beta$ is related to the size and conductivity of the sample. Furthermore, both the $\alpha$ and $\beta$ parameter are also dependent on the absolute temperature.

The Signal-to-Noise Ratio (SNR) increases with increasing $B_{0}$ and the proton density, $\rho$ inside the tissue of the imaged sample, as stated below:

$S N R \propto B_{0} \cdot \rho$.

As earlier stated the SNR is also affected by the design of the RF coil and is inversely proportional to the size, $d$ of the reception coil. The SNR can thus be further maximized by using a coil that optimally surrounds the volume of the imaged sample, since $n$ very small elements are used for signal detection.

Furthermore, the SNR is also affected by imaging-sequence parameters, thus being the image resolution and scan time. More precisely the SNR is directly proportional to the ${ }_{3} \mathrm{D}$ imaging resolution and to the square root of the scan time, according to the following formula:

$$
\mathrm{SNR} \propto 3 \mathrm{D}_{\text {ImagingResolution }} \cdot \sqrt{\text { ScanTime }} .
$$

Furthermore, the resolution (pixel size) in each direction $(x, y)$ is dependent on the Field of View (FOV) and the number of frequency, $\mathrm{N}_{x}$ and phase encoding steps, $\mathrm{N}_{\mathrm{y}}$, according to the formula below:

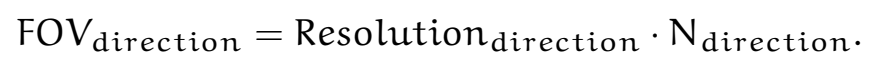




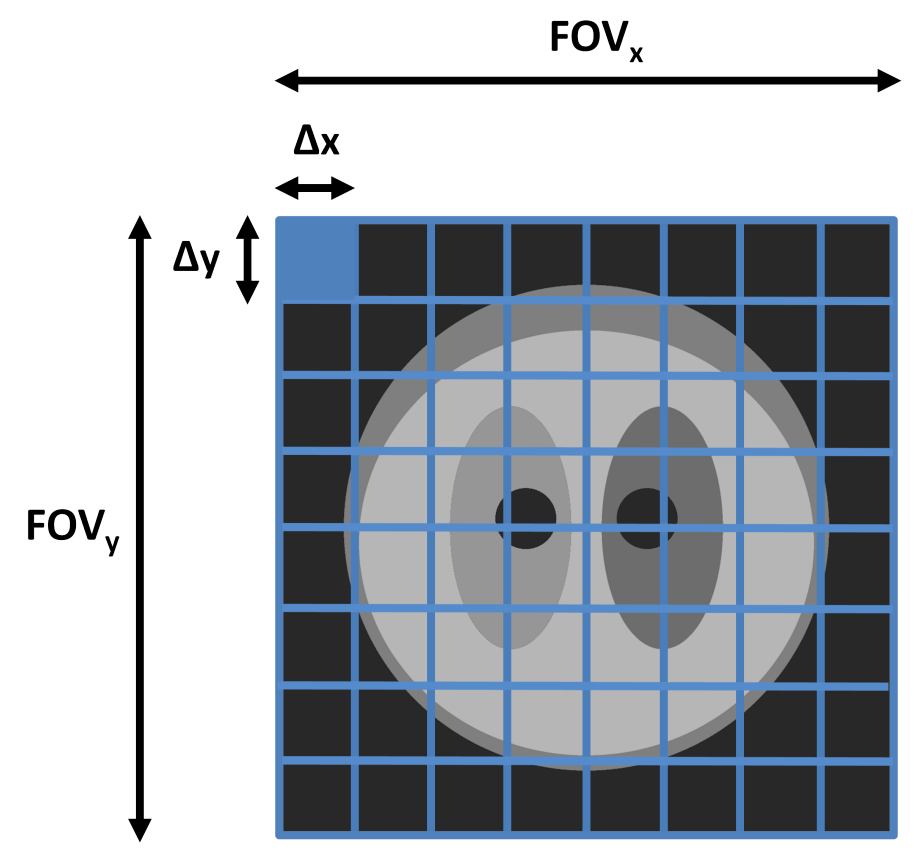

Matrix: $8 \times 8$

Figure 25: Relationship between the k-space, image resolution and FOV.

Moreover the scan time is dependent on the Number of Averages, $\mathrm{N}_{A V G}$, corresponding to several collections of each line in the k-space, as well as the Number of phase encoding steps and the read out time. The SNR dependency can thus be written as:

$$
\mathrm{SNR} \propto \Delta x \cdot \Delta y \cdot \Delta z \cdot \sqrt{\mathrm{N}_{A V G} \cdot \mathrm{N}_{x} \cdot \mathrm{N}_{y} \cdot \mathrm{N}_{z} \cdot \Delta \mathrm{t}}
$$

where $\Delta x \cdot \Delta y \cdot \Delta z$ is the product of the image resolution in each direction, xyz, $N_{x} \cdot N_{y} \cdot N_{z}$ is the product of the frequency and phase encoding steps and $\Delta t$ is the time for reading one pixel in the $x-$ direction of the k-space. The expression can also be rewritten using $\mathrm{T}_{\text {read }}=\mathrm{N}_{\mathrm{x}} \cdot \Delta \mathrm{t}$, where $\mathrm{T}_{\text {read }}$ refers to the time it takes to read an entire line in the $x$-direction.

$$
\mathrm{SNR} \propto \Delta \mathrm{x} \cdot \Delta \mathrm{y} \cdot \Delta z \cdot \sqrt{\mathrm{N}_{\mathrm{AVG}} \cdot \mathrm{N}_{\mathrm{y}} \cdot \mathrm{N}_{z} \cdot \mathrm{T}_{\text {read }}}
$$

According to the expression above there is an interplay between the three imaging parameters, SNR, Resolution and Scan time. The SNR can be increased by either decreasing the spatial resolution (which is equal to increasing the FOV, while keeping the same image matrix) or by increasing the scan time. 


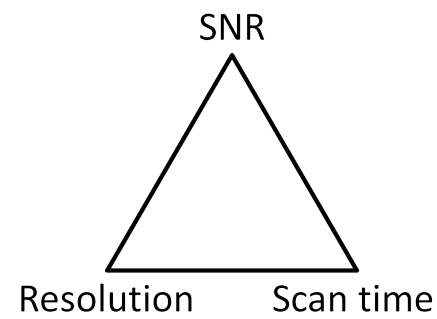

Figure 26: Illustration of the trade off between SNR, Resolution and Scan Time in MRI.

For this thesis work MR experiments were conducted with a ${ }_{3} \mathrm{D}$ spinecho (3DSE) imaging sequence using the following parameters: FOV $26 \times 26 \times 26 \mathrm{~mm}$, imaging matrix $128 \times 128 \times 128$, TE $2 \mathrm{~ms}$, TR $200 \mathrm{~ms}$, number of averages 2, and total scan time $2 \mathrm{~h}$, with an isotropic image resolution of 203 micrometers/pixel, using a 9.4 Tesla (400 Mhz) $\mu$-MRI scanner at the Jošef Stefan Institute in Ljubliana, Slovenia. Furthermore, MRI-imaging with both short $\mathrm{TE}$ and $\mathrm{TR}$, correspond to $\mathrm{T}_{1}$ weighted imaging. Figure 27 shows an MR slice of a scanned mouse lung sample.

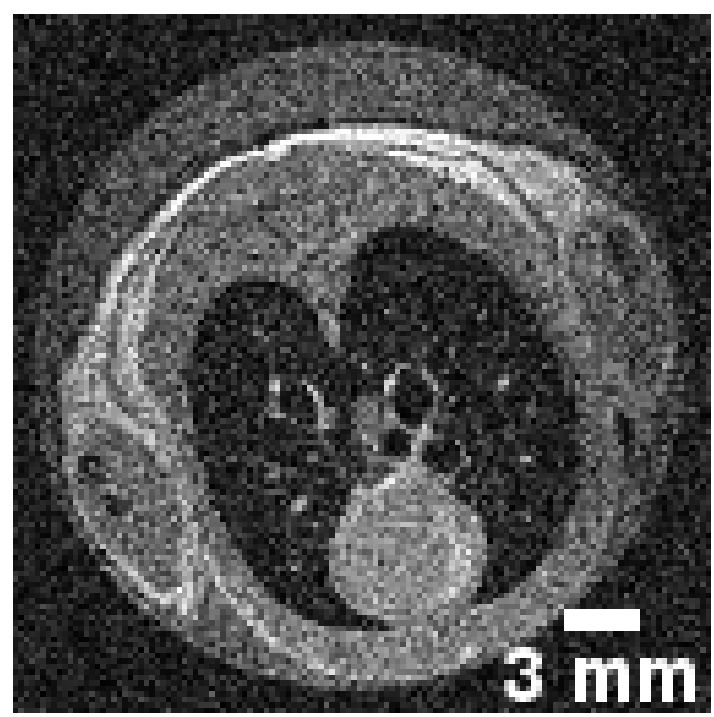

Figure 27: Shows the lung data for a mouse scanned according to the protocol mentioned above, pixel resolution $=203 \mu \mathrm{m}$. 

After acquiring an image the next natural step is to apply various image processing steps, including e.g. segmentation, in order to create a more enhanced image, which will facilitate further visualization and/or image analysis steps. Visual inspection in $3 \mathrm{D}$ is useful for finding certain image details, which might otherwise be missed if only assessing the data in $2 \mathrm{D}$.

Image analysis can be used to support the observations of the visualized data, based on quantifiable numbers. The goal of image analysis is to extract numerical values from the images, through the application image parameters that quantitatively describe various properties or structures in a given image. Automated quantitative image analysis ensures both objective and reproducible results [20].

Multi modal imaging by e.g. CT and MRI, followed by image fusion allows the extraction of synergistic information, by both visual and quantitative analysis, which will lead to more accurate and reliable diagnosis [20].

\subsection{IMAGE QUALITY}

The quality of an image is directly related to the physical property being imaged with a given modality [20], as well as to the scanning parameters of the system, such as the pixel size and scanning time. The quality in an image is commonly quantified with 1) Signal-toNoise Ratio (SNR) - which is defined as the mean intensity of the investigated object, divided with the standard deviation of a homogeneous region and 2) the Contrast-to-Noise Ratio (CNR) - which is defined as the difference in mean intensity between two objects, divided with the standard deviation of a homogeneous region [20].

$$
\begin{aligned}
& \mathrm{SNR}_{\mathrm{a}, \mathrm{c}}=\frac{\mu(\mathrm{a})}{\sigma(\mathrm{c})} \\
& \mathrm{CNR}_{\mathrm{a}, \mathrm{b} \mid \mathrm{c}}=\frac{\mu(\mathrm{a})-\mu(\mathrm{b})}{\sigma(\mathrm{c})}=\mathrm{SNR}_{\mathrm{a}, \mathrm{c}}-\mathrm{SNR}_{\mathrm{b}, \mathrm{c}}
\end{aligned}
$$

For improved image quality, SNR and CNR should in general be maximized, if feasible, with respect to the given scanning conditions [20]. However, in parallel to maximizing the SNR and CNR, it is also important to consider the sharpness of the image. By applying a median 
filter on an obtained slice, the SNR and CNR can easily be maximized, but such a procedure will introduce blurring of the sample edges. In Paper I both the CNR and blurring effects are evaluated for phaseretrieved in-line phase contrast images of a mouse lung and compared to conventional Propagation-based imaging (PBI) images.

\subsection{SEGMENTATION TECHNIQUES}

The ability to successfully segment sample components from each other is crucial for any further quantitative analysis or 3 D-rendering. One of the most common segmentation approaches is simple intensity thresholding [63], where the components are segmented based on their grey level value, proportional to their LAC. The utilization of grey level thresholding becomes challenging however, when there is to much noise in the images or when the sample components experience similar Linear Attenuation Coefficient (LAC) values.

A direct threshold based segmentation of the lung envelope also containing CAs presents some further challenges, since the there is an overlap of the LAC values, in between 1) lung tissue and other tissue present in the chest region, 2) air in the lung and air present below the skin and and 3) contrast agent present inside the lung envelope and rib cage bones. Figure 28 shows a comparison between grey level thresholding of Contrast Agent (CA) and lung tissue for Absorption (Abs), Phase Contrast ( $\mathrm{PhC}$ ) and Phase Retrieval (PhR) simulated images of the chest region. It is shown that the specified threshold optimal for segmenting the contrast agent, also segments rib cage bones (Figure $28 \mathrm{ABC}$ ) and $\mathrm{PhC}$ edge effects around the trachea air/tissue interface for the PhC image in B). Furthermore, the specified threshold optimal for segmenting lung tissue, also segments other tissue in DEF). 


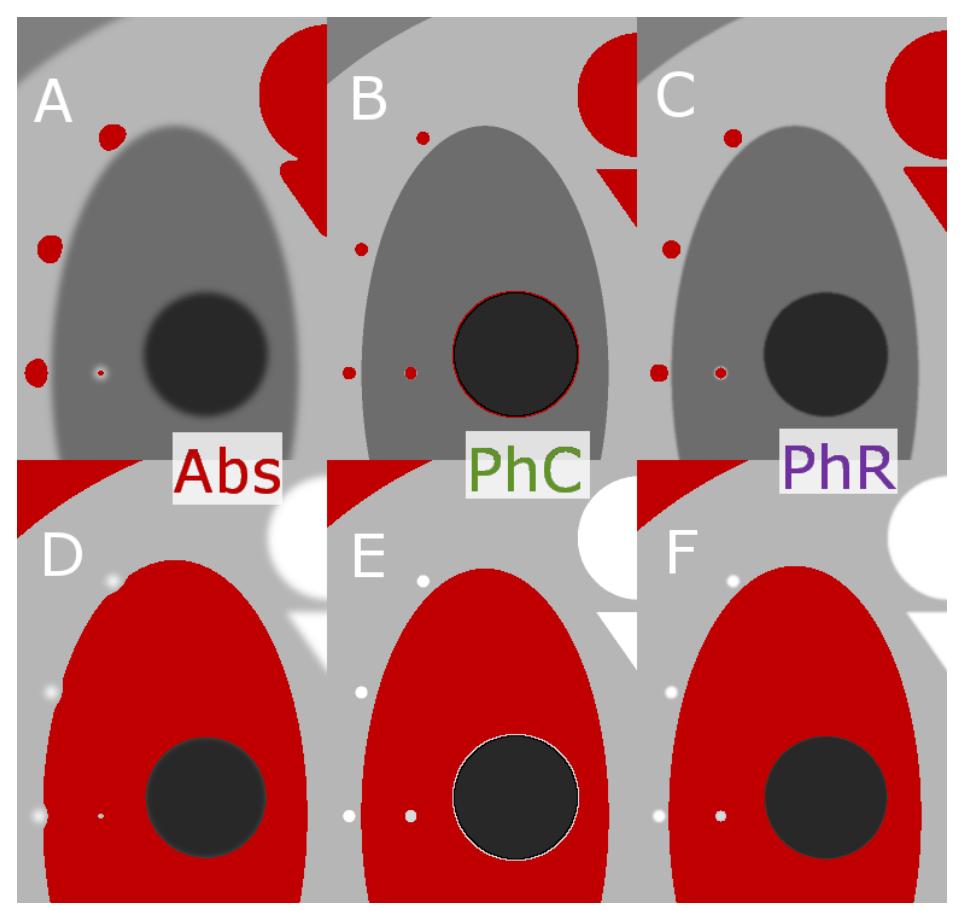

Figure 28: $A B C$ ) shows the effect of the an appropriate threshold for segmenting CA present inside the lung and DEF) the effect of an applied threshold for segmenting lung tissue for simulated Abs, $\mathrm{PhC}$ and PhR images of the chest region.

Therefore, in order to only segment the lung envelope and CA present inside the lung, there is hence the need for more advanced segmentation techniques. Examples of more advanced segmentation techniques are gradient based methods [64], level set and active contours [65], graph based approaches [66, 67] and region growing [68, 69].

However, the final choice of segmentation technique also depends on sample specific properties, in this case e.g. lung disease alterations and acquisition related parameters, e.g. CNR, resolution and the utilization of contrast agents.

For the segmentation of the lung envelope, a region growing algorithm [70] was applied, including the distribution of so called seeding (starting) points [71] inside the lung envelope, that continue to grow until no more neighboring pixels with the specified grey level range of air-to-soft-tissue can be located.

The applied region growing procedure was followed by the application of standard image processing procedures and final thresholding, which was proven to be successful for segmenting both the lung envelope, as well as the CA present inside the lung, as further described in Paper III. 
The proposed image processing scheme is further explained in Figure 29, where simulated images of the chest region have been used. Step 1) shows segmentation step using region growing, in order to only segment the lung envelope. In step 2) a hole fills algorithm is applied, in order to fill the void space of the CA. The obtained mask is the multiplied with the original image in step 3) giving a masked image only containing the lung envelope, which is used for thresholding the air, tissue and CA components in step ${ }_{5} \mathrm{~B}$ ). In side step 4 ) the original image was subtracted with the masked image of the lung envelope and the obtained imaged was used the threshold the bones of the rib cage in step $5 \mathrm{~A}$ ). In paper III it was also shown that this image processing scheme also could be translated to clinical Abs images of the lung, as well as on $\mu$-MRI images of the lung, as shown in Paper V.

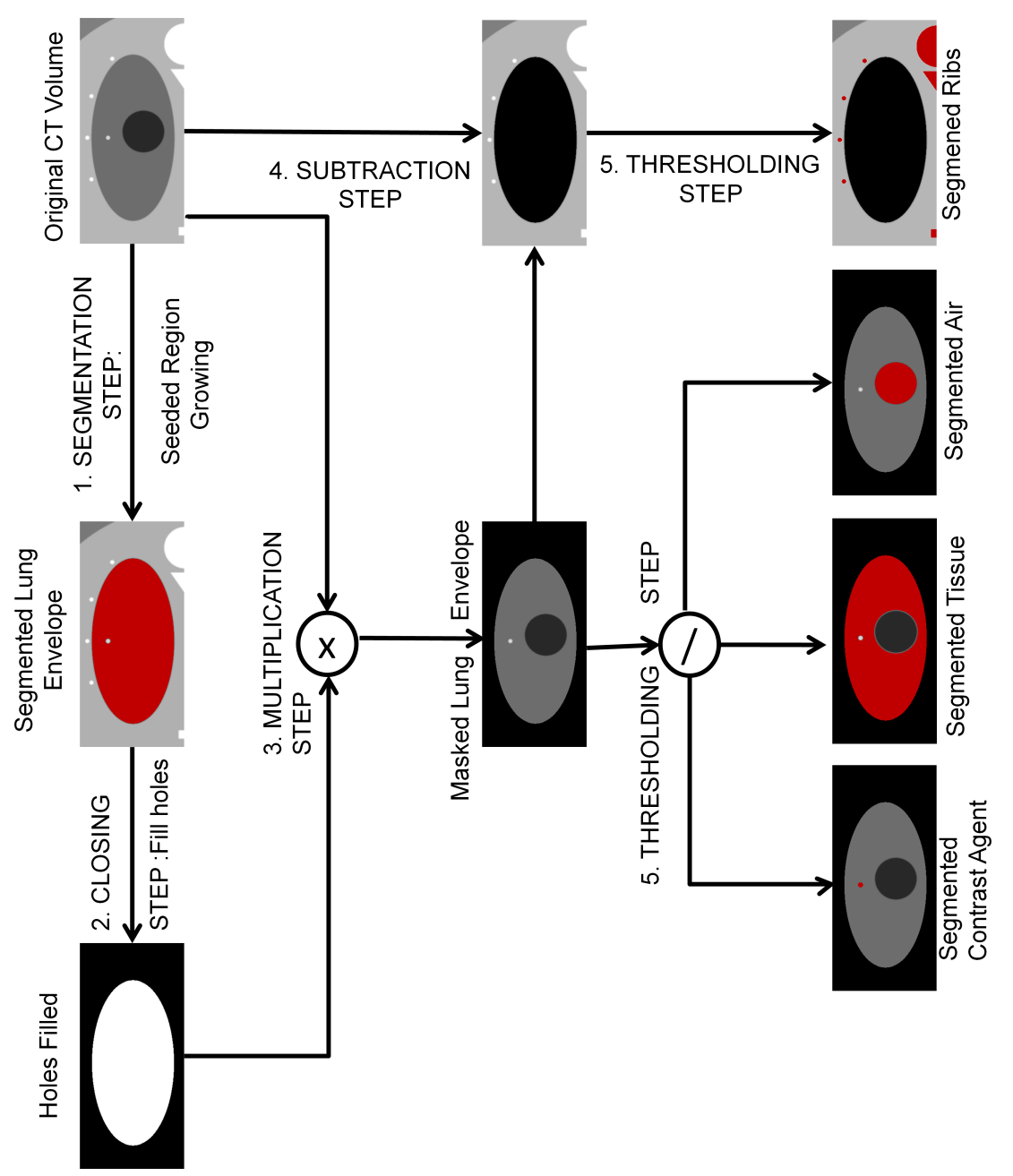

Figure 29: Outline of image processing scheme for separating the lung envelope from other components with similar attenuation coefficients in the chest region. 


\subsection{VOLUME RENDERING}

Following the scheme outlined in Figure 29 the four segmented components in step 5) air, tissue, contrast agent and ribs can be successfully rendered in ${ }_{3} \mathrm{D}$, thereby emphasizing the effects of the asthmatic attack, compared to the healthy control, as shown in Figure 30. In this thesis work the VG Studio 2.2 software (Volume Graphics $\mathrm{GmbH}$, Heidelberg, Germany) was used for 3 D-rendering.

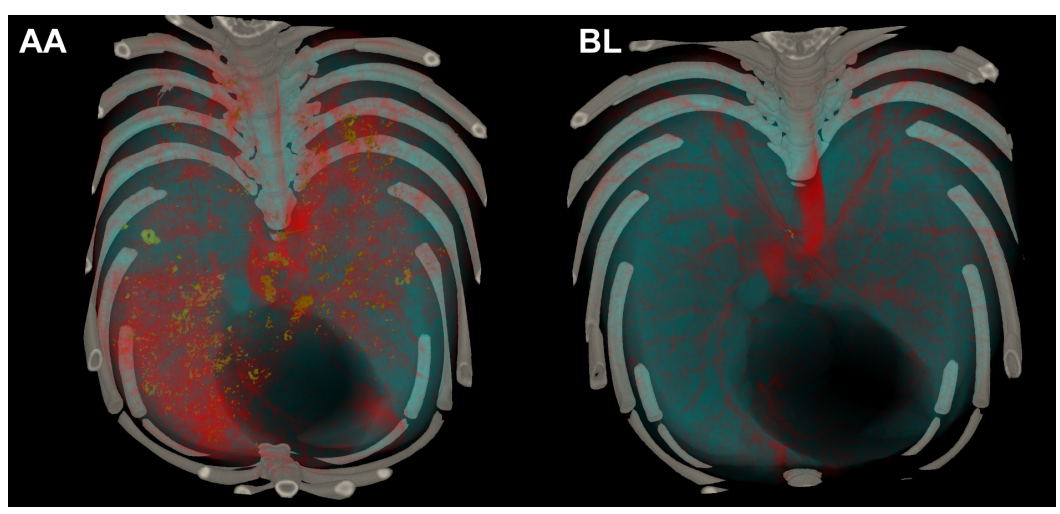

Figure 30: Volume rendering of acute asthma (AA) and blank (BL) showing air (cyan), soft-tissue (red) and $\mathrm{BaSO}_{4}$ loaded macrophages (yellow). For AA the $\mathrm{BaSO}_{4}$ loaded macrophages are found in close vicinity to the tissue component, showing airway wall thickening, which is a common hallmark of asthma. Image from Larsson et al. [72]. Reprinted with permission. (Copyright 2015 IOP Publishing Ltd).

\subsection{SELECTION OF VOLUME OF INTEREST}

Image analysis, as further described under Section $5 \cdot 5$, is commonly performed on smaller, yet representative sub-volume of the sample, referred to as Volume Of Interest (VOI), instead of analyzing the entire, in this case segmented lung data set.

VOI selection is usually done on the original data set, prior to segmentation. For the given lung data sets, the positioning of a VOI in the lung envelope (Figure 31), would thus reduce the segmentation issues earlier explained in Figure 28, from a four-component to a threecomponent classification process, where the different components are made up by 1) Air, 2) Tissue, 3) Contrast agent, 4) Rib cage bones and $\mathrm{N}$ ) any other component in the chest region, with a similar LAC (grey value) as any of the former components.

Both segmented VOIs or entirely segmented data sets can be used for further quantitative analysis, as addressed under Section 5.5. However, some quantitative parameters, such as e.g. skeleton analysis are 
required to be applied directly on the VOIs, instead of on the entire data set, which is related to implementation details of the parameters in mind.

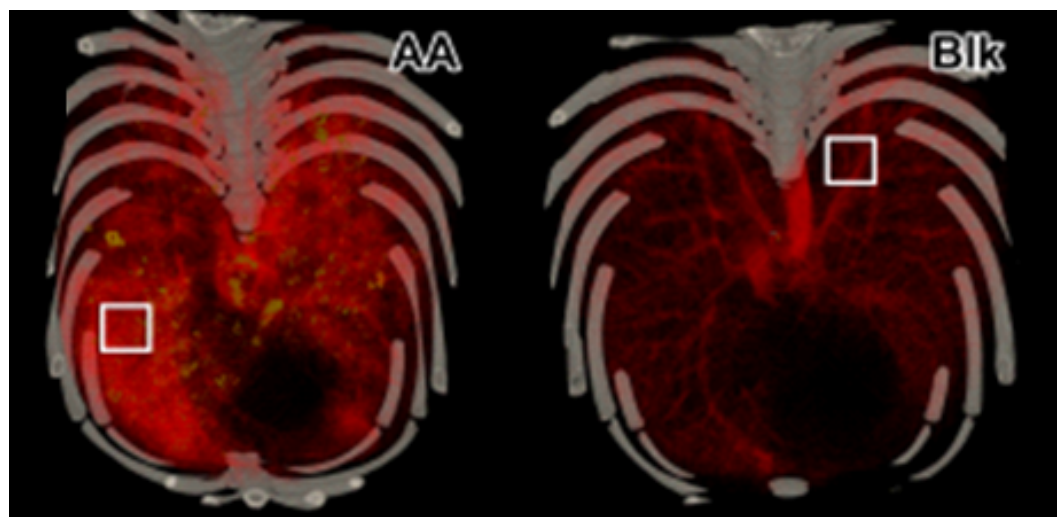

Figure 31: Volume rendering of acute asthma (AA) and blank (BL) showing soft-tissue (red) and $\mathrm{BaSO}_{4}$ loaded macrophages (yellow). Selected positions of VOIs are indicated with white squares. Image from Dullin, dal Monego, Larsson et al. [34]. Reprinted with permission. (Copyright 2015 International Union of Crystallography).

Moreover, a representative VOI should be positioned far away from the sample borders, in order to avoid the selection of non-sample specific parts. The VOI should also have a sufficiently large size, in order to successfully represent the features of the larger sample, thereby making sure that the extracted quantitative parameters are stable and not being affected by the size of the chosen VOI. This concept is also referred to as macroscopic homogenization [73] or representative elementary volume [74]. A key principal when defining the size of a VOI is to choose a size that is at least one order of magnitude larger than the characteristic size of the investigated structures of the sample [75].

Furthermore, where applicable it is is also recommended to extract more than one VOI, which have been spread out in a non-overlapping manner over the sample, thereby obtaining both a mean and a Standard Deviation (SD) for the analyzed parameter [75]. This will allow to evaluate both the size and position dependency of the VOIs, in relation to the quantified results, where a too low SD might suggest that 1 ) the VOI size is too small in comparison to the structural size of the sample components or 2) the VOI size is instead too large, thus resulting in minor changes of the extracted mean values, where any differences would be leveled out [75]. Each VOI is used for extracting a set of quantitative parameters. The optimal VOI size might also vary slightly for each considered quantified parameter. Therefore, it is important to chose a VOI size that provides the best trade off for all the quantified parameters [75]. 


\section{$5 \cdot 5$ QUANTITATIVE \& STATISTICAL IMAGE ANALYSiS}

For certain images with complex structures details, visual inspection can often be quite challenging, both $2 \mathrm{D}$ - and ${ }_{3} \mathrm{D}$-based one. In such cases quantitative analysis of user selected Volume Of Interest (VOI)s can often be a helpful tool, in order to differentiate between two samples. Quantitative analysis can of course also be used side by side, to support or confirm the observed visual results.

Examples of common quantitative image parameters are e.g. Percentage Volume (PercVol), Structure Thickness (StTh), Structure Separation, Structure Number, degree of anisotropy, fractal dimension and skeleton analysis. However, when working with preclinical or clinical images, such e.g. images of the lung it is important to chose quantitative image parameters that can easily be understood by clinicians and experts in the field, in this case in the field of lung imaging [72]. Such chosen parameters are therefore the PercVol and StTh, where the latter is shown in 32. The PercVol is calculated as the ratio between the amount of voxels corresponding to e.g. the soft-tissue divided by the total amount of voxels present in the given VOI. The computation of the StTh is based on the Parallel plate model [76], where complex sample structures are approximated a network of plates, which mean thickness is the StTh of the quantified component.

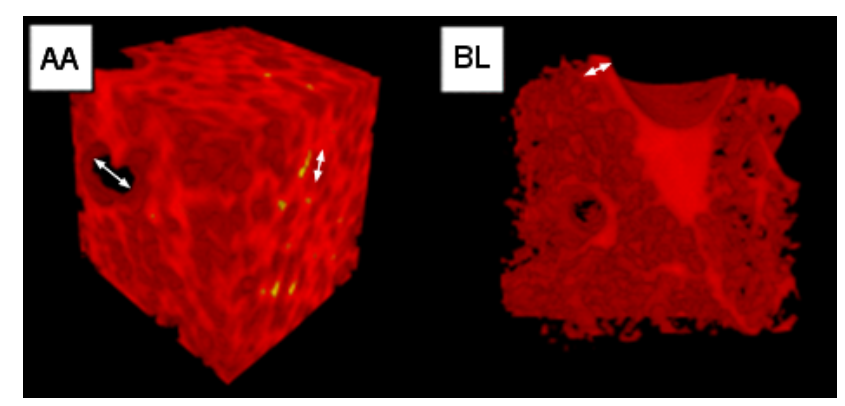

Figure 32: Selected vOIs from Figure 31 for acute asthma (AA) and blank (BL). White double arrows show StTh (from left to right) for Air, $\mathrm{BaSO}_{4}$ loaded macrophage clusters and Soft-tissue. Modified image from Dullin, dal Monego, Larsson et al. [34]. Reprinted with permission. (Copyright 2015 International Union of Crystallography).

The two above mentioned parameters were quantified with the Pore $3 \mathrm{D}$ $[77,78]$ software library for 3 D quantitative analysis, developed by the SYRMEP group (Elettra, Italy). Here in after, the quantified parameters were evaluated with statistical analysis, in order to confirm if or not there were any statistical differences in between the samples. Statistical analysis was performed using the MINITAB software (Minitab Ltd; Coventry, UK), as shown in Paper II, III and V. 


\subsection{IMAGE REGISTRATION}

When scanning a sample with two different modalities, in this case CT and MRI or when performing a repeated scan of a sample at separate time points with only one modality, slight variations in the sample acquisition orientation $(x, y, z)$ can thus be expected. This opens up the need for image registration of the sample data, in order to find a spatial correspondence between the images. Registration of images from a sample scanned by two modalities, is referred to as intrasubject multi modality co-registration [20], meanwhile the registration of images from a sample scanned with the same modality, is referred to as intra-subject single modality co-registration. Furthermore, modality related differences of the imaging capturing parameters, such as the image size, image resolution and image quality, also limit further multi modality image registration [20]. Therefore, in order to facilitate the registration of the MRI slices with the CT slices, some prior image processing can be performed.

For the lung samples scanned with both $\mathrm{SR} \mu$-CT and $\mu$-MRI during this thesis work, there was hence also the need for some further image registration, with the goal of extract synergistic information from fused images. In order to realize this idea, an image processing scheme was outlined, as further described in Paper V, where the MRI slices were first upscaled to the same image size as the CT data. Secondly the rib cage bones in the СT images were thresholded and set to the same grey level as the surrounding tissue, in order to make the CT data more similar to the MRI data, since T1-weighted images do not allow the visualization of bones, due to their very low water content. Figure 33 shows the outline of the hereby described image processing and registration methodology, here using simulated CT and MRI lung data.

When it comes to selecting a suitable image registration algorithm, there are two main categories 1 ) rigid body transformations, which assumes no shape changes of the sample structures, in between the compared images and 2) non-rigid affine body transformations, suitable for performing image shearing of the compared images, where structural shape changes may be present [20]. 


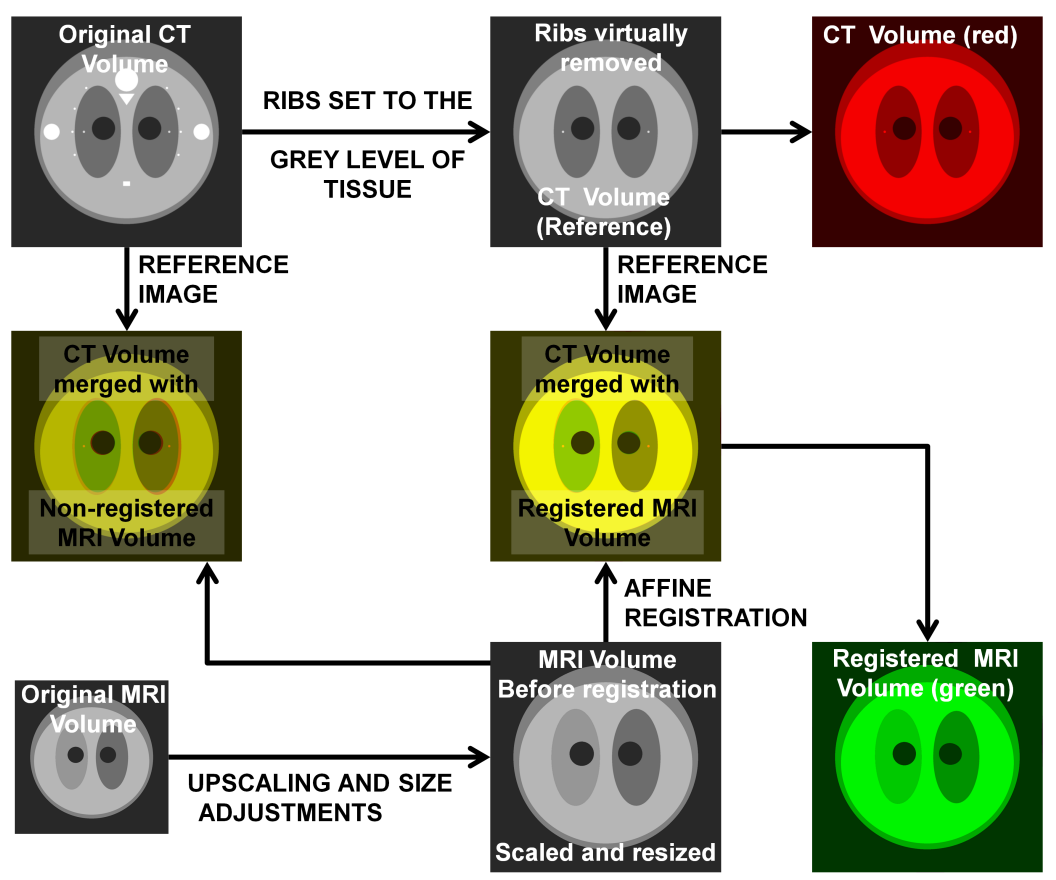

Figure 33: Image processing and registration scheme of СТ (colored in red) and MRI (colored in green) lung images.

In this thesis work a fully automatic elastic/affine image registration algorithm, developed by Sorzano et al. [79] was used, since the lung showed some shape differences in between the CT and MRI data sets, as further described in Paper V.

Figure 34 shows an enlargement of the fused MRI and CT lung data set (both non-registered and registered), which is used to for finding synergistic information [20], as demonstrated in Paper V.

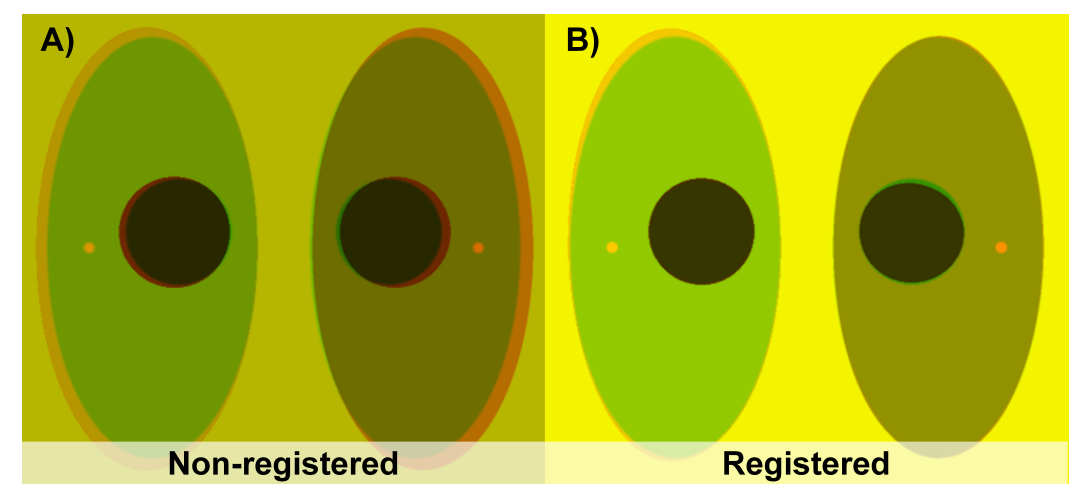

Figure 34: Image fusion of lung images of CT data (in red) and MRI data (in green) of a) non-registered data and b) of elastically registered data. Please notice the improved overlapping of the lung envelopes visualized by both CT and MRI in b). 



\subsection{PAPER I:}

\section{Objective:}

To investigate the potentials and benefits of single-distance phase retrieval lung imaging, using in-line free propagation Phase Contrast X-ray Computed Tomography (PCX-CT).

\section{Materials and Methods:}

In-line free propagation SR Phase Contrast X-ray Computed Tomography (PCX-CT) was performed of an in-situ mouse lung sample at three different sample-to-detector distances, being 7, 30 and $100 \mathrm{~cm}$ at an energy of $22 \mathrm{keV}$, spatial resolution of $9 \mu \mathrm{m}$, Field of View (FOV) of 18 $\mathrm{mm} \times 12 \mathrm{~mm}, 1800$ projections. In order to reconstruct an image without edge effects, with predominantly the real part (delta-distribution) of the complex refraction index, a single-distance in-line Phase Retrieval (PhR) algorithm based on the Transfer of Intensity Equation (TIE) equation was applied, with a delta-to-beta ratio set to 1950 (calculated value for standardized lung tissue). Phase-retrieved slices were also compared with Propagation-based imaging (PBI) slices (also referred to as Phase Contrast (PhC) slices), where no PhR had been applied. In order to extract info about the image quality a set of parameters were extracted, thus being the Contrast-to-Noise Ratio (CNR) between the air and soft-tissue, the Edge-Enhancement Index (EEI), based on a line profile applied on the air-to-soft-tissue interface. Furthermore, in order to compare the steepness of the edges a sigmoid function was used to interpolate the data of the line profile. The extracted steepness-of-fit parameter reflects the increment of blurring of the edges in the reconstructed slices.

\section{Results:}

The acquired PhC slices show a mix of absorption-based contrast and edge effects, which are further enhanced with an increasing sampleto-detector distance. The reconstructed PhR slices showed more than a tenfold higher CNR and more than a 2-fold higher EEI, compared to the PhC slices for all the given sample-to-detector distances. The steepness-of-fit parameter increased between $5 \%$ and $8 \%$ for the PhR 
data scanned at various sample-to-detector distances, meanwhile the same parameter for the PhC data showed an increase of a minimum of $15 \%$, thereby confirming that the blurring is stronger in the PhC scans, than in the PhR scans. The histogram of the phase-retrieved data sets show two clearly distinguished grey value intervals, represented by air and soft tissue, thus allowing further grey level thresholding.

\section{Discussion:}

The results revealed that for PhR data of lungs the CNR can be further increased by scanning at longer sample-to-detector distances, where excessive PhC edge effects can be suppressed, while only minor decrement of the sharpness can be expected. The availability of a more sensitive scanning technique, will allow for a more precise analysis of lung structural alterations in mouse models with various lung diseases.

\subsection{PAPER II:}

\section{Objective:}

To develop a functional imaging approach utilizing in-line free propagation PCX-CT for the assessment of lung structural changes and the detection of Ba sulfate loaded alveolar macrophages, injected into an asthmatic mouse model.

\section{Materials and Methods:}

An immortalized murine alveolar macrophage cell line (MH-S) was labelled ex vivo with both a CT contrast agent, as well as a fluorescent label, wherein after they were injected intratracheally into an Mild Acute Asthma (MAA), Blank (BL) and Control (CN) mice ( $\mathrm{CN}_{1}$ and $\mathrm{CN}_{2}$ ). Herein after optical imaging was performed by 2dimensional (2D) Fluorescence Reflectance Imaging (FRI). The mice were then sacrificed, lungs were kept in situ and inflated with air, wherein after they were scanned with Synchrotron Radiation Computed Microtomography ( $\mathrm{SR} \mu-\mathrm{CT}$ ) in the $\mathrm{PhC}$ regime at a sample-todetector distance of $30 \mathrm{~cm}$. Otherwise the scanning parameters were the same as the one used in Paper I. A single-distance in-line PhR algorithm based on the Born equation was applied. The phase-retrieved images were further divided into thin rectangular VOIs in the horizontal, vertical and transvertical plane and quantitatively analyzed in terms of amount and structure thickness of the air, soft-tissue and barium component. Statistical analysis for detecting significant differences in between the samples was applied using a one-way 
ANOVA test with Tukey 90\% simultaneous confidence intervals. The lungs were then sectioned for histology, wherein after a Periodic Acid-Schiff (PAS) staining was applied, in order to investigate the bronchial wall thickness and mucus production. Further investigations by fluorescence microscopy was also applied, in order to verify the location of the injected dialkylcarbocyanine dye (DiD) and Balabelled cells inside the tissue of both asthmatic and control mice. Lung sections were also investigated by means of High-Resolution Synchrotron-Radiation-based X-ray Phase-Contrast Computed Microtomography (SR HR $\mu-\mathrm{CT}$ ) at an energy of $17.5 \mathrm{keV}$ and PhR based on a Holo-Tomo reconstruction algorithm was applied.

Results:

In vivo Near Infrared Fluorescence (NIRF) imaging showed a strong increase in fluorescence intensity over the lung area $24 \mathrm{~h}$ after the i.t. instillation of a DiD - and Ba-labelled macrophages, when compared with the pre-scan. The results obtained from the SR $\mu$-CT scans revealed a high concentration and specific accumulation of $\mathrm{BaSO}_{4}$ loaded macrophages inside the asthmatic lung tissue. ${ }_{3} \mathrm{D}$-renderings of the segmented lung tissue revealed an increased soft tissue content in the MAA sample, compared to the healthy controls. Quantitative analysis of the soft-tissue showed a $61 \%$ increase for the PercVol and a $48 \%$ increase of the StTh for the MAA sample, in comparison to the controls. The applied statistical test showed a significant difference between the MAA lung and all the controls for the PercVol and the StTh parameter for both the airways and soft tissue. SR HR $\mu$-CT slices showed an increased wall thickness for the MAA lung, with respect to a control lung. $\mathrm{BaSO}_{4}$ loaded macrophages could be observed in both MAA and $\mathrm{CN}$ lung, where they tended to be more closely accumulated in high dense cell regions in the MAA lung, while being more spread out in the $\mathrm{CN}$ lung. The results from the fluorescent microscopy revealed the presence of DiD-labelled macrophages in high cellular density areas, with an increased wall thickness for the MAA lung sample. The CN lung showed no effects of high dense cellular regions nor increased wall thickness and the observed macrophages were more widely distributed. The PAS-staining of lung sections showed an increased wall thickness in the MAA lung, as well as red dots, related to produced mucus. The CN lung showed no increased wall thickness nor effects of mucus production.

\section{Discussion:}

This article demonstrated for the first time, to our knowledge, the usage of $\mathrm{BaSO}_{4}$ loaded macrophages as a contrast agent for CT-based cell tracking in an experimental allergic airways disease model, while 
simultaneously depicting both lung structural alterations and functional information about the migration of macrophages.

The detection of macrophages inside the lung tissue, using SR $\mu-\mathrm{CT}$, was also supported by results from SR HR $\mu$-CT and fluorescent microscopy, thus suggesting an active migration of the injected macrophages from the airspace into the tissue [34]. Results from PAS-staining of histology sections also showed an increase of the wall thickness.

\subsection{PAPER III:}

\section{Objective:}

To establish a general investigative methodology for quantitative image analysis in the sagittal, coronal and transversal orientation of CT data sets of lungs (both preclinical and clinical) with various lung diseases, containing a contrast agent for enhanced imaging.

\section{Materials and Methods:}

The preclinical data sets analyzed in this study were the same once as analyzed in Paper II. A semi-automatic image post processing methodology was outlined, in order to successfully segment the lung parenchyma, consisting of a well-established image processing algorithms. Herein after the left and right lung side were divided into stripe shaped volume of interests VOIs in the transversal, sagittal and coronal orientation and investigated with the two quantitative parameters, PercVol and structural thickness StTh. A set of statistical tests were followed, in order to determine if there were any statistical significant differences in between the samples.

Results:

For the Mild Acute Asthma (MAA) lung, the right lung side showed a higher content of soft-tissue together with a lower amount of air content, in comparison with the healthy Blank (BL) and Control (CN) (CN1 \& CN2) lungs. The opposite effect was seen in the left lung side for the MAA lung sample. The denser tissue regions coincided with the positions of the $\mathrm{BaSO}_{4}$ loaded macrophages. Quantitative analysis of the tissue PercVol confirmed an increase of $81 \%$ and $47 \%$ for the right and left lung side respectively for the MAA lung sample, compared to the BL, CN1 and CN2 lungs. The tissue StTh showed an increase of $69 \%$ and $37 \%$ for the right and left lung side respectively for the MAA lung sample. The StTh of the $\mathrm{BaSO}_{4}$ loaded macrophage clusters in the right and left lung side of the MAA lung showed an increase of $38 \%$ and 
$64 \%$ respectively, compared to the lung samples CN1 and CN2. The MAA lung showed a broader variation of the recorded values for the given two quantitative parameters, in between the left and right lung side, than the BL, CN1 and CN2 lungs. Statistical analysis revealed that for the MAA lung the air PercVol was significantly smaller, meanwhile the tissue PercVol was significantly larger than all the remaining lungs (BL, CN1 and CN2). For the StTh parameter, significantly smaller values were detected for the air StTh in the right lung side and significantly larger values for the tissue StTh for the MAA lung, than compared to all the remaining lung samples, thus implying that the effect of the asthmatic attack was stronger in the right lung side. Furthermore, both the right and left lung side of the MAA lung had significantly higher StTh values for the Ba sulfate filled macrophage clusters, compared to all the remaining lung samples.

\section{Discussion:}

The hereby presented quantitative parameters (PercVol and StTh) were shown to be usable for the evaluation of asthma in a preclinical mouse model.

In general it was revealed that for the PercVol of the given VOIs, certain directions along the $\mathrm{X}_{-}, \mathrm{Y}-$-, Z-axis of the scanned lung images are more sensitive for the detection of smaller local structure variations, which can otherwise be missed if only evaluating the VOIs along one preferred axis direction. Prior to defining an overall averaged mean based on data from all these directions, which would level these smaller location-related variations, it is important to verify if the smaller variations plays an important aspects or not.

The outlined analysis methodology was also translated from a preclinical level, investigating lung structural differences in asthmatic mice, to a clinical level, where various lung diseases in patients could be analyzed by the same protocol. This article therefore helped to confirm the importance of preclincial research, using high end imaging strategies, also for clinical diagnosis, using standard imaging devices.

The outlined analysis methodology protocol was applied only to ${ }_{3} \mathrm{D}$ data sets obtained by means of $\mathrm{CT}$, but can of course be utilized for evaluating lung images obtained by other ${ }_{3} \mathrm{D}$ imaging techniques, e.g. IH MRI. With further developments in the area of both CT and MRI lung imaging, the presented methodology could serve as in important tool in evidence based medicine in a near future. 
6.4 PAPER IV:

\section{Objective:}

To evaluate optimized cell uptake methodologies of MRI/CT contrast agents for dual-modal cell tracking of macrophages in both MRI and CT.

\section{Materials and Methods:}

The same alveolar cell line as used in paper II was cultured with 1) the same $\mathrm{BaSO}_{4} \mathrm{CT}$ contrast agent (containing Sorbitol) as used in paper II and 2) an MRI contrast agent, with CT capabilities, based on GdNP. 1 million cells were incubated with the contrast agents with 1 ) a varying culturing time set to $2 \mathrm{~h}, 4 \mathrm{~h}, 8 \mathrm{~h}$ and $24 \mathrm{~h}$ and 2) varying culturing concentration between 0.4-1.5 mM Ba and 0.5-2.5 mM GdNP and a fixed culturing time of $2 \mathrm{~h}$. The labelled cells were put into plastic tubes and scanned with SR $\mu-\mathrm{CT}$ at an energy of $17.0 \mathrm{keV}$, in order to evaluate the contrast enhancement. In a second step the effect of co-loading the cells with both the $\mathrm{CT}$ and MRI contrast agent inside the same cells (for $2+2$ hours) was investigated. In a third step it was investigated if capped/immersed GdNP to Sorbitol would boost the cell uptake further. The cells were then first scanned with $\mu$-MRI, followed by SR $\mu$-CT scanning. A WST-1 test was also applied, measuring the metabolic activity of the cells, which was also proportional to the cell viability.

\section{Results:}

The $\mathrm{BaSO}_{4}$ loaded macrophages showed a higher contrast enhancement in $\mathrm{CT}$, than the GdNP for both varying incubation time and incubation concentration. It was shown that the cell uptake for both the contrast agents could be approximated by a negative 2:nd degree function of the incubation time, while as the cell uptake increased linearly as a function of the incubation concentration for both the investigated contrast agents. The WST-1 test also showed a high metabolic activity for macrophages loaded with either 1.5-2.0 mM of Gd or 0.75 $\mathrm{mM}$ of $\mathrm{Ba}$ at incubation times ranging from $2-24$ hours.

The co-loading of both GdNP at a concentration of $2.0 \mathrm{mM}$ of $\mathrm{Gd}$ and $\mathrm{BaSO}_{4}$ at a concentration of $0.75 \mathrm{mM}$ of $\mathrm{Ba}$ inside the same macrophages showed a decrease of $11 \%$ of the LAC in CT, as well as a decrease of $6 \%$ of the TI-contrast in MRI, as in comparison to the obtained signal from only measuring on $\mathrm{BaSO}_{4}$ or GdNP loaded macrophages in each 
modality.

Macrophages incubated with GdNP capped to Sorbitol for 4-8 hours at an incubation concentration of 2.0-5.0 $\mathrm{mM}$ showed a much higher metabolic activity of the cells, than pure GdNP incubated according to the same protocol. Furthermore, it was also observed that when macrophages were incubated with GdNP capped to Sorbitol for 48 hours at an incubation concentration of $10.0 \mathrm{mM}$, the quantified metabolic activity of the cells was similar to that of macrophages incubated with pure GdNP at an incubation concentration of $5.0 \mathrm{mM}$ of Gd.

\section{Discussion:}

CT requires a higher amount of contrast agent in order to be detected, while as MRI is sensitive enough to detect the effect of lower concentrations of contrast agents, where instead a too high concentration of contrast agent would lead to a so called black out of the T1-weighted signal in MRI. In this context it is therefore difficult to optimize the cell loading of GdNP to give an optimal contrast in both CT and MRI at the same time.

Furthermore, our observations also support the fact that Sorbitol might both aid the uptake the contrast agent of the cells, as well as acting to decrease the toxic effects of Gd on the cells.

The idea to of inject a mixture of either GdNP or $\mathrm{BaSO}_{4}$ loaded alveolar macrophages into an asthmatic mouse, might therefore be a valid alternative path, in order to keep both the CT and MR-signal maximized.

\subsection{PAPER V:}

\section{Objective:}

To investigate the feasibility of dual-modal CT-MRI cell tracking, macrophages loaded with either an MRI or CT contrast agent were injected in a mouse model with Severe Acute Asthma (SAA), by means of SR $\mu$-CT and $\mu$-MRI.

\section{Materials and Methods:}

In this study the preclinical data set consisted of a mouse model with SAA, intracheally injected with both 1) 4 million alveolar macrophages loaded with commercial $\mathrm{BaSO}_{4}$ contrast agent for CT or 2) 2 million alveolar macrophages loaded with GdNP as a contrast agent for MRI. 
The lung samples were scanned ex vivo at an energy of $22 \mathrm{keV}$ and with a 9.4 Tesla $\mu$-MRI scanner using short Time to Echo (TE) of 2 ms. The outlined image processing protocol mentioned in Paper III, was hereby applied on both CT and MRI lung data sets, prior to the following image registration of the CT and MRI data sets. The following quantitative parameters were computed from both the CT and MRI lung data sets: 1) soft tissue mean value and 2) soft tissue percentage volume. These parameters were calculated from each slice of every respective data set. Statistical analysis for determining the presence of any significant differences in between the samples was performed, followed by a correlation analysis between the extracted MRI, CT and histology parameters.

\section{Results:}

For the CT lung data sets, an increased soft tissue PercVol of $130 \%$ and $178 \%$ were detected in the SAA Ba/GdNP and SAA lung respectively, compared to the Severe Control (SCN). The SAA Ba/GdNP sample presented high absorbing spots found inside the denser tissue regions. For the corresponding MRI lung data sets, an increased soft tissue PercVol of $105 \%$ and $8 \%$ were detected in the SSA Ba/GdNP and SAA lung respectively, compared to the control lung SCN. The soft tissue mean value of the CT data sets showed a decrease of $3 \%$ and $2 \%$ for the SSA Ba/GdNP and SAA lung respectively, compared to the SCN lung. For the corresponding MRI lung data sets, an increased soft tissue mean value of $5 \%$ and $4 \%$ were instead seen for the SSA $\mathrm{Ba} / \mathrm{GdNP}$ and SAA lung respectively, compared to the SCN lung. The applied correlation analysis revealed a total negative correlation between the soft tissue mean value in $\mathrm{CT}$ and the soft tissue mean value in MRI.

The fused images showed that in the very same positions of the $\mathrm{BaSO}_{4}$ loaded macrophage clusters, as imaged by CT, there was an absence of the T1-contrast of the soft-tissue in the MR image, as indirectly increased by the presence of non-clustered GdNP loaded macrophages in the tissue.

\section{Discussion:}

The results from the correlation analysis suggest that the soft tissue in the asthmatic samples has a lower density, as observed by CT and a higher water content, as observed in MRI. Dual modal CT-MRI cell tracking of macrophages loaded with a CT or MRI contrast agent, will in each modality be detected in different manners. The way that the presence of contrast agent loaded macrophages are detected either by 
CT or MRI is related to the very technical differences in the way that images are created in the two modalities CT and MRI.

In CT the LAC needs to be as high as possible, which is fulfilled when macrophages loaded with a $\mathrm{CT}$ contrast agent, e.g. $\mathrm{BaSO}_{4}$ are clustered together, with a diameter equal or bigger than the image resolution. In MRI on the other hand the presence of macrophages stained with a positive MRI contrast agent, e.g. Gd is detected indirectly through the increase of the T1-weighted-signal, coming from the surrounding $1 \mathrm{H}$ protons (either inside the cells or the from the soft tissue), where their relaxation speed is slowed down by Gd. This study hence reported different values for the amount of soft tissue PercVol detected either by CT or MRI. The observed soft tissue in the CT-slices is in fact a mixture of both soft tissue and produced mucus (which are inseparable by $\mathrm{CT}$ ), where the latter is due to an indirect enhancement of the Ti-contrast, due to the presence of GdNP loaded macrophages in the tissue.

The observed decrease of the T1-contrast of the soft-tissue around the positions of the $\mathrm{BaSO}_{4}$ loaded macrophages, is most likely related to a black out of the T1-weighted signal, due to a too high concentration of $\mathrm{Gd}$, under the consideration that the $\mathrm{GdNP}$ and $\mathrm{BaSO}_{4}$ loaded macrophages are clustered in the same regions and possibly also further effected by the diamagnetic properties of Ba being able to cause a decrease of the T1-contrast. In this context CT allows the detection of clustered macrophages, while as MRI permits an indirect T1enhancement of the lung-tissue, due to non-clustered macrophages present in the tissue. In context the combination of using both a contrast agent for CT and one for MRI in a dual-modal CT-MRI approach permits us to extract true synergistic information about the role of macrophages in asthmatic lung tissue, which could not have been realized if only performing the study in only one of the two modalities. 

The aim of the here presented thesis was to evaluate if Gadolinium nanoparticles (GdNP)s that have already been proven to be a good Contrast Agent (CA) in MRI also can act as a dual-modal CA for both MRI and CT. As the contrast in CT is related to the atomic number, $\mathrm{Z}$ and ultimately the X-ray Mass Attenuation Coefficient (MAC) of the scanned material, which are both higher in Gd, compared to for instance $\mathrm{Ba}$, which is routinely used as a CA for $\mathrm{CT}$, the usability of GdNP also for CT presents a valid hypothesis.

However, since it is a well-known fact that the MR-signal decays more rapidly if the Gd concentration is too high in one spot, the main challenge of this work was to use GdNP at a relative low concentration of Gd for CT. Therefore, Synchrotron in-line Phase Contrast (PhC) CT with its known increase in sensitivity was used to investigate the CT capabilities of GdNP. Today effective clinical contrast agents already exist for both MRI and CT, although these CAs lack strategies for specifically targeting sites of interest. Therefore the focus in this thesis was turned to the usage of macrophages, having the possibility to engulf large particles, allowing an effective loading of the hereby discussed GdNPs and exploiting them as carriers of the CA to home to inflammatory sites.

The results in this thesis showed that GdNP can be detected by means of Synchrotron Radiation Computed Microtomography (SR $\mu$-CT). However, the crucial factor when selecting a CA to be used for cell tracking with $\mathrm{CT}$, is not solely dependent on the MAC-value, where the main factor is instead related to the uptaken amount of the material by the cells, while still making sure that the cell viability is acceptable. In Paper IV it was shown that Gadolinium nanoparticles (GdNP) can be loaded into immune cells, such as murine alveolar macrophages and a contrast difference between GdNP loaded and pure macrophages could be observed by both $\mathrm{CT}$ and MRI. As a reference for determining an optimal contrast in $\mathrm{CT}$, a pure CA developed for $\mathrm{CT}$ and based on Barium Sulfate $\left(\mathrm{BaSO}_{4}\right)$ in a suspension of Sorbitol (sugar molecule) was used. The uptake of GdNP could however be optimized by increasing the Gd concentration, the incubation time or by immersing the GdNP in Sorbitol, as shown in Paper IV. However, while trying to optimize the Gd uptake for $\mathrm{CT}$, a too high concentration of Gd leads to a decay of the T1-weighted signal in MRI, as well as to a decreased cell viability. The investigated GdNP can hence not be optimized for 
both CT and MRI at the same time.

The usage of a Gd containing dual-modal CA for both CT and MRI could therefore benefit from the combination with a metal primarily used in CT CA, such as gold in the work presented by Alric et al. [18] using gadolinium chelate coated gold nanoparticles and or with iodine as proposed by Ahmad et al. [17] using Iodine Gadolinium nanoparticles (ICGdNP)s. In a parallel study (not shown in this thesis work), we also investigate the CT contrast capabilities of Zinc Gadolinium nanoparticles (ZnGdNP) [80, 81, 82]. The measured LAC of pure ZnGdNP in solution was much higher, than for pure GdNP. However, the contrast differences of ZnGdNP loaded macrophages, was only slightly higher than for GdNP loaded macrophages, thus suggesting that the crucial factor for performing cell tracking with $\mathrm{CT}$ is still related to the cell uptake of the given CA.

In order to permit an optimal contrast of CA loaded macrophages in both $\mathrm{CT}$ and MR a mixture of GdNP and $\mathrm{BaSO}_{4}$ loaded murine alveolar macrophages were used at a ratio of 2:4 million cells and injected into mice of an allergic airway inflammation model (mimicking human asthma), to show the potential usage of the CAs. Furthermore, it was also assumed that the $\mathrm{BaSO}_{4}$ and GdNP loaded macrophages behaved in the same way. The results revealed complementary information about the macrophage migration patterns, where clustered macrophages could be observed by means of both SR $\mu$-CT, meanwhile the indirect effect of freely distributed non-clustured macrophages could be observed, as an increment of the T1-contrast of the softtissue, image by $\mu$-MRI, as shown in Paper V. Furthermore, fused images of the CT and MRI lung data set showed that the positions of the $\mathrm{BaSO}_{4}$ loaded macrophage clusters imaged by $\mathrm{CT}$, corresponded to positions of missing T1-enhanced soft-tissue contrast in the MR image, mainly related to a black out of the T1-weighted-signal, due to a too high concentration of $\mathrm{Gd}$ in these spots. 
The work performed in this thesis presents a general pipeline analysis approach for evaluating the potentials of dual-modal CT-MRI cell tracking using intracellular CAs and is hence not limited to the used CAs in this thesis. The initial idea was however to investigate if GdNP could be used as an intracellular CA for both CT and MRI. Since GdNP presented further challenges related to the optimal concentration needed for detection in MRI and CT and followed toxicity issues, a combination with $\mathrm{BaSO}_{4}$ was therefore performed. Furthermore, $\mathrm{BaSO}_{4}$ was initially used for testing the detectability of CA loaded macrophages by means of SR $\mu-C T$, as shown in Paper II.

Although combinations of Gd with other materials such as gold and iodine, primarily used in CAs for $\mathrm{CT}$, have already been proven efficient $[18,17]$, these studies does not reveal the applicability of these CAs as intracellular CAs for the purpose of performing cell tracking in both CT and MRI. The crucial factor for being able to perform MRICT cell tracking is therefore dependent on the uptaken material of the cells, where for an optimal contrast in CT it is crucial that the CT core material for is packed as close as possible inside the cell (high intracellular concentration) for increased contrast, meanwhile for optimal contrast in MRI it is on the contrary important that the MRI core material is more spread out within the cell (low intracellular concentration), in order to avoid a decay of the MR signal.

A common issue always discussed for the use of nanoparticles is their ultimate fate within the body. Therefore, it would also be interesting to study the fate of the GdNP once the CA loaded macrophages eventually die. This could e.g. be done by attaching a radioactive tracer to the GdNP and then using a high sensitive gamma counter to measure the radioactivity from each organ of the mouse.

Future aspects of the hereby presented work would also include surface modifications of the GdNP by attaching a tag for specific recognition of a given surface molecule present on a given cell type of interest, thereby allowing specific cell targeting. Such an approach is however not really needed when dealing with macrophages, since macrophages are capable of engulfing all foreign pathogens.

Since smaller particles are usually taken up unspecifically by cells in every organ of the body, another way of realizing specificity without 
modifying the surface, would be to only increase the size of the GdNP, so that predominantly macrophages are capable of engulfing them. This would allow a direct injection of pure GdNP into asthmatic mice, followed by a homing of the indulgent macrophages (already present in the host) to the inflammatory sites, thereby allowing to study the role of alveolar macrophages in asthma in more detail. Such an idea would also remove the need for in-vitro cell labeling approaches using immortalized macrophages.

Since size modification of the GdNP would make them specific for predominantly macrophages, a further theranostic approach could be to couple the GdNP to a drug, that would be released once the particledrug complex breaks down and locally administrate the drug at the site of inflammation, due to the homing of the macrophages here.

Recent studies have shown that air-filled micro bubbles, primarily developed as a CAs for Ultrasound (US) can be used as CA in the PhC regime of CT [83]. Therefore, a future idea would be to coat air-filled micro bubbles with a layer of GdNP, there by allowing for both optimal detection in both PhC CT and MR at the same time. Such an approach would hence rule out the need for a CT core material, since PhC CT is more sensitive than Abs based CT, while as the issue of the decaying MR-signal, due to a too high Gd concentration can be avoided. 
In February 2010 I arrived in Trieste, Italy with 2 bags and half a year in front of me to write my Master's thesis. That half a year suddenly turned into years and now almost 6 years later, I am soon to submit my PhD thesis. When I look back those 2 bags I once arrived with have now in fact turned into a home and with a family of my own that I cherish. There are many persons I would like to thank for their contribution to my life puzzle. First of all I would like to thank Dr. Johan Söderström (Uppsala University) for initially recommending me to pursue my Master's thesis in Trieste.

Secondly I would like to thank my co-supervisor (both for my Master's and PhD thesis) Dr. Giuliana Tromba (Sincrotrone Trieste, Italy), who saw potentials in me already at an early stage of my career and introduced me to the life of research. I would also like to thank my both my main supervisors Prof. Agostino Accardo (University of Trieste) and Prof. Kajsa Uvdal (Linköping University), who have enabled me to develop my skills in each of their respective areas of expertise, through extensive meetings and discussions, both in Italian and in my mother tongue.

Furthermore, I would also like to thank all my present and former colleagues at the SYMREP Beamline (Sincrotrone Trieste, Italy), especially Dr. Francesco Brun (second co-supervisor for my Master's thesis), Dr. Sara Mohammadi, Dr. Diego Dreossi, Dr. Nicola Sodini and Dr. Lucia Mancini for their collaboration and encouragements during these years.

I would also like to thank my former and present colleagues at Biomedical Instrumentation and Signal Processing Laboratory (University of Trieste) were I have had my second office from time to time, especially Dr. Miloš Ajčevič, Dr. Elisa Fornasa, Dr. Monica Cusenza, Dr. Mariangela Genna, Serena Pacilé, Raffaele Calabrese, Pierluigi D'Antrassi and Irene Lasorsa, with whom I have shared many nice moments and have encouraged me to improve my Italian.

I also thank my former and present colleagues in the Molecular Surface Physics and Nanoscience group (Linköping University), especially Natalia Abrikossova, Dr. Caroline Brommesson, Dr. Maria Ahrén, Dr. Linnéa Selegård, Dr. Cecilia Vahlberg, Dr. Zhangjun Hu, Dr. Xuanjun Zhangm Andreas Skallgren and Peter Eriksson for interesting 
discussions and company during my stays in Linköping.

Last but not least I would also like to thank our collaborations partners Cluster in Biomedicine in Trieste, Italy, especially Dr. Simeone dal Monego, Andrea Lorenzon, Dr. Chiara Garrovo, Dr. Stefania Biffi and the Jožef Stefan Institute (JSI) in Ljubljana, Slovenia, especially Prof. Igor Serša, Dr. Urša Mikac and Ana Sepe, as well as Dr. Tina Pavlin (University of Bergen, Norway) for teaching me the principles of MR and for presenting me to the group at JSI. I also thank our collaboration partner University Hospital of Göttingen/Max Planck Institute for Experimental Medicine in Göttingen, Germany, especially Dr. Christian Dullin, Prof. Frauke Alves, Bärbel Heidrich, Sarah Garbote, Roswitha Streich, Dr. Jeannine Missbach-Güntner and Julia Schirmer. I would also like to deliver a special thank you to Dr. Christian Dullin, with whom I have carried out a substantial amount of beamtime experiments and discussions, also during night shifts. During my thesis work you have had many different roles, both friend, colleague and functioned as a second unofficial co-supervisor. I hope that we will be able to carry out more interesting research together in the future. Thank you!

I would also like to thank all my friends and family in both Sweden, Italy, Slovenia and Croatia and across the globe for all their encouragements during my PhD. You know who you are. I would also like to direct a special thank you to Per Janson and Robert Almquist from my home town for all the nice moments we spent together and to my friends Viktor Johansson, Per-Erik Eriksson and Roberto Appio (MAX IV Laboratory) for hosting me in Bergen, Stockholm and Lund, when I was undertaking some PhD-courses. I would also like to thank Markus Tammia och Robert Almquist for proof-reading of both the English and Swedish version of the Abstract.

Finally I would like to thank my lovely wife Tea Larsson and our daughter Alina, for their support and assistance during my thesis writing. Your happiness and laughter will keep me happy for eternity.

Emanuel Larsson

October, 2015 . 
[1] Burton L Henke, Eric M Gullikson, and John C Davis. X-ray interactions: photoabsorption, scattering, transmission, and reflection at $\mathrm{E}=50-30,000 \mathrm{eV}, \mathrm{Z}=1-92$. Atomic data and nuclear data tables, 54(2):181-342, 1993.

[2] John E Hall. Guyton and Hall textbook of medical physiology. Elsevier Health Sciences, 2015.

[3] Anna Hedlund. MRI Contrast Enhancement and Cell Labeling using $\mathrm{Gd}_{2} \mathrm{O}_{3}$ Nanoparticles. PhD thesis, Linköping University, 2011.

[4] Hanns-Joachim Weinmann, RC Brasch, WR Press, and GE Wesbey. 6.4 Characteristics of gadolinium-DTPA complex: a potential NMR contrast agent. Classic Papers in Modern Diagnostic Radiology, page 416, 2005.

[5] U.S. Food, Drug Administration (FDA) Center for Drug Evaluation, and Research. Magnevist FDA Approval History, 2015. [website] http://www.accessdata.fda.gov/scripts/ cder/drugsatfda/index.cfm?fuseaction=Search. Overview\& DrugName=MAGNEVIST, Accessed October 15, 2015.

[6] Jean-Luc Bridot, Anne-Charlotte Faure, Sophie Laurent, Charlotte Riviere, Claire Billotey, Bassem Hiba, Marc Janier, Véronique Josserand, Jean-Luc Coll, Luce Vander Elst, Robert Muller, Pascal Roux, Stéphane Perriat, and Olivier Tillement. Hybrid gadolinium oxide nanoparticles: multimodal contrast agents for in vivo imaging. Journal of the American Chemical Society, 129(16):5076-5084, 2007.

[7] Marc-André Fortin, Rodrigo M Petoral Jr, Fredrik Söderlind, Anna Klasson, Maria Engström, Teodor Veres, Per-Olof Käll, and Kajsa Uvdal. Polyethylene glycol-covered ultra-small $\mathrm{Gd}_{2} \mathrm{O}_{3}$ nanoparticles for positive contrast at $1.5 \mathrm{~T}$ magnetic resonance clinical scanning. Nanotechnology, 18(39):395501, 2007.

[8] Michael Alexander McDonald and Kenneth L Watkin. Investigations into the physicochemical properties of dextran small particulate gadolinium oxide nanoparticles. Academic radiology, 13(4):421-427, 2006.

[9] Ja Young Park, Myung Ju Baek, Eun Sook Choi, Seungtae Woo, Joo Hyun Kim, Tae Jeong Kim, Jae Chang Jung, Kwon Seok Chae, Yongmin Chang, and Gang Ho Lee. Paramagnetic ultrasmall gadolinium oxide nanoparticles as advanced T I MRI contrast 
agent: account for large longitudinal relaxivity, optimal particle diameter, and in vivo T I MR images. ACS nano, 3(11):3663-3669, 2009 .

[10] Rodrigo M Petoral Jr, Fredrik Söderlind, Anna Klasson, Anke Suska, Marc A Fortin, Natalia Abrikossova, Linnéa Selegård, PerOlov Käll, Maria Engström, and Kajsa Uvdal. Synthesis and characterization of $\mathrm{Tb}_{3}+$-doped $\mathrm{Gd}_{2} \mathrm{O}_{3}$ nanocrystals: a bifunctional material with combined fluorescent labeling and MRI contrast agent properties. The Journal of Physical Chemistry C, 113(17):69136920, 2009.

[11] Fredrik Söderlind, Henrik Pedersen, Rodrigo M Petoral, PerOlov Käll, and Kajsa Uvdal. Synthesis and characterisation of $\mathrm{Gd}_{2} \mathrm{O}_{3}$ nanocrystals functionalised by organic acids. Journal of colloid and interface science, 288(1):140-148, 2005.

[12] Maria Ahrén, Linnéa Selegård, Anna Klasson, Fredrik Söderlind, Natalia Abrikossova, Caroline Skoglund, Torbjörn Bengtsson, Maria Engström, Per-Olov Käll, and Kajsa Uvdal. Synthesis and characterization of PEGylated $\mathrm{Gd}_{2} \mathrm{O}_{3}$ nanoparticles for MRI contrast enhancement. Langmuir, 26(8):5753-5762, 2010.

[13] Zhangjun $\mathrm{Hu}$, Maria Ahrén, Linnéa Selegård, Caroline Skoglund, Fredrik Söderlind, Maria Engström, Xuanjun Zhang, and Kajsa Uvdal. Highly Water-Dispersible Surface-Modified $\mathrm{Gd}_{2} \mathrm{O}_{3}$ Nanoparticles for Potential Dual-Modal Bioimaging. Chemistry-A European Journal, 19(38):12658-12667, 2013.

[14] Johan L Bloem and John Wondergem. Gd-DTPA as a contrast agent in CT. Radiology, 171(2):578-579, 1989.

[15] Aidan D Quinn, Neil J O'Hare, Fintan J Wallis, and Graham F Wilson. Gd-DTPA: an alternative contrast medium for CT. Journal of computer assisted tomography, 18(4):634-636, 1994.

[16] David S Gierada and Kyongtae T Bae. Gadolinium as a CT contrast agent: assessment in a porcine model. Radiology, 210(3):829834, 1999.

[17] Md Wasi Ahmad, Wenlong Xu, Sung June Kim, Jong Su Baeck, Yongmin Chang, Ji Eun Bae, Kwon Seok Chae, Ji Ae Park, Tae Jeong Kim, and Gang Ho Lee. Potential dual imaging nanoparticle: $\mathrm{Gd}_{2} \mathrm{O}_{3}$ nanoparticle. Scientific reports, 5, 2015.

[18] Christophe Alric, Jacqueline Taleb, Géraldine Le Duc, Céline Mandon, Claire Billotey, Alice Le Meur-Herland, Thierry Brochard, Francis Vocanson, Marc Janier, Pascal Perriat, Stéphane Roux, and Olivier Tillement. Gadolinium chelate 
coated gold nanoparticles as contrast agents for both X-ray computed tomography and magnetic resonance imaging. Journal of the American Chemical Society, 130(18):5908-5915, 2008.

[19] M. Marinescu, M. Langer, A. Durand, C. Olivier, A. Chabrol, H. Rositi, F. Chauveau, T.H. Cho, N. Nighoghossian, Y. Berthezène, F. Peyrin, and M. Wiart. Synchrotron Radiation Micro-Computed Tomography as a new method to detect iron oxide nanoparticles in the brain. Molecular Imaging in Biology, 15(5):552-559, 2013.

[20] Fabian Kiessling, JB Pichler, and Peter Hauff. Small animal imaging. Springer, 2011.

[21] Michael FW Festing and Douglas G Altman. Guidelines for the design and statistical analysis of experiments using laboratory animals. ILAR journal, 43(4):244-258, 2002.

[22] Daniel G Hackam and Donald A Redelmeier. Translation of research evidence from animals to humans. Jama, 296(14):17271732, 2006.

[23] Pablo Perel, Ian Roberts, Emily Sena, Philipa Wheble, Catherine Briscoe, Peter Sandercock, Malcolm Macleod, Luciano E Mignini, Pradeep Jayaram, Khalid S Khan, et al. Comparison of treatment effects between animal experiments and clinical trials: systematic review. Bmj, 334(7586):197, 2007.

[24] Daniel G Hackam. Translating animal research into clinical benefit. BMJ: British Medical Journal, 334(7586):163, 2007.

[25] Pietro Croce. Vivisection or science? An investigation into testing drugs and safeguarding health. Zed Books, 1999.

[26] Graham J Lieschke and Peter D Currie. Animal models of human disease: zebrafish swim into view. Nature Reviews Genetics, 8(5):353-367, 2007.

[27] $\mathrm{NC}_{3}$ Rs - National Centre for the Replacement Refinement \& Reduction of Animals in Research, 2015. [website] https://www. nc3rs.org.uk/the-3rs, Accessed October 15, 2015.

[28] M. Andrea Markus, Joanna Napp, Thomas Behnke, Miso Mitkovski, Sebastian Monecke, Christian Dullin, Stephen Kilfeather, Ralf Dressel, Ute Resch-Genger, and Frauke Alves. Tracking of inhaled near-infrared fluorescent nanoparticles in lungs of skh-1 mice with allergic airway inflammation. ACS Nano, 2015. PMID: 26513457.

[29] Theo Vos, Abraham D Flaxman, Mohsen Naghavi, Rafael Lozano, Catherine Michaud, Majid Ezzati, Kenji Shibuya, 
Joshua A Salomon, Safa Abdalla, Victor Aboyans, et al. Years lived with disability (YLDs) for 1160 sequelae of 289 diseases and injuries 1990-2010: a systematic analysis for the Global Burden of Disease Study 2010. The Lancet, 380(9859):2163-2196, 2013.

[30] J Carmichael, Ian C Paterson, P Diaz, GK Crompton, AB Kay, and IW Grant. Corticosteroid resistance in chronic asthma. BMJ, 282(6274):1419-1422, 1981 .

[31] Global Network Asthma. The global asthma report 2014. [website] http://www.globalasthmareport.org/, Accessed October 15,2015 .

[32] Y Mizue, S Ghani, L Leng, C McDonald, P Kong, J Baugh, SJ Lane, J Craft, J Nishihira, SC Donnelly, et al. Role for macrophage migration inhibitory factor in asthma. Proceedings of the National Academy of Sciences of the United States of America, 102(40):14410-14415, 2005.

[33] Christian Dullin, Emanuel Larsson, Giuliana Tromba, Andrea M. Markus, and Frauke Alves. Phase-contrast computed tomography for quantification of structural changes in lungs of asthma mouse models of different severity. Journal of Synchrotron Radiation, 22(4):1106-1111, Jul 2015.

[34] Christian Dullin, Simeone dal Monego, Emanuel Larsson, Sara Mohammadi, Martin Krenkel, Chiara Garrovo, Stefania Biffi, Andrea Lorenzon, Andrea Markus, Joanna Napp, Tim Salditt, Agostino Accardo, Frauke Alves, and Giuliana Tromba. Functionalized synchrotron in-line phase-contrast computed tomography: a novel approach for simultaneous quantification of structural alterations and localization of barium-labelled alveolar macrophages within mouse lung samples. Journal of Synchrotron Radiation, 22(1):143-155, 2015. [website] http://dx.doi.org/10. 1107/S1600577514021730, Accessed October 15, 2015.

[35] Michelle M Epstein. Do mouse models of allergic asthma mimic clinical disease? International archives of allergy and immunology, 133(1):84-100, 2004.

[36] Innocent N Mbawuike and Herbert B Herscowitz. MH-S, a murine alveolar macrophage cell line: morphological, cytochemical, and functional characteristics. Journal of Leukocyte Biology, 46(2):119-127, 1989 .

[37] Jeffrey G Penfield and Robert F Reilly. What nephrologists need to know about gadolinium. Nature Clinical Practice Nephrology, 3(12):654-668, 2007. 
[38] Lucian Farcal, Fernando Torres Andón, Luisana Di Cristo, Bianca Maria Rotoli, Ovidio Bussolati, Enrico Bergamaschi, Agnieszka Mech, Nanna B Hartmann, Kirsten Rasmussen, Juan Riego-Sintes, et al. Comprehensive in vitro toxicity testing of a panel of representative oxide nanomaterials: First steps towards an intelligent testing strategy. Plos One, 2015.

[39] Avinash C. Kak and Malcolm Slaney. Algorithms for Reconstruction with Nondiffracting Sources, chapter 3, pages 49-112. IEEE PRESS, 1987.

[40] David M. Paganin. X-ray sources, optical elements, and detectors, chapter 3. Oxford Series on Synchrotron Radiation. Oxford University Press, 2006.

[41] David Attwood. Soft x-rays and extreme ultraviolet radiation: principles and applications. Cambridge university press, 1999.

[42] Sincrotrone Trieste S.C.p.A, Trieste, Italy BL 6.1 R Synchrotron Radiation for MEdical Physics (SYRMEP) Beamline, 2015. [website] http://www.elettra.eu/elettra-beamlines/syrmep.html, Accessed October 15, 2015.

[43] A. Abrami, F. Arfelli, R. C. Barroso, A. Bergamaschi, F. Billè, P. Bregant, F. Brizzi, K. Casarin, E. Castelli, V. Chenda, L. Dalla Palma, D. Dreossi, C. Fava, R. Longo, L. Mancini, R. . Menk, F. Montanari, A. Olivo, S. Pani, A. Pillon, E. Quai, S. R. Kaiser, L. Rigon, T. Rokvic, M. Tonutti, G. Tromba, A. Vascotto, C. Venanzi, F. Zanconati, A. Zanetti, and F. Zanini. Medical applications of synchrotron radiation at the SYRMEP beamline of ELETTRA. Nuclear Instruments and Methods in Physics Research, Section A: Accelerators, Spectrometers, Detectors and Associated Equipment, 548(1-2):221-227, 2005.

[44] Harold Elford Johns and John Robert Cunningham. The Interaction of Ionizing Radiation with Matter, chapter 5, pages 133-166. Charles C. Thomas, Publisher, 4 edition, 1983.

[45] Xizeng $\mathrm{Wu}$, Hong Liu, and Amin Yan. Phase-contrast X-ray tomography: Contrast mechanism and roles of phase retrieval. European journal of radiology, 68(3):S8-S12, 2008.

[46] Max Langer, Peter Cloetens, and Françoise Peyrin. Regularization of phase retrieval with phase-attenuation duality prior for 3-D holotomography. Image Processing, IEEE Transactions on, 19(9):2428-2436, 2010.

[47] S.C. Mayo, T.J. Davis, T.E. Gureyev, P.R. Miller, D. Paganin, A. Pogany, A.W. Stevenson, and S.W. Wilkins. X-ray phasecontrast microscopy and microtomography. Optics Express, 11(19):2289-2302, 2003. 
[48] Xizeng $\mathrm{Wu}$ and Hong Liu. A general theoretical formalism for X-ray phase contrast imaging. Journal of X-ray Science and Technology, 11(1):33, 2003.

[49] Xizeng $\mathrm{Wu}$ and Hong Liu. Clinical implementation of x-ray phase-contrast imaging: Theoretical foundations and design considerations. Medical physics, 30(8):2169-2179, 2003.

[50] A Snigirev, I Snigireva, V Kohn, S Kuznetsov, and I Schelokov. On the possibilities of $x$-ray phase contrast microimaging by coherent high-energy synchrotron radiation. Review of Scientific Instruments, 66(12):5486-5492, 1995.

[51] SW Wilkins, TE Gureyev, D Gao, A Pogany, and AW Stevenson. Phase-contrast imaging using polychromatic hard X-rays. Nature, 384(6607):335-338, 1996.

[52] A Pogany, D Gao, and SW Wilkins. Contrast and resolution in imaging with a microfocus x-ray source. Review of Scientific Instruments, 68(7):2774-2782, 1997.

[53] Xizeng $\mathrm{Wu}$ and Hong Liu. Clarification of aspects in in-line phase-sensitive x-ray imaging. Medical Physics, 34(2):737-743, 2007 .

[54] Sara Mohammadi, Emanuel Larsson, Frauke Alves, Simeone dal Monego, Stefania Biffi, Chiara Garrovo, Andrea Lorenzon, Giuliana Tromba, and Christian Dullin. Quantitative evaluation of a single-distance phase-retrieval method applied on in-line phasecontrast images of a mouse lung. Journal of Synchrotron Radiation, 21(4):784-789, Jul 2014. [website] http://dx.doi.org/10.1107/ S1600577514009333, Accessed October 15, 2015.

[55] David Paganin, SC Mayo, Tim E Gureyev, Peter R Miller, and Steve W Wilkins. Simultaneous phase and amplitude extraction from a single defocused image of a homogeneous object. Journal of microscopy, 206(1):33-40, 2002.

[56] Eric Gullikson. Index of Refraction, 2015. [Online Calculator, website] http://henke.lbl.gov/optical_constants/ getdb2. html, Accessed October 15, 2015.

[57] J H Hubbell and S M Seltzer. X-Ray Mass Attenuation Coefficients, 2015. [Online Reference Table, website] http://physics. nist.gov/PhysRefData/XrayMassCoef/tab2.html, Accessed October $15,2015$.

[58] John H Hubbell and Stephen M Seltzer. Tables of x-ray mass attenuation coefficients and mass energy-absorption coefficients $1 \mathrm{kev}$ to $20 \mathrm{mev}$ for elements $\mathrm{z}=1$ to 92 and 48 additional substances of dosimetric interest. Technical report, National Inst. 
of Standards and Technology-PL, Gaithersburg, MD (United States). Ionizing Radiation Div., 1995.

[59] DR White, J Booz, RV Griffith, JJ Spokas, and IJ Wilson. Tissue substitutes in radiation dosimetry and measurement. ICRU Report, 44, 1989 .

[6o] Paul C Lauterbur et al. Image formation by induced local interactions: examples employing nuclear magnetic resonance. Nature, 242(5394):190-191, 1973.

[61] P Mansfield and PK Grannell. "Diffraction" and microscopy in solids and liquids by NMR. Physical Review B, 12(9):3618, 1975.

[62] Peter Mansfield. Multi-planar image formation using NMR spin echoes. Journal of Physics C: Solid State Physics, 10(3):L55, 1977.

[63] N. Otsu. A threshold selection method from gray level histograms. IEEE Trans. Syst. Man Cybern., 9(1):62-66, 1979.

[64] Xavier Geets, John A. Lee, Anne Bol, Max Lonneux, and Vincent Grégoire. A gradient-based method for segmenting FDG-PET images: methodology and validation. European Journal of Nuclear Medicine and Molecular Imaging, 34(9):1427-1438, 2007.

[65] Aparna Kanakatte, Jayavardhana Gubbi, Bala Srinivasan, Nallasamy Mani, Tomas Kron, David Binns, and Marimuthu Palaniswami. Pulmonary tumor volume delineation in PET images using deformable models. In 3oth Annual International Conference of the IEEE, pages 3118-3121. IEEE, Engineering in Medicine and Biology Society, EMBS, 2008.

[66] U. Bagci, Jianhua Yao, Jesus Caban, Evrim Turkbey, Omer Aras, and Daniel J. Mollura. A graph-theoretic approach for segmentation of PET images. In Engineering in Medicine and Biology Society, EMBC, 2011 Annual International Conference of the IEEE, pages 8479-8482. IEEE, 2011.

[67] Fei Yang and Perry W. Grigsby. Delineation of FDG-PET tumors from heterogeneous background using spectral clustering. European Journal of Radiology, 81(11):3535-3541, 2012.

[68] Hua Li, Wade L Thorstad, Kenneth J Biehl, Richard Laforest, Yi Su, Kooresh I Shoghi, Eric D Donnelly, Daniel A Low, and Wei Lu. A novel PET tumor delineation method based on adaptive region-growing and dual-front active contours. Medical Physics, 35(8):3711-3721, 2008.

[69] Ellen Day, James Betler, David Parda, Bodo Reitz, Alexander Kirichenko, Seyed Mohammadi, and Moyed Miften. A region growing method for tumor volume segmentation on PET images 
for rectal and anal cancer patients. Medical Physics, 36(10):4349$4358,2009$.

[7o] REGION GROW, Exelis Visual Information Solutions, CO, USA, 2015. [Computer Program, website], http://www.exelisvis. com/docs/REGION_GROW. html, Accessed June 30, 2015.

[71] Rolf Adams and Leanne Bischof. Seeded region growing. IEEE Transactions on Pattern Analysis and Machine Intelligence, 16(6):641647, 1994.

[72] Emanuel Larsson, Giuliana Tromba, Kajsa Uvdal, Agostino Accardo, Simeone dal Monego, Stefania Biffi, Chiara Garrovo, Andrea Lorenzon, and Christian Dullin. Quantification of structural alterations in lung disease - a proposed analysis methodology of CT scans of preclinical mouse models and patients. Biomedical Physics \& Engineering Express, 1(3):035201, 2015. [website] http: //dx.doi.org/10.1088/2057-1976/1/3/035201, Accessed October $15,2015$.

[73] Joachim Ohser and Katja Schladitz. $3 D$ Images of Materials Structures: Processing and Analysis. John Wiley \& Sons, Weinheim, Germany, 2009.

[74] J. Bear. Dynamics of Fluids in Porous Media. American Elsevier Publishing Company, Inc, New York, London, Amsterdam, 2nd edition, 1967 .

[75] Francesco Brun. Development of algorithms and methods for threedimensional image analysis and biomedical applications. PhD thesis, University of Trieste, 2012.

[76] A.M. Parfitt, M.K. Drezner, F.H. Glorieux, J.A. Kanis, H. Malluche, P.J. Meunier, S.M. Ott, and R.R. Recker. Bone histomorphometry: standardization of nomenclature, symbols, and units. Report of the ASBMR Histomorphometry Nomenclature Committee. Journal of bone and mineral research : the official journal of the American Society for Bone and Mineral Research, 2(6):595-610, 1987.

[77] Sincrotrone Trieste S.C.p.A, Trieste, Italy Porezd, A SaaS for Quantitative Analysis of 3d Images, 2015. [Computer Program, website], http://www. elettra.eu/pore3d/, Accessed October 15,2015 .

[78] Francesco Brun, Lucia Mancini, Parnian Kasae, Stefano Favretto, Diego Dreossi, and Giuliana Tromba. Porezd: a software library for quantitative analysis of porous media. Nuclear Instruments and Methods in Physics Research Section A: Accelerators, Spectrometers, Detectors and Associated Equipment, 615(3):326-332, 2010. 
[79] Carlos Ó S Sorzano, Philippe Thévenaz, and Michael Unser. Elastic registration of biological images using vector-spline regularization. Biomedical Engineering, IEEE Transactions on, 52(4):652663,2005 .

[8o] Linnéa Selegård. Synthesis, Surface Modification, and Characterization of Metal Oxide Nanoparticles: Nanoprobes for Signal Enhancement in Biomedical Imaging. PhD thesis, Linköping University, 2013.

[81] Linnéa Selegård, Volodymyr Khranovskyy, Fredrik Söderlind, Cecilia Vahlberg, Maria Ahrén, Per-Olov Käll, Rositza Yakimova, and Kajsa Uvdal. Biotinylation of $\mathrm{ZnO}$ nanoparticles and thin films: a two-step surface functionalization study. ACS applied materials E interfaces, 2(7):2128-2135, 2010.

[82] Annika Lenz, Linnéa Selegård, Fredrik Söderlind, Arvid Larsson, Per Olof Holtz, Kajsa Uvdal, Lars Ojamäe, and Per-Olov Käll. ZnO nanoparticles functionalized with organic acids: an experimental and quantum-chemical study. The Journal of Physical Chemistry C, 113(40):17332-17341, 2009.

[83] Yan Xi, Rongbiao Tang, Yujie Wang, and Jun Zhao. Microbubbles as contrast agent for in-line $\mathrm{x}$-ray phase-contrast imaging. Applied Physics Letters, 99(1):011101, 2011. 

Part I

PAPER I 



\section{Papers}

The articles associated with this thesis have been removed for copyright reasons. For more details about these see:

http://urn.kb.se/resolve?urn=urn:nbn:se:liu:diva-122607 